\title{
Abstracts of the 7th International Workshop on AT, November, 1997, Clermont-Ferrand, France
}

\author{
Absence of mutations in the ATM gene in breast cancer patients with severe responses to \\ radiotherapy
}

J.M. Appleby ${ }^{1}$, J.B.P. Barber ${ }^{1}$, E. Levine ${ }^{1}$, J.M. Varley ${ }^{1}$, A.M.R. Taylor ${ }^{2}$, T. Stankovic ${ }^{2}$, J. Heighway ${ }^{1}$, C. Warren ${ }^{1}$ and D. Scott ${ }^{1}$

${ }^{l}$ CRC Section of Molecular Genetics, Paterson Institute for Cancer Research, Christie Hospital (NHS) Trust, Manchester M20 9BX, UK

${ }^{2}$ CRC Institute for Cancer Studies, University of Birmingham, Medical School, Birmingham, B15 2TA, $U K$

In reviewing the available epidemiological data on A-T heterozygotes in 1994, Easton [1] produced best estimates of $0.5 \%$ for the population frequency, 3.9 for the increased relative risk of breast cancer and $3.8 \%$ for their frequency amongst breast cancer cases, but pointed out the wide confidence intervals on these estimates. The latter figure is intriguingly close to estimated proportion of $5 \%$ of breast cancer cases who sustain severe normal tissue damage after standard radiotherapy regimes [2]. It has also been shown that cultured cells from A-T heterozygotes and from some severely reacting (SR) patients show a modest increase in radiosensitivity in clonogenic assays utilising low dose rate or fractionated exposures [3].

The above observations have led to the prediction that a substantial proportion of SR patients may carry $A T M$ mutations and that mutation screening could be used as a predictive test for adverse reactions to radiotherapy [4].

We have screened the complete coding sequence of the ATM gene in 16 SR breast cancer patients and 7 SR patients with other cancers, using the restriction endonuclease fingerprinting (REF) assay. Twelve of the breast cancer cases had shown severe acute reactions in our own prospective study of 202 unselected patients. In our hands the REF assay has a sensitivity of about $70 \%$ so, using figures of $5 \%$ for the incidence of SR reactions and 4\% for the frequency of A-T heterozygotes amongst breast cancer cases, we would have expected to detect 9 ATM mutations amongst the 16 breast cancer patients tested if $A T M$ mutations confer elevated clinical radiosensitivity. No mutations were detected $(\mathrm{p}<0.001$ for observed $v$ expected). Neither were there any mutations amongst the non breast cancer cases. A polymorphism at $5557 \mathrm{G} Æ A$ (aspartic acidÆasparagine) was seen in 8 of the 23 patients. With respect to the function of the $A T M$ gene this is not a significant change.

Our results indicate either that $A T M$ mutations do not lead to in vivo radiosensitivity or that the frequency of A-T heterozygotes amongst breast cancer cases is overestimated, or both. Recent estimates of the latter, since the review by Easton [1], are 3.4\% (3/88) for patients with a family history of A-T type tumours, $0.5 \%(2 / 401)$ for early onset cases [6], and $6.6 \%$, estimated indirectly from a study of breast 
cancer incidence within 99 A-T families? There are also reports of 3 breast cancer patients with ATM mutations showing no adverse reactions to radiotherapy [6,8]. These early results suggest that screening for ATM mutations in cancer patients may not be of value in predicting complications from radiotherapy.

\title{
Acknowledgment
}

This study was funded by the Cancer Research Campaign and the National Radiological Protection Board, UK.

\section{References}

[1] Easton, D.F. Int. J. Radiat. Biol. 66 (suppl), (1994) 177-182.

[2] Ribeiro, G.G. et al. Clin. Oncol. 5, (1993) 278-283.

[3] Dahlberg, W.K. and Little, B.J. (1995) Clin. Cancer Res. 1, 785-790.

[4] Norman A. et al. (1992) Radiother. Oncol. 23, 196-197.

[5] Vorechovsky, I. et al. (1996) Cancer Res. 56, 4130-4133.

[6] Fitzgerald, M.G. et al. (1997) Nature Genet. 15, 307-310.

[7] Athma, P. et al. (1996) Cancer Genet. Cytogenet. 92, 130-134.

[8] Ramsay, J. et al. (1996) Lancet, 347, 1627.

\section{An immunohistochemical analysis of cerebellar changes in ataxia-telangiectasia patients}

\author{
Sara Becker-Catania ${ }^{1}$, David E. Hill ${ }^{2}$, Harry V. Vinters ${ }^{1}$ and Richard A. Gatti ${ }^{1}$ \\ ${ }^{I}$ Department of Pathology, UCLA School of Medicine, Los Angeles, CA, USA \\ ${ }^{2}$ Oncogene Research Products, Cambridge, MA, USA
}

An analysis of ten ataxia-telangiectasia (A-T) post-mortem cerebellum samples was undertaken to gain new insight into the extent and cause of the neurodegeneration seen in patients. Previous studies have documented a variety of neuronal changes within the cerebellum, primarily the loss of Purkinje cells (PC), the presence of dysmorphic or ectopic PC, abnormal dendritic arborization, thinning of the molecular and granule cell layers, increased numbers of Golgi cells, and shrinkage and loss of the deep nuclei. We used an antibody to the protein product of the gene responsible for familial adenomatous polyposis coli (APC), which forms an insoluble complex with B-catenin and stains astrocytes, oligodendrocyte cell bodies, as well as PC bodies, dendrites, and axons, the latter of which project to the deep nuclei of the cerebellum. In patients, the APC antibody highlighted ectopic Purkinje cells both in the granule cell and molecular layers. Purkinje cell loss was evident in all of the patients as well as thickened dendrites and a lack of secondary and tertiary dendritic tree structure. All of the A-T patients had increased numbers of dysmorphic axons with "frayed" areas compared to age-matched controls. Five of the patients had more numerous and prominent staining of clumped and thickened axon fibers than the seventy-year old control. Interestingly, several of the patients had increased numbers of APC-positive cells adjacent to the regions of axonal degeneration. In two normal infants, one normal child, and two adult controls, axons within the white matter of the cerebellum stained uniformly. The diameter was consistent along the length of the axon and no breaks were observed. A seventy-year old control showed 
some regions of gaps in the axons possibly suggesting a degenerative process associated with aging supported by the increased numbers of dysmorphic axons seen in older control cerebellums.

In order to extend our analysis of the axonal changes observed and to possibly identify the type of cell present in the regions of degeneration, we used an antibody to CD68, a microglial cell marker. Microglial cells are known to become activated in response to neuronal injury. Five of the ten AT patients showed increased numbers of CD68-positive cells in the white matter, and four also had increased numbers in the molecular and granule cell layers compared to controls. Of these five patients, four were sib pairs. In control cerebellums, the number of CD68-positive cells increased with age, reaching a peak at middle age and continuing to old age. In middle-aged and elderly control cerebellums, CD68-positive cells were mostly confined to the white matter with an occasional positive cell in the molecular layer; infant and young control cerebellums contained positive cells only in the white matter. Since axonal degeneration was suggested due to the gaps and frayed appearance of the axons, a myelin stain was used to look for myelin loss within the white matter. No myelin loss was seen in the white matter of the A-T cerebellums compared to age-matched control cerebellums. Since A-T cerebellums have marked atrophy with tissue compression, the actual numbers of axons/mm2 may not be significantly decreased, which may explain why the myelin stain appeared normal. The use of an antibody to both the $70 \mathrm{kD}$ and $200 \mathrm{kD}$ neurofilament protein demonstrated normal appearing basket cell processes, but within the molecular layer of patient cerebellums, enlarged axons, loss of interneurons, disorganization, and a "knarled" appearance of the parallel fibers were observed. Several patients also had thickened axons within the white matter, which suggests problems with axoplasmic flow. Axoplasmic flow abnormalities have been documented in older control brains and may represent an age-related degenerative process.

Antibody which stains neural cell adhesion molecule (N-CAM) recognizes several sizes of cell surface glycoproteins responsible for mediating cell-cell adhesion. Control cerebellums showed diffuse staining in the molecular layer and white matter with frequent immunopositive cells and processes within the white matter. A-T patients had normal levels of immunopositive cells within the white matter but more intense staining of the molecular layer, which may be due to the compression of cerebellar tissue.

Staining of A-T patient cerebellum sections with an antibody to glial fibrillary acidic protein (GFAP), which recognizes astrocytes and ependymal cells within the CNS, showed increased amounts of reactive astrocytes within the granule cell layer of most patients. Astrocytes normally act to modulate and metabolically support neural cells. Increased levels of reactive astrocytes within the depleted granule cell layer are not unexpected, as astrocytes have been reported to mimic both the phenotype and function of macrophage and monocyte cells in regions of neuronal injury within the CNS. In summary, we have examined ten A-T cerebellums with antibodies to APC, CD68, neurofilament, N-CAM, and GFAP, comparing them to control cerebellums. In addition to the previously documented cerebellar changes, we have found a loss of secondary and tertiary dendrites of the PC, evidence of PC axonal hypertrophy and disruptions in axoplasmic flow, indicative of degeneration. We have also found increased numbers of CD68-positive cells, as well as the loss of interneurons and disorganization of the parallel fibers within the molecular layer. It has been proposed that the primary lesion in the CNS of A-T patients is the degeneration of the Purkinje cell. Evidence found in this study shows abnormalities in both the PC dendrites and axons, with CD68-positive cells present. The PC receive input from several interneurons and are the sole output of the cerebellar cortex. The influence of spinocerebellar and corticocerebellar afferents and efferents on Purkinje cell physiology and function should not be dismissed as a potential primary cause for the pathological changes seen in the A-T CNS. Ongoing studies are addressing the relationship of the cerebellum and $\mathrm{PC}$ to the thalamus, basal ganglia and cortex. 


\section{Mutation analysis of the ATM gene in unselected breast cancer patients}

Regina Bendix ${ }^{1}$, Britta Skawran ${ }^{1}$, Thilo Doerk ${ }^{1}$, Marion Nicke ${ }^{1}$, Christine Volkmann ${ }^{1}$, Kerstin Potthast ${ }^{1}$, Dieter Schnalke ${ }^{2}$, Marianne Twardowski ${ }^{2}$, Johann H. Karstens ${ }^{2}$, Jurg Schmidtke ${ }^{1}$ and Manfred Stuhrmann ${ }^{1}$

${ }^{1}$ Institute of Human Genetics and ${ }^{2}$ Department of Radiation Therapy and Experimental Oncology, Medical School Hannover; D-30625 Hannover, Germany

The ATM gene that is mutated in ataxia telangiectasia (AT) encodes a large nuclear protein with a possible role in the repair of radiation-induced DNA damage. To test the postulated role of AT heterozygosity in the development of breast cancer, we have initiated a mutation screening of the ATM gene in a large cohort of randomly selected breast cancer patients who underwent radiotherapy at our center. After scanning one-third of the coding region by single-strand conformation analysis of genomic PCR products from 200 patients and subsequent genomic sequencing of samples with an aberrant migration, three of the patients were found to be heterozygous for amino acid substitutions flanking the kinase domain, whereas none was found to harbour a truncating mutation. These results do not exclude a causative role of AT mutations for breast cancer, but their frequency may have been overestimated by previous epidemiological studies and large-scale studies are needed to confirm the association of ATM mutations or variants with breast cancer.

\section{Effect of myo-inositol on cerebellar and T-cell function in patients withataxia-telangiectasia}

P. Bingham, G. Berry and K. Sullivan

Manifestations of Ataxia telangiectasia (AT) include progressive cerebellar ataxia, immunodeficiency, and cancer. The defective gene (ATM) has sequence homology with the gene encoding phosphatidylinositol 3 phosphokinase (PI-3 kinase). Phosphoinositides play a role in signal transduction, and it has been suggested that the ATM protein is part of a nuclear signal transduction system involved in DNA repair at various stages of the cell cycle. These observations raise the possibility that the molecular pathogenesis of AT involves a deficiency in the conversion of phosphatidylinositides (PtdIns) to phosphatidylinositol-3(4,5)-phosphate [PtdIns-3(4,5)-P]. The content of PtdIns in cell membranes depends upon intracellular levels of myo-inositol, which is actively transported into neurons and other cell types. Myo-inositol levels, in turn, reflect a combination of de novo synthesis from glucose, and dietary intake. Considering the possibility that neurological manifestations of AT stem from abnormal synthesis of PtdIns-3(4,5)-P, we have initiated a clinical protocol to test the hypothesis 1) that individuals with AT have decreased levels of PtdIns-3-P in circulating lymphocytes relative to age-matched controls; and 2) that AT patients show improvement in cerebellar functioning along with increases in PtdIns-3-P in response to pharmacologic doses of myo-inositol.

The study design is a placebo-controlled, double-blind, randomized, cross-over trial of the neurological and biochemical effects of dietary supplementation with myo-inositol. Myo-inositol or placebo is consumed 5 times per day at a dose calculated to raise levels from $20-50 \mathrm{~mm}$ to the range of $100-200 \mathrm{~mm}$ for one month $(600 \mathrm{mg} / \mathrm{kg} / \mathrm{day}$, approximately 20 times average dietary intake of myo-inositol). Outcome measures for statistical analysis include changes in a composite cerebellar function score, and in 
lymphocyte myo-inositol/inositolphospholipid levels, before and after myo-inositol supplementation. Levels of myo-inositol and PtdIns-3-P are obtained from lymphocytes at baseline and immediately after consumption of the study medicine for one month. Membrane-bound phosphoinositides are measured by gas chromatography following hydrolysis of the phospholipids isolated from chloroform/methanol extracts of cell membranes. Cerebellar function is assessed through analysis of a) standard cerebellar function examination (videotaped), b) handwriting samples, and c) infrared oculography. Neurological examinations are done before, during and after myo-inositol/placebo administration.

We plan to begin data analysis of this pilot study once 25 patients have completed the protocol. To date 6 patients have been enrolled.

\title{
The ATM mutation spectrum in the Dutch population
}

\author{
A. Broeks ${ }^{1}$, A. Floore ${ }^{1}$, N. Russell ${ }^{2}$, F. van Leeuwen ${ }^{3}$, K. Jaspers ${ }^{4}$, A. de Klein ${ }^{4}$ and L. van 't Veer ${ }^{1}$ \\ Department of ${ }^{1}$ Molecular Pathology, ${ }^{2}$ Radiotherapy and ${ }^{3}$ Epidemiology, The Netherlands Cancer \\ Institute, Plesmanlaan 1211066 CX, Amsterdam, the Netherlands \\ ${ }^{4}$ Dept Cell Biology and Genetics, The Erasmus University Rotterdam, Rotterdam, the Netherlands
}

Individuals with the autosomal recessive disorder Ataxia Telangiectasia (A-T), homozygous for a mutation in the ATM gene, have a 100-fold increased cancer risk. A-T cells are unable to respond normally to specific forms of radiation induced DNA-damage, they exhibit abnormally high levels of spontaneous apoptosis and are remarkably sensitive to ionizing radiation and radiomimetic chemicals. Several previous studies have suggested that in particular female ATM heterozygotes are also predisposed to cancer, with an estimated relative risk for breast cancer of 3.8 .

Increased breast cancer risk has been demonstrated following various radiation exposures. The purpose of our study is to determine the contribution of ATM heterozygosity to the risk of radiationinduced breast cancer and consequently whether female individuals, heterozygote for ATM, have an increased risk for developing radiation-induced breast cancer.

To facilitate the identification of mutations in Dutch ATM-heterozygote individuals, we have analyzed the incidence of specific ATM mutations in the Dutch population. Since approximately $75 \%$ of all mutation in ATM results in a truncated protein we use the Protein Truncation Test (PTT) to determine the mutations. We have examined 19 'Dutch' A-T individuals of which eleven were found to be compound heterozygotes and eight homozygote for a mutant ATM allele. We were able to detect $83 \%$ of all mutations, $75 \%$ was detected with PTT. Thirteen mutations were found only once, three were found twice and only one mutation was found in three individuals. Genotyping of the A-T individuals by using microsatelite markers revealed that individuals sharing mutations share a common haplotype (at least for the marker D11S2179 located in the ATM gen). No common founder could be detected in the Dutch population.

To determine the role of ATM-heterozygosity in radiation-induced breast cancer we are conducting three case control studies. Cases are defined as patients who developed breast cancer following therapeutic or diagnostic radiation. We selected forty patients with breast cancer following radiation therapy for Hodgkin's disease, fifty with contralateral breast cancer following radiation for their first breast cancer and sixty who developed breast cancer after diagnostic mammographic screening following a diagnosis of benign breast disease. For each case four age-matched controls were selected, patients who received the same treatment and did not develop breast cancer. The ATM status of all cases and controls 
is examined in peripheral blood lymphocytes by PTT and sequence analysis. In statistical analysis the proportion of ATM heterozygotes will be compared between the cases with breast cancer and their matched controls.

Until now eleven 'breast-cancer after irradiation for Hodgkin's disease' cases have been analyzed for mutations in ATM. In one case a truncated protein could be detected using PTT. Sequence analysis showed that this truncation was a result of alternative splicing of an additional exon. This exon is located in intron 28 and is called exon 28B. This phenomenon has been shown previously in A-T patients with a less severe phenotype, due to alternative splicing. They all contain an additional 137bp insert (exon 40B) in their cDNA. To investigate the consequence of the alternatively spliced additional exon, quantitative PCR analysis will be necessary to discover which proportion of ATM mRNA contains the alternatively spliced exon 28B.

Further analysis and completion of the case control studies will be required to draw any conclusions concerning the role of ATM heterozygosity in radiation induced breast cancer.

\title{
Genetic and physical mapping of the Nijmegen Breakage Syndrome gene region at 8q21
}

\author{
K. Cerosaletti ${ }^{1}$, C. Vissinga ${ }^{1}$, P.R. Cooper ${ }^{2}$, N.J. Nowak ${ }^{2}$, T.B. Shows ${ }^{2}$, E. Lange ${ }^{3}$, M. Boehnke ${ }^{3}$, \\ A.M.R. Taylor ${ }^{4}$, C.M.R. Weemaes ${ }^{5}$, D. Smeets ${ }^{5}$, K. Komatsu ${ }^{6}$, R.A. Gatti ${ }^{7}$ and P. Concannon ${ }^{1}$ \\ ${ }^{I}$ Virginia Mason Research Center and Department of Immunology, University of Washington School of \\ Medicine, Seattle, WA, USA \\ ${ }^{2}$ Roswell Park Cancer Institute, Buffalo, NY, USA \\ ${ }^{3}$ University of Michigan School of Public Health, Ann Arbor, MI, USA \\ ${ }^{4}$ University of Birmingham Medical School, Birmingham, UK \\ ${ }^{5}$ University Hospital of Nijmegen, Nijmegen, the Netherlands \\ ${ }^{6}$ Department Radiation Biology, Hiroshima University, Hiroshima 734, Japan \\ ${ }^{7}$ UCLA School of Medicine, Los Angeles, CA, USA
}

Nijmegen Breakage Syndrome (NBS) is a rare autosomal recessive disorder characterized by microcephaly, a birdlike face, growth retardation, immunodeficiency, and a significantly increased incidence of cancer. NBS cells display many of the same cellular phenotypes that characterize ataxiatelangiectasia cells including chromosomal instability, radiation sensitivity, and impaired cell cycle checkpoint control in response to ionizing radiation. However, both genetic, and functional complementation data indicate that these syndromes are genetically distinct. Saar et al. [1] have reported genetic linkage between markers at human chromosome 8q21 and NBS. We have previously reported localization of a gene for NBS to human chromosome 8q21-24 by complementation of radiation sensitivity in microcell hybrids [2]. We have now used linkage analysis of NBS pedigrees from the US, UK, Netherlands and Germany to confirm and extend this localization. Examination of recombinant chromosomes within these NBS pedigrees defined a $6.6 \mathrm{cM}$ minimal region for an NBS gene flanked by the markers D8S1757 and D8S270. Within this region, a significant allelic association was detected with the marker D8S1811. A physical map consisting of more than 90 PAC and BAC clones centered around D8S1811 has been assembled. Additional markers flanking D8S1811 have been identified and genotyped in an expanded panel of NBS families. These data reveal a common founder haplotype present in many, but not in all, NBS pedigrees. Inferred ancestral recombination events affecting this common haplotype limit the NBS gene to a region of approximately $1 \mathrm{Mb}$. 


\section{References}

[1] Saar et al. $A J H G$ 60, (1997) 605-610.

[2] Matsuura et al. AJHG 60, (1997) 1487-1494.

\section{An anti-sense constuct of full-length ATM cDNA imposes a radiosensitive phenotype on normal cells}

Philip Chen, Ning Zhang, Magtouf, Shaun Scott, Kum Kum Khanna, Dianne Watters and Martin Lavin

Queensland Cancer Fund Research Laboratories, The Queensland Institute of Medical Research, PO Royal Brisbane Hospital, Herston, Brisbane, QLD. 4029, Australia

The human genetic disorder ataxia-telangiectasia (A-T) is a multi-system disease manifested by abnormalities to the immune, nervous and endocrine systems [1]. A-T is a primary immunodeficiency involving both the cellular and humoral arms of the immune system resulting in progressive respiratory infection and bronchiostasis in some cases [2]. The most debilitating aspect of the disease is the cerebellar ataxia manifested by ataxic gait and truncal movements, dysarthric speech and involuntary movements. Degenerative changes in the brain occur predominantly in the cerebellum and involve primarily the loss of Purkinje and granular cells [2].

At the cellular level A-T is characterized by chromosome instability, hypersensitivity to ionizing radiation and inefficient cell cycle checkpoint activation. The A-T gene was initially mapped to chromosome 11q22-23 by Gatti et al [3], and more recently isolated by positional cloning [4]. This gene, ATM, occupies $150 \mathrm{~kb}$ of genomic DNA and codes for a $13 \mathrm{~kb}$ mRNA with an open reading frame of $9.165 \mathrm{~kb}$. The ATM protein is related to a family of phosphatidylinositol 3-kinase (PI3-kinase). ATM is localized to both the nucleus and cytoplasmic vesicles. Its nuclear localization is compatible with a role in sensing damage in DNA and the recent demonstration that ATM binds to and activates the nonreceptor protein tyrosine kinase, c-abl provides additional support for its role in cell cycle control [5].

The recent cloning of full-length ATM cDNA and its utilization to correct several aspects of the radiosensitive phenotype in A-T cells provides further confirmatory evidence that a single gene defect is responsible for the A-T phenotype[6]. In that study, induced expression of ATM from a metallothionein promoter enhanced the survival of irradiated A-T cells; decreased radiation-induced chromosome aberrations; reduced radioresistant DNA synthesis and partially corrected defective cell cycle checkpoints and induction of stress-activated protein kinase. Expression of a carboxy terminal region of ATM, which contains the PI3-kinase domain in a retroviral vector, complemented some aspects of the radiosensitive phenotype in A-T cells including radiosensitivity, radioresistant DNA synthesis and chromosome breakage [7]. In that study also, expression of a fragment containing a leucine zipper motif in a human tumour cell line abrogated the S-phase checkpoint and enhanced chromosome breakage. In another study, Ziv et al [8] show that ectopic expression of ATM in A-T cells restored normal sensitivity to ionising radiation and the radiomimetic drug neocarzinostatin, and a normal pattern of post-irradiation DNA synthesis, which represents a S-phase checkpoint. Here we describe the cloning of the full-length ATM cDNA in the anti-sense orientation and its utilization to abrogate various aspects of the radioresistant phenotype in normal control cells.

The effectiveness of expression of this construct in control cells was monitored by loss of ATM protein which was evidence over a period 6-12 h after induction. Even at $6 \mathrm{~h}$ post-irradiation the amount of 
ATM is markedly reduced. It seems likely that reduction of the ATM protein even to the extent of $50 \%$ as predicted in A-T heterozygotes alters the response to ionising radiation.

It is well established that cells with the mutated form of ATM are hypersensitive to ionising radiation. Here we investigated whether elimination of the ATM protein in normal cells might lead to a radiosensitive phenotype. Radiosensitivity was determined by measuring cell viability and levels of radiation-induced chromosome aberrations. Induction of anti-sense ATM cDNA in C3ABR cells with $\mathrm{CdCl} 2$ markedly increased the sensitivity of these cells to radiation but not quite to the same extent as observed in the A-T cell line, AT1ABR. Uninduced, transfected cells displayed a viability pattern similar to that of the parental control cell line. Expression of anti-sense ATM increased the number of induced chromosome aberrations per metaphase by about 2-fold, but was somewhat below that observed in A-T cells. Again when anti-sense ATM was expressed under the control of the metallothionein promoter a radioresistant pattern of DNA synthesis was exhibited by C3ABR cells, very similar to that in AT1ABR.

Furthermore, the expression of anti-sense ATM cDNA led to the abrogation of the G1/S checkpoint as evidence from the loss of the p53 response and that of its downstream effector, p21/WAF1, postirradiation. The extent of accumulation of transfected cells in $\mathrm{G} 2 / \mathrm{M}$ phase $24 \mathrm{~h}$ post-irradiation was similar to that observed in A-T cells and the induction of stress-activated protein kinase by ionising radiation was prevented by anti-sense ATM cDNA expression. These data demonstrate that full-length ATM anti-sense cDNA, by reduction the amount of ATM protein, is effective in imposing a series of known defects characteristic of A-T phenotype.

\section{References}

[1] Border, E. Ataxia-telangiectasia: an overview. In: R.A. Gatti and M. Swift (Eds), Ataxia-telangiectasia. New York, Alan R. Liss, (1985) 1-63. Kroc Found. Ser. 19.

[2] Sedgwich, R.P and Boder, E. In: Hereditary Neuropathies and Spinocerebellar Atrophies. De Jong J.M.B.V. ed. (1990) 347-432. Elsevier Science Publishers, Amsterdam.

[3] Gatti, R.A., Berkel, I., Boder, E. et al. Nature 336, (1988) 577-580.

[4] Savitsky, K., Bar-Shira, A., Gilad, S. et al. Science 268, (1995) 1749-1753.

[5] Khanna, K.K., Yan, J., Watters, D., Hobson, K., Beamish, H., Spring, K., Shiloh, Y., Gatti, R. and Lavin, M. J. Biol. Chem. 272, (1997) 9489-9495.

[6] Zhang, N., Chen, P., Khanna, K.K., Scott, S., Gatei, M., Kozlov, S., Watters, D., Spring, K., Yen, T. and Lavin, M. Proc. Natl. Acad. Sci. USA 94, (1997) 8021-8026.

[7] Morgan, S.E., Lovly, C., Pandita, T.K., Shiloh, Y and Kastan, M.S. Mol. Cell. Biol. 17, (1997) 2020-2029.

[8] Ziv, Y., Bar-Shira, A., Pecker, I., Russell, P., Jorhensen, T.J., Tsarfati, I. and Shiloh, Y. Oncogene 15, (1997) $159-167$.

\section{Proneness to cancer in italian Ataxia Telangiectasia families}

L. Chessa ${ }^{1}$, S. Prudente ${ }^{1}$, M. Piane ${ }^{1}$, O. Fiorani ${ }^{2}$ and G. Zei ${ }^{2}$

${ }^{I}$ Department of Experimental Medicine, Section of Genetic Metabolic Diseases, University "La Sapienza", Roma, Italy

${ }^{2} I G B E$ CNR, Pavia, Italy 


\section{Introduction}

Ataxia Telangiectasia (AT) heterozygotes (1-3\% of the general population) were worldwide referred to show high proneness to cancer, i.e. two-threefold the general population, six-fold for breast cancer $[1,4,6,9]$.

AT is rare but not infrequent in Italy, spread off all the country. In Italy a Registry for Ataxia Telangiectasia (RIAT) was set up in 1986 together with a Cell Repository. The RIAT data were computed on database to study the incidence of cancer in these families. One-hundred-ten AT families have been identified to date. Previous epidemiological studies [2] confirmed that AT patients suffer lymphoma and leukemia, rarely carcinoma or meningioma. Anamnestic data concerning 71 AT families show a significant increase of neoplasias [3].

\section{Materials and Methods}

The Italian Registry for Ataxia Telangiectasia, containing the data regarding 110 AT families, is continuously updated asking clinical and anamnestic informations to the physicians or directly to the families. In 86 families the informations received were complete (name, birthplace and birthdate; if dead, place, date and cause of death) for the parents, the sibs, the aunts/uncles and the grandparents of the probands. Data were incomplete for cousins, great-aunts/uncles and great-grandparents.

The estimate of the relative risk for an AT relative to die for cancer was obtained with the method of the "maximum likelihood" [8]. The association between AT and cancer was analyzed comparing the mortality for all types of cancer and for the different tumors in the relatives of AT homozygotes versus the mortality for cancer and for specific tumors in the matched general population. The estimate was based on the comparison of the frequency of deaths for tumor between the components of the AT families and the general population matched for sex, class of age and date of death. The period of death of the AT relatives under study was of about 30 years, from 1965 to 1995 . During this period the mortality rates in the Italian population were generally growing, with strong variations between the specific tumors. We chosen the mortality data of two years, 1973 and 1986, considered representative of this change and of the consequent variations in the estimate of the risk.

\section{Results \\ EPIDEMIOLOGIC DATA \\ Risk of death for all types of cancer}

Considering the frequency of deaths for cancer and for other causes between the male and female relatives of AT patients, subdivided for classes of age and relationship with the proband, the mortality rates for specific age were, in the AT families, always higher than in the general population in the two periods considered. The estimates of the relative risk confirmed the high proneness to cancer in the AT carriers, with values very similar to those referred in the literature.

\section{Risk of death for specific tumors}

The data regarding the great-aunts/uncles and the great-grandparents in the AT families were not used in the analysis of the frequency of deaths for different types of cancer because they were incomplete. Nevertheless, they could not modify too much the risk estimate, due to the low probability of heterozygosity of these relatives.

The comparison of the rates of mortality for the tumors most frequent in the Italian AT families with the values in the matched population using the log likelihood ratio test showed a significant increase of the mortality values in the AT male relatives for gastric, liver and prostatic cancer but not lung cancer. In the AT female relatives the mortality for breast, gastric, uterine and liver cancer appears significantly higher than in the matched population; nevertheless the low numbers allow us to consider these results with caution. 
The breast cancer is the most frequent tumor in the aunts and in the grandmothers of the AT probands. The estimate of the relative risk versus the 1973 matched population is 3.8, with a confidence interval $>1$ (1.37-6.23). Due to the increase of the mortality rates for this type of tumor during the years, the estimate of the relative risk when compared to the 1986 population is lower (2.4), with a confidence interval leading to a value $<1$ in the inferior limit.

The AT families newly incoming will probably modify the risk values but not the evidence of the strong association between the AT gene and the predisposition to cancer.

\section{MOLECULAR DATA}

Until the identification of the $A T M$ gene [7], there was no possibility to correlate the epidemiologic data on the cancer incidence in AT families with the heterozygosity status, except for the parents, obligate carriers. Twenty-five different mutations were recovered in 46 Italian AT patients from 37 different families [5,7, personal data]. The segregation analysis in these families was performed on DNA and/or RNA extracted from the lymphoblastoid cell lines stored in the RIAT Cell Repository. The heterozygosity was confirmed in the parents, obligate heterozygotes. Ninety-two out of one-hundredthirty relatives were shown to be heterozygous while thirty-eight resulted as wildtype. No significative difference in the incidence of cancer was observed between the two groups.

\section{Conclusions}

The cloning of the ATM gene allowed the direct identification of the AT heterozygotes; nevertheless the study of the cancer predisposition in the AT families is impaired by the fact that DNA is often not available from the relatives dead for cancer. In our opinion, the indirect method proposed by Swift and coworkers is still useful to analyze large samples of anamnestic data to study the association between AT and cancer.

\section{Acknowledgment}

This work was partially supported by Telethon grant E.337 to L.C.

\section{References}

[1] Borresen, A.L., Anderson, T.I., Tretli, S., Heiberg, A., Moller, P. Breast cancer and other cancers in Norwegian families with ataxia-telangiectasia. Genes Chromosomes Cancer 2, (1990) 339-340.

[2] Chessa, L. and Fiorilli, M. Epidemiology of ataxia-telangiectasia in Italy. In: Ataxia-Telangiectasia. NATO ASI Series, vol H 77. (1993) R.A. Gatti and R.B. Painter eds., Berlin, Springer, 191-197.

[3] Chessa, L., Lisa, A., Fiorani, O., Zei, G. Ataxia-Telangiectasia in Italy: Genetic analysis. Int. J. Radiat. Biol. 66, (1994) S31-S33,.

[4] Easton, D.F. Cancer risks in A-T heterozygotes. Int. J. Radiat. Biol. 66, (1994) S177-S182.

[5] Gilad, S., Khosravi, R., Shkedy, D., Uziel, T., Ziv, Y., Savitsky, K., Rotman, G., Smith, S., Chessa, L., Jorgensen, T.J., Harnik, R., Frydman, M., Sanal, O., Portnoi, S., Goldwicz, Z., Jaspers, N.G.J., Gatti, R.A., Lenoir, G., Lavin, M.F., Tatsumi, K., Wegner, R.D., Shiloh, Y. and Bar-Shira, A. Predominance of null mutations in ataxia-telangiectasia. Hum. Molec. Genet. 5, (1996) 433-439.

[6] Pippard, E.C., Hall, A.J., Barker, D.J.P., Bridges, B.A. Cancer in homozygotes and heterozygotes of AtaxiaTelangiectasia and Xeroderma Pigmentosum in Britain. Cancer Res. 48, (1988) 2929-2932.

[7] Savitsky, K., Bar-Shira, A., Gilad, S., Rotman, G., Ziv, Y., Vanagaite, L., Tagle, D.A., Smith, S., Uziel, T., Sfez, S., Ashkenazi, S., Pecker, I., Fridman, M., Harnik, R., Patanjali, S.R., Simmons, A., Clines, G.A., Sartiel, A., Gatti, R.A., Chessa, L., Sanal, O., Lavin, M.F., Jaspers, N.G.J., Taylor, A.M.R., Arlett, C.F., Miki, T., Weissman, S.M., Lovett, M., Collins, F.S., Shiloh, Y. A single Ataxia Telangiectasia gene with a product similar to PI-3 kinase. Science 268, (1995) 1749-1753. 
[8] Swift, M., Cohen, J. and Pinkham, R. A maximum-likelihood method for estimating the disease predisposition of heterozygotes. Am. J. Hum. Genet. 26, (1974) 304-317.

[9] Swift, M., Morrell, D., Massey, R.B., Chase, C.L. Incidence of cancer in 161 families affected by AtaxiaTelangiectasia. New Engl. J. Med. 325, (1991) 1831-1836.

\section{Polish patients with Nijmegen breakage syndrome. Clinical and genetic studies}

Krystyna H. Chrzanowska ${ }^{1}$, M. Krajewska-Walasek ${ }^{1}$, M. Bialecka ${ }^{1}$, E. Bernatowska ${ }^{2}$, E. Kostyk ${ }^{5}$, A.T. Midro ${ }^{6}$, M. Metera ${ }^{3}$, B. Goryluk-Kozkiewicz ${ }^{1}$, H. Gregorek ${ }^{2}$, J. Michalkiewicz $^{2}$, K. Madaliñski $^{2}$ and A. Brzeziñska ${ }^{4}$

${ }^{1}$ Department of Genetics, ${ }^{2}$ Immunology, ${ }^{3}$ Endocrinology and ${ }^{4}$ Clinical Psychology, Children's Memorial Health Institute, Warsaw, Poland

${ }^{5}$ Department of Genetics, Polish-American Children's Hospital, Collegium Medicum, Jagiellonian University, Cracow, Poland

${ }^{6}$ Department of Clinical Genetics, Medical University, Bialystok, Poland

Nijmegen breakage syndrome (NBS) is a rare autosomal recessive entity classified as an ataxia telangiectasia (AT) related disorder. Combined immunodeficiency, chromosomal instability, hypersensitivity to ionizing radiation and enhanced predisposition to malignancy are common for both conditions, but clinical presentation is clearly different. NBS patients show microcephaly, distinct facial appearance, growth retardation, normal serum a-fetoprotein levels and lack of the neurocutaneous manifestations of AT. The recent mapping of the NBS gene to chromosome $8 \mathrm{q} 21$ demonstrates that NBS is genetically distinct from AT [2]. The disease appears to be prevalent among Eastern and Central European populations, in particular among the Polish and Czech people.

Since our first report on 11 Polish NBS patients [1], further 23 cases have been identified at the CMHI in Warsaw, plus another 5 referred to us bringing the total number of studied patients to 39 (from 31 families), 20 females and 19 males. A detailed clinical, cytogenetic, immunological and biochemical investigations were performed to make an accurate diagnosis. Chromosome instability was present in all patients, and 7 or 14 rearrangements were found in $5 \%$ to $55 \%$ mitoses. The most characteristic immunologic findings were: 1) deficiency of IgG subclasses which is found in $100 \%$ of patients, even if total IgG levels are normal, 2) very low proportion of helper "virgin" cells and very high proportion of NK cells, which are also characteristic for AT. Twelve cases of malignancy were noted $(31 \%)$ in our material, including 11 lymphomas (8 of B-cell type) and 1 case of medulloblastoma; in all but one cases malignant trasformation occurred before the age of 15 years.

Follow-up observation of the entire group permitted us to study the evolution of physical and intellectual development. Serial measurements of height, weight and head circumference on 39 NBS patients were analyzed in comparison with age-matched healthy controls. Microcephaly, the major symptom of the disorder, is found in almost all of the children from birth and, in the first phase of development lasting about 2 years, is progressive. After an initial period of distinct growth inhibition lasting from birth to about the second year of life, a short period of accelerated growth occurs and later on the rate of physical growth stabilizes and resembles that in healthy children although, in absolute terms, on a significantly lower level. The observed abnormal female pubertal development (primary amenorrhea, lack of development of genital organs and breasts) induced us to analyze gonadal function in both sexes. Endocrinological investigations were performed in a total of 16 females and 11 males, of 
whom 4 and 6 respectively, reached pubertal age. Plasma concentrations of gonadotropins (FSH, LH), estradiol $\left(\mathrm{E}_{2}\right)$ in females, testosterone $(\mathrm{T})$ in males, prolactin, TSH, T, DHEA-S and b-hCG were quantitated by radioimmunoassay. Markedly elevated concentrations of FSH (from 65.0 to $167.0 \mathrm{IU} / \mathrm{ml}$ ) and LH (from 16.6 to $33.0 \mathrm{IU} / \mathrm{ml})$, as well as very low $\mathrm{E}_{2}$ levels $(<5.5 \mathrm{pg} / \mathrm{ml})$ were found in all 4 girls investigated at pubertal age, 3 of whom are currently over 18 years old. A serum FSH level $>40 \mathrm{IU} / \mathrm{ml}$ exceeds all values during normal menstrual cycles, as well as the usual diagnostic criterion for menopause. Repeated pelvic ultrasonography showed small homogenic ovaries and infantile uteruses. The results in 9 out of 12 investigated pre-pubertal girls also showed elevated concentrations of gonadotropins in relation to age (in 3 of them FSH levels exceeded $40 \mathrm{IU} / \mathrm{L}$, in 6 were below, but much higher than the reference values for age). From our observations it is obvious that affected females fail to reach sexual maturity due to hypergonadotropic hypogonadism. These findings clearly indicate ovarian failure. The results in pre-pubertal girls may predict a very high incidence of ovarian dysfunction in this syndrome. In the studied males, the levels of gonadotropins (FSH, LH) and testosterone corresponded to Tanner's classification of sexual maturity for boys. It seems that the pituitary - gonad axis in boys is intact. Further observation is needed before a final statement can be made on gonadal function in males.

General intellectual function was assessed with individually administered general intelligence tests in 35 patients. Retest scores, from 2 to 5 in number, were obtained from 19 subjects. Most of the patients tested in infancy and early childhood had IQ scores indicating normal or borderline intelligence, and demonstrated striking psychomotor hyperactivity as well as short attention span. Shifting towards a lower level of the intellectual function was observed at school age, and become more evident in subjects aged over 14 years (at that age, all tested patients were mildly or moderately retarded). In the analysis of the cognitive functions a specific decline in arithmetic, short term memory and abstraction faculty was found. It may be suspected that the decline in IQ is associated with neurological processes and needs to be investigated further.

Genealogical files including birthplaces of the ancestors of most of the probands were traced back four generations whenever possible. Our genealogical studies to date did not reveal consanguinity either among the parents or between the families.

\section{References}

[1] Chrzanowska, K.H., Kleijer, W.J., Krajewska-Walasek, M. et al. Am. J. Med. Genet. 57, (1995) 462-471.

[2] Saar K., Chrzanowska K.H., Stumm M. et al. Am. J. H. Genet. 60, (1997) 605-601.

\section{Assessment of the neurodegeneration in Ataxia Telangiectasia}

Thomas O. Crawford, Allen S. Mandir, Maureen Lefton-Grief, Steve Goodman, Haydar Sengul, Jerry A. Winklestein and Howard M. Lederman

Department of Neurology and Pediatrics, Johns Hopkins University, Baltimore, MD USA

Development of a clinical scale of the neurodegeneration of ataxia telangiectasia (AT) is important to prognosis and to the assessment of therapeutic interventions. Individual patient prognosis is difficult given that some cases may have a milder form with prolonged survival and less severe neurologic impairment. We report here the development of a disease-specific multi-dimensional clinical scale that 
outlines the AT phenotype in a cross-sectional manner, and the application of the scale to 50 consecutive patients.

Among patients less than 18 years there exists a clear linear relationship between age and the cumulative AT scale score $(\mathrm{r}=-0.73)$. Although these data reflect a cross sectional assessment of the disease rather than course of individuals, the high correlation coefficient and the data on 6 sibships where the average of the siblings' regressions agrees with the overall slope and intercept of the under 18 year old group - suggest that this is a good starting hypothesis about individual prognosis. There exist two distinct groups of patients, one with a severe and predictable phenotype and one with a mild and more widely variable phenotype. These groups likely represent patients with either full or partial disabling mutations of the ATM gene. This scale provides for earlier identification of individuals belonging to each of these groups.

The independent value of the 10 sub-scale measures indicates there is substantial variability in the character of the neurodegeneration from individual to individual, despite the high correlation of age to the overall score. This variability presents special difficulties for outcome assessment measures in treatment trials: there is need for an instrument that is at once practical, reliable, sensitive, broadly applicable across the range of affected individuals, and meaningful to patients as a surrogate for important functional abilities.

\section{Ataxia Telangiectasia cells are not deficient in poly (ADP-ribose) polymerase activity following $\gamma$ - ray and $\mathrm{H}_{2} \mathrm{O}_{2}$ treatment}

Françoise Dantzer, Josiane Ménissier de Murcia and Gilbert de Murcia

Ecole Supérieure de Biotechnologie de Strasbourg, UPR 9003 du CNRS, Laboratoire correspondant du CEA $n^{\circ} 14$, Boulevard Sébastien Brant, F-67400 Illkirch-Graffenstaden, France

Ataxia telangiectasia (AT) is an autosomal recessive disorder marked by progressive cerebellar ataxia and oculocutaneous telangiectases. Cell lines established from patients with AT exhibit a defect in DNA repair as well as cell cycle checkpoint abnormalities after ionising radiation. Both defects may contribute to the genomic instability and increased radiosensitivity observed in AT cells [1].

Poly(ADP-ribose) polymerase(PARP) is a zinc-finger enzyme involved in the detection of DNA strand breaks in the nuclei of most proliferating eukaryotic cells. In response to these breaks, PARP catalyses the transfer of the ADP-ribose moiety from its substrate, $\mathrm{NAD}^{+}$, to a limited number of protein acceptors involved in the maintenance of chromatin architecture or in DNA metabolism (heteromodification), including PARP itself (automodification) [2].

A number of similarities between PARP and ATM suggest that both proteins may be components of a single DNA damage-signalling apparatus: (i) PARP and ATM are both nuclear proteins and show the same tissue distribution [3,4]; (ii) both activities are activated after DNA damage [2,5]; (iii) recently, PARP $-/-$ mice, like ATM $-/-$ mice, were observed to exhibit acute radiation sensitivity, manifested particularly in the gastrointestinal tract, leading to the death of the mutant animal in less than seven days $[6,7]$.

It was previously investigated whether a difference in PARP activity could account for the enhanced sensitivity of AT cells to ionising radiation, these studies however, resulted in conflicting data $[8,9]$. Therefore, in this work we decided to re-evaluate the PARP response in the ATM background. 
Lymphoblastoid cell lines from AT patients (AT13) and normal individuals (1104) were irradiated with $\gamma$-ray $\left(10 \mathrm{~Gy}\right.$ ) at $4{ }^{\circ} \mathrm{C}$ or treated with $\mathrm{H}_{2} \mathrm{O}_{2} 1 \mathrm{mM}$ at $37^{\circ} \mathrm{C}$ and poly (ADP-ribosyl) ation activity was analysed by indirect immunofluorescence labelling of the ADP-ribose polymer by the $10 \mathrm{H}$ monoclonal antibody. A strong nuclear punctuated pattern was detected at the same extend in normal as well as in AT cells after $\gamma$-irradiation and $\mathrm{H}_{2} \mathrm{O}_{2}$ treatment, yet absent in control non damaged cells. Thus, our results revealed no deficiency in $\gamma$-ray and $\mathrm{H}_{2} \mathrm{O}_{2}$ stimulated poly(ADP-ribose) synthesis in the AT cell lines tested.

The translational expression of PARP in normal and in AT cells was assessed by western blot analysis using a monoclonal anti-PARP antibody and by an activity blot technique as described by Simonin et al [10]. The results show that the AT cell lines tested are not deficient in the expression of the PARP protein as well as the associated poly(ADP-ribosyl)ation activity.

In order to monitor the distribution of PARP activity in the cell cycle of AT cells following damage, we performed a flow cytometric analysis. PARP activity was detected using the $10 \mathrm{H}$ monoclonal antipoly(ADP-ribose) antibody whereas DNA content was measured by propidium iodide incorporation. The profile of poly(ADP-ribosyl)ation activity in the cell cycle was the same in AT as in normal cells after $\gamma$ irradiation and $\mathrm{H}_{2} \mathrm{O}_{2}$ treatment and showed an increase of polymer formation in S and $\mathrm{G} 2$ phases of the cell cycle. These results are in agreement with an important role of PARP controlling the genome integrity during DNA replication and preventing cells from passing the G2/M transition unless their genome has been repaired.

Our work shows that PARP activity is normal in AT cells suggesting at least, one of two possible alternatives: (i) PARP activity occurs upstream of ATM protein function, as a sensor of damage leading to the cell cycle arrest, apoptosis or DNA repair. (ii) PARP is involved in a distinct but similar pathway to that requiring ATM: both proteins are implicated in transducing the damage signal to the cell cycle regulators (Fig 1). In view of these two hypotheses, it was of interest to identify a possible interaction between PARP and ATM. To this end, we performed immunoprecipitation in HeLa cell extracts. We show that ATM is co-immunoprecipitated with PARP in HeLa cell extracts using a monoclonal antiPARP antibody. To define the biological significance of PARP/ATM interaction, ATM-dependent c-abl tyrosine kinase activation will be studied in PARP -/- cells and double knockout mice (ATM-/-; PARP $-/-)$ are also in progress.

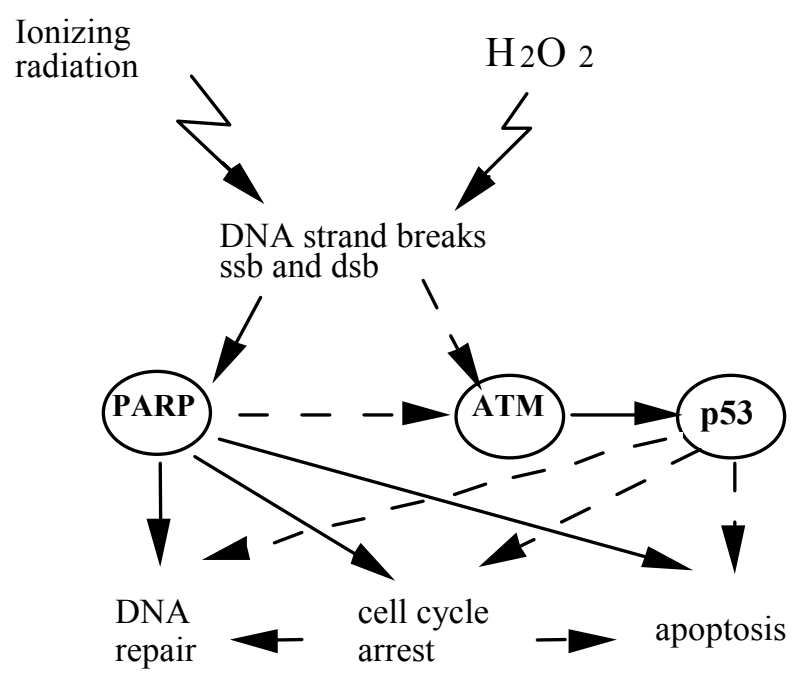

Fig. 1. 


\title{
References
}

[1] Lavin, M.F. Ataxia Telangiectasia H77. (1993) NATO ASI Series, 235-255.

[2] de Murcia, G. et al. TIBS 19, (1994) 172-176.

[3] Chen, G. et al. J. Biol. Chem. 271, (1996) 33693-33697.

[4] Concha et al. Exp. Cell. Res. 180, (1989) 353-366.

[5] Baskaran, R. et al. Nature 387, (1997) 516-519.

[6] Ménissier de Murcia, J. et al. PNAS, 94, (1997) 7303-7307.

[7] Barlow, C. et al. Cell 86, (1996) 159-171.

[8] Edwards, M.J. et al. Nature 287, (1980) 745-747.

[9] Zwelling, L.A. et al. Mutation Res. 120, (1983) 69-78.

[10] Simonin, F. et al. Anal. Biochem. 195, ( 1991) 226-231.

\section{Mutation analysis of the ATM gene in ataxia-telangeictasia families}

\author{
Thilo Doerk
}

Institute of Human Genetics, Medical School Hannover, D-30625 Hannover, Germany

The German ATM Consortium: T. Doerk, R. Bendix, B. Skawran, M. Stuhrmann, N. Sandoval, M. Platzer, A. Rosenthal, R. Wegner, K. Sperling, Y. Shiloh, A. Baumer, U. Bernthaler, H. Sennefelder, M. Brohm, B.H.F. Weber, D. Schindler.

Following the cloning of the ataxia telangiectasia gene over two years ago, several efforts have been made to investigate the molecular basis of this disease by the characterisation of different mutations within the ATM gene. Mutation analysis of the ATM gene provides a basis for structure-function studies and for genotype-phenotype correlations, and strongly improves the genetic counselling in affected families. In order to coordinate these efforts in Germany, the German ATM Consortium has formed in early 1996 and has collected and analysed samples from 61 families with members affected by ataxia telangiectasia. Clinical diagnosis was made on the basis of classical symptoms such as ataxia, telangiectasia, elevated AFP and altered immunoglobulin profiles, and was confirmed by increased cellular sensitivity to X-irradiation in cytogenetic analyses of radiation-induced chromosome breakage or flow cytometric analyses of cell cycle abnormalities. All patients in our study were apparently unrelated. After informed consent was obtained, genomic DNA was extracted from EDTA blood samples of the patients and, whenever possible, their parents. In a few cases, lymphoblastoid cell lines or fibroblasts served as the source for the extraction of genomic DNA. As sequence information of the entire ATM gene is now available [1], it has become possible to amplify any intragenic region of interest from genomic DNA. We have designed a screening strategy mainly based on exon scanning sequencing of genomic PCR products and supported by RT-PCR analysis to confirm the disease-causing nature of some mutations. A set of 75 PCR primer pairs was used to amplify all 66 exons including adjacent intron sequences from genomic DNA of 61 patients with ataxia telangiectasia. The PCR products were sequenced on both strands using dye-terminator chemistry and automated sequencing followed by two rounds of editing with the XGAP program. Identified mutations were verified by independent direct analysis, e.g. by restriction enzyme analysis. Whenever possible, chromosomal phase was determined by the analysis of parental samples. By this approach we have identified a total of 42 different mutations which are scattered throughout the entire ATM gene. These mutations account for 63 of the 122 AT 
alleles, corresponding to a detection rate of about 52\%. Approximately two-thirds of the identified mutations are expected to inactivate the ATM protein by premature termination or truncation. Truncating mutations were distributed throughout the entire gene without apparent clustering. One terminating mutation was located downstream of the predicted kinase domain, indicating that even premature stop codons in the very final part of the ATM protein exert deleterious consequences. Approximately onethird of the identified mutations are single base substitutions leading to an amino acid change. Only two of these missense substitutions were found to be common polymorphisms also in normal controls. The first, P1054R in exon 24, was three times more frequent on the AT alleles than on random control chromosomes, but this overrepresentation appeared to be due to its allelic association with the probable splicing mutation 3576G->A on half of the AT chromosomes. The second, D1853N in exon 39, had an allele frequency of about $15 \%$ in both, the AT and the control group. The other missense substitutions appear to be rare candidate AT mutations, although further studies are required to confirm their pathogenic nature. Two missense mutations were located in the PI-3-kinase signature, whereas none was found within the proposed leucine zipper and abl-binding site regions. A single amino acid deletion omitting one of three consecutive valines in exon 56 was identified in one homozygous German AT patient. Apart from two dozen variants and polymorphisms of uncertain biological significance, a few intronic substitutions affected the exon-flanking splice site consensus sequences. Some substitutions in the conserved splice dinucleotide signals were confirmed by RT-PCR analysis to cause skipping of the adjacent exon in lymphocyte ATM mRNA transcripts. Three different mutations of the last base of an exon, respectively, also led to exon skipping. In another patient, homozygosity for a substitution at the less conserved position +3 of the splice donor site was associated with the complete loss of the preceding exon in ATM mRNA transcripts from lymphoblastoid cells. Only three of the 42 mutations that we have identified so far, viz. 1563delAG, 3576G->A and R2443X, have previously been reported in other populations. It will thus be interesting to determine by haplotype analysis whether these mutations represent recurrent mutational events or whether they share a common ancestor. Only five of the mutations in our study panel were observed in more than one family, and none of these was particularly frequent. Our findings demonstrate an extensive allelic heterogeneity of ataxia telangiectasia in German AT patients and also indicate that a complete detection of ATM gene mutations in the molecular diagnosis of AT may require a combination of different approaches, one of which could be the direct sequencing of the entire ATM coding region from genomic DNA samples.

\title{
References
}

[1] Platzer et al. Genome Res. 7, 592-605.

\section{Never again joy without sorrow: the impact on siblings and parents of individuals with ataxia- telangiectasia}

\author{
J.H. Fanos ${ }^{1}$, R.A. Gatti ${ }^{2}$, H.M. Lederman ${ }^{3}$, D.A. Tagle ${ }^{1}$ and J.A. Winkelstein ${ }^{3}$ \\ ${ }^{I}$ National Human Genome Research Institute, NIH, Bethesda, MD, USA \\ ${ }^{2}$ University of California, Los Angeles, CA, USA \\ ${ }^{3}$ Johns Hopkins University School of Medicine, Baltimore, MD, USA
}


The ATM gene, mutated in ataxia telangiectasia (A-T), has been identified by positional cloning. The discovery of ATM will allow the identification of A-T heterozygotes, who may be at increased risk of cancer. The aims of this study were to assess levels of understanding of the genetics of A-T and attitudes toward carrier testing in families of A-T affected individuals. One hundred and three individuals (68 parents, and 35 adult or adolescent siblings) were interviewed. Eighty-four percent of parents would like their child tested for carrier status before the age of 18. Eighty-two percent of parents believed heterozygosity to be associated with increased health risks. Only nine percent of parents knew each well sibling had a two-thirds chance of being a carrier; $79 \%$ underestimated the risk. Of the 26 adult siblings, $85 \%$ believed that, if there is a child with A-T, both parents have to be carriers. Seventy-three percent of adult siblings believed heterozygosity to be associated with increased health risks. Seventy-six percent of adult siblings knew the A-T gene had been identified; $92 \%$ percent said they would request carrier testing for themselves if testing were available; $69 \%$ would test their child for carrier status before the age of 18 .

Siblings struggle with the psychological impact of a genetic burden outside the genetic counseling system, and have numerous misconceptions surrounding carrier status and genetics of A-T. Parents and siblings need emotional support from the time of diagnosis in order to comprehend genetic implications for their lives.

\title{
Acknowledgment
}

Funded by an Intramural Award, Medical Genetics Branch, National Human Genome Research Institute, NIH (to J.H.F.).

\section{The yeast tel1 gene can substitute for atm in suppressing hyperrecombination and radiosensitivity}

\author{
E. Fritz ${ }^{1}$, T. Petes ${ }^{2}$ and M.S. Meyn ${ }^{1,3}$ \\ Departments of Genetics ${ }^{I}$ and Pediatrics ${ }^{3}$, School of Medicine, Yale University, 333 Cedar Street, SHM-I- \\ 322, New Haven, CT 06510, USA \\ ${ }^{2}$ Department of Biology, University of North Carolina, Chapel Hill NC, USA
}

The S. cerevisiae TEL1p protein is the member of the ATM family of large kinases that has the greatest sequence homology to ATM. We here show that overexpression of TEL1 in AT fibroblasts complements radiation-induced apoptosis and high spontaneous intrachromosomal recombination rates, phenotypic defects typically seen in AT cells.

For expression of the TEL1 gene in mammalian cells, the whole insert of pSP21 was cloned into the expression vector pRep5. Expression of TEL1 in stably transfected AT fibroblasts (AT5BIVA) was detected by RT-PCR. Phenotypic analyses of stably transfected AT cells showed that TEL1-transfected cells were partly complemented with regard to radiation-induced apoptosis when compared to parental AT cells, vector-transfected controls and controls containing a truncated TEL1 version. Colony survival after irradiation of TEL1-transfected AT cells and streptonigrin-selected subclones was only slightly enhanced compared to parental AT cells and transfected controls. The ability of TEL1 to partially complement radiosensitivity in AT cells resembles earlier data obtained in S. cerevisiae, showing that an extra copy of TEL1 can compensate the sensitivity of MEC1 mutants to DNA-damaging agents.

One manifestation of genomic instability of AT cells is a high recombination rate. Analysis of the frequency and rates of spontaneous intrachromosomal recombinational events in TEL1-transfected AT 
cells was performed by histochemical staining of recombination-positive cells. The fraction of primary TEL1-transfected A-T colonies containing cells with detectable recombination events $(0.15 \%)$ was significantly lower than the fraction of recombination-positive colonies of vector-transfected controls $(2.3 \%)$, or A-T colonies harboring the truncated version of the TEL1 construct $(1.65 \%)$. Moreover, fluctuation analyses showed that the spontaneous recombination rate of TEL1-transfected AT cells was suppressed to $\sim 10 \%$ of the rates in parental AT cells or vector controls.

We conclude that TEL1 can functionally substitute for ATM with regard to radioprotection and control of spontaneous intrachromosomal recombination in AT cells. The ability of TEL1 to complement specific defects in AT cells may be the result of amino acid domains that are functionally equivalent between the ATM and TEL1 proteins. Phenotypic analysis of TEL1-transfected AT cells may thus ultimately aid the functional analysis of different ATM domains.

\title{
Loss of heterozygosity (LOH) at the ATM locus in colorectal adenocarcinomas
}

\author{
Maria Grancho ${ }^{1}$, Jacques-Olivier Bay ${ }^{1}$, Sandrine Gosse-Brun ${ }^{2}$, David Pernin ${ }^{1}$, Pascale Rio ${ }^{1,3}$, \\ Alain Daver ${ }^{2}$ and Yves-Jean Bignon ${ }^{1}$ \\ ${ }^{1}$ Laboratoire d'Oncologie Moléculaire INSERM CRI 9502 \& EA 2145, Centre Jean Perrin, BP 392, \\ 63011 Clermont-Ferrand, France \\ ${ }^{2}$ Service de Radiothérapie, Centre Paul Papin, 2 rue Moll, 49036 Angers, France \\ ${ }^{3}$ INSERM U71, BP 184, 63005 Clermont-Ferrand, France
}

Ataxia-telangiectasia (A-T) is an autosomal recessive childhood disease resulting from mutation in the ATM gene [1]. One of the cardinal features of this disorder is the genetic predisposition to cancer. Lymphomas of B-cell origin and acute lymphocytic leukemias are the most common malignancies in A-T patients [2]. However, in patients over the age of 15, non-lymphoid cancers such as stomach, liver, uterine and ovarian carcinomas become more prevalent. A-T heterozygotes may also have an increased tendency to develop cancers. The degree of risk to A-T carriers is still unclear. The latest estimate of the relative risk for cancer is 3.8 and for breast cancer in particular is 3.9. Adenocarcinomas such as gastric and breast cancers are observed more frequently in heterozygotes [3].

Colorectal tumors are the second most common cancer in the general population. Familial aggregations have been described, such as the hereditary non-polyposis colorectal cancer syndrome (HNPCC). The mutated genes observed in this syndrome (hMSH2, hMLH1, hPMS1 and hPMS2) are involved in the DNA mismatch repair process [4]. However, additional genes appear to be involved in colorectal carcinogenesis (e.g. K-RAS-2, DDC, TP53, cMYC). The "multistep" model of Vogelstein et al. gives a hypothesis of the correlation between clinicopathological variables and genetic alterations of oncogenes or tumor suppressor genes. Most of these genes are involved in the cell cycle regulation [5]. According to the DNA Damage Surveillance Network model (DSN) described by Meyn, ATM activates cell cycle checkpoints including the p53-dependant G1/S checkpoint and also promotes survival of the cell [6].

Loss of heterozygosity studies (LOH) on chromosome 11q and more specifically at the ATM locus in ovarian, head and neck, and breast cancers suggest that one or more tumor suppressor genes may be located in this chromosomal region. In breast cancer, the incidence of LOH at the ATM locus is estimated to be 30 to $40 \%$ [7]. 
To further investigate the role of ATM in colorectal adenocarcinomas we have examined 82 tumors compared to normal control DNA from the same patients for LOH using five microsatellite markers flanking ATM. D11S1816 and D11S1819 are both proximal to ATM, D11S2179 is within the gene and D11S1294 and D11S1818 are distal. The total distance between D11S1816 and D11S1818 is $1.4 \mathrm{cM}$. Our population consisted of 4 stage A (Dukes), 39 stage B, 33 stage C and 6 stage D.

The incidence of allelic loss per informative patient was as follows:

$19.4 \%$ at the marker D11S1816, $18.3 \%$ at D1 $1 \mathrm{~S} 1819,12.8 \%$ at D11S2179, $17.2 \%$ at D11S1294 and $12.2 \%$ at D11S1818. The level of $\mathrm{LOH}$ found at $11 \mathrm{q} 23.1$ was less than the 25 to $30 \%$ generally considered significant for a loss of a locus in cancer. Thus, it appears that the loss of one ATM allele is not commonly involved in colon cancer.

Because microsatellite instability (MI) is common in colon cancer particulary in HNPCC, we looked for MI at the loci we tested for LOH. We found seven cases of microsatellite instability at D11S1294 and one case at D11S1816 out of 820 alleles tested across the five loci. The statistical analysis showed a correlation between MI and LOH at D11S1294, and the location of the tumor. Tumors of the left colon had more LOH while tumors of the right colon showed more genomic instability $(p<0.05 ; c 2=7.1)$. The p-values should improve with larger sample size. Also, the finding of MI at a single locus in these eight cases needs to be verified at additional microsatellites to establish that they are due to defects in mismatch repair, rather than an isolated errors.

\section{References}

[1] Savitsky, K. et al. A single gene with a product similar to PI-3 kinase and Rad 3+ is mutated in ataxia telangiectasia. Science 268, (1995) 1749-1753.

[2] Morrell, D. et al. Mortality and cancer incidence in 263 patients with ataxia telangiectasia. J. Natl. Cancer Inst. 77, (1986) 89-92.

[3] Easton, D.F. Cancer risks in AT heterozygotes. Int. J. Radiat. Biol. 66, (1994) 177-182.

[4] Marra, G. Hereditary nonpolyposis colorectal cancer: the syndrome, the genes, and historical perspectives. $J$. Natl. C. Inst. 87, (1995) 1114-1125.

[5] Vogelstein, B. et al. Genetic alterations during colorectal tumor development. N. Engl. J. Med. 319, (1988) $525-532$.

[6] Meyn, M.S. Ataxia-Telangiectasia and cellular responses to DNA damage. Cancer Res. 55, (1995) 5991-6001.

[7] Hampton, G.M. et al. Loss of heterozygosity in sporadic human breast carcinoma: a common region between 11q22 and 11q23.3. Cancer Res. 54, (1994) 4586-4589.

The role of the Nijmegen Breakage Syndrome in the p53 mediated response to DNA damage produced by ionising radiation

Janet Hall ${ }^{1}$, Michèle Vuillaume ${ }^{1}$, Wim Jongmans ${ }^{1}$, Krystyna Chrzanowska $^{2}$, Dominique Smeets ${ }^{3}$ and Karl Sperling ${ }^{4}$

${ }^{1}$ Unit of Mechanisms of Carcinogenesis, International Agency for Research on Cancer, 150 cours Albert Thomas, 69372, Lyon Cedex 08, France

${ }^{2}$ Department of Human Genetics, The Children's Memorial Health Institute, Al. Dzieci Polskich 20, 04736 Warsaw, Poland

${ }^{3}$ Department of Human Genetics, University Hospital Nijmegen, P.O. Box 9101, 6500 HB Nijmegen, the Netherlands 
${ }^{4}$ Institute of Human Genetics, Virchow-Klinikum der Humboldt Universität zu Berlin, Augustenburger Platz 1, D-133353 Berlin, Germany

The functionality of the p53-mediated pathway, activated in response to DNA damage has been assessed in primary fibroblast cell cultures and EBV-transformed lymphoblastoid cell lines derived from Nijmegen Breakage Syndrome (NBS) patients. This autosomal recessive disease is characterized by microcephaly, growth and mental retardation, chromosomal instability, radiosensitivity, and high cancer incidence [1]. Changes in p53 protein levels were significantly reduced and delayed in all the NBS fibroblast cell cultures and lymphoblastoid cell lines examined compared to normal cultures over a $4 \mathrm{~h}$ period post-irradiation (5 Gy). The transcriptional activation of WAF1/CIP1(p21) mRNA was also lower in the NBS fibroblast cultures after such treatment.

Mean increases in WAFl/Cip1(p21) mRNA of $3.1 \pm 1.1$ and $5.3 \pm 1.4$ were observed $2 \mathrm{hrs}$ and $4 \mathrm{hrs}$ after exposure to $5 \mathrm{~Gy}$ ionising radiation in $12 \mathrm{NBS}$ fibroblast cultures compared with mean increases of $9.4 \pm 3.0$ and $14.0 \pm 3.1$ at $2 \mathrm{hrs}$ and $4 \mathrm{hrs}$ post-irradiation in 7 normal fibroblast cultures. In contrast, the increase in p53 protein and WAFl/CIPl(p21) mRNA expression following exposure to the alkylating agent methylmethane sulphonate $(100 \mu \mathrm{g} / \mathrm{ml})$ was similar in both NBS and normal cell cultures. In agreement with an abrogated p53 function, NBS cells exposed to ionizing radiation show an abnormal cell cycle arrest at G1-S and a prolonged accumulation of cells in G2-phase [2]. These responses are remarkably similar to those seen in cell lines derived from Ataxia telangiectasia patients, a clinically and genetically distinct disease and suggest that both gene products are involved in the activation of the p53 mediated damage response following exposure to ionising radiation.

\title{
Acknowledgment
}

The financial support to JH from the EU contract number (ERB CHRX-CT 940581) is gratefully acknowledged.

\section{References}

[1] Chrzanowska et al. Am. J. Med. Genet. 57, (1995) 462-471.

[2] Jongmans et al. Mol. Cell Biol. 17, (1997) 5016-5022.

\section{Role of the ataxia-telangiectasia gene in radiation sensitivity and breast cancer}

\author{
J. Hall ${ }^{1}$, M. Vuillaume ${ }^{1}$, W. Jongmans ${ }^{1}$, A. Brémond ${ }^{2}$, J.P. Gérard ${ }^{3}$ and P. Romestaing ${ }^{3}$ \\ ${ }^{1}$ International Agency for Research on Cancer, Lyon, France \\ ${ }^{2}$ Centre Régional Léon Bérard, Lyon, France \\ ${ }^{3}$ Service de Radiothérapie-Oncologie, Centre Hospitalier Lyon Sud, Pierre Benite, France
}

Several studies have shown that a significant proportion (up to 16\%) of breast cancer patients show an exaggerated acute or late reaction of normal tissues following radiotherapy which correlates with in vitro radiosensitivity. In order to assess the role of the Ataxia Telangiectasia (ATM) gene in radiation 
sensitivity, lymphoblastoid cell lines have been established from breast cancer patients showing an adverse skin reaction to radiotherapy (EORTC-RTOG grading of $\geq 3$ ). Cell survival analysis following in vitro exposure to ionising radiation has demonstrated that these breast cancer $(\mathrm{BC})$ cell lines showed a level of cell killing intermediate to that observed between AT homozygote and normal lymphoblastoid cell lines. The induction of the p53 protein following exposure to ionising radiation was found to be significantly reduced in all the $\mathrm{BC}$ cell lines examined. The relative increase of $\mathrm{p} 53$ protein in the treated cells compared to the untreated cells $4 \mathrm{hrs}$ after exposure to $5 \mathrm{~Gy}$ ionising radiation was $3.5 \pm 0.5$ in $12 \mathrm{BC}$ lines, $2.5 \pm 1.2$ in 10 AT homozygote cell lines, $4.9 \pm 2.3$ in 7 AT heterozygote cell lines and $7.2 \pm 1.1$ in 7 normal cell lines. These preliminary results would suggest that there is a germ line alteration responsible for the adverse skin reactions to radiotherapy observed in these $\mathrm{BC}$ patients and the results obtained on the p53 inducibility are indicative of an alteration in the ATM signaling pathway. The mutation status of the $A T M$ gene in these $\mathrm{BC}$ lines is presently being investigated.

\section{Acknowledgement}

Financial support to JH from the European Union (grant CT94051), Association pour la Recherche sur le Cancer and La Ligue Nationale Contre Le Cancer, Comité Départemental du Rhône are gratefully acknowledged.

\section{Linkage analyses in ataxia telangiectasia variants}

J.A.P. Hiel ${ }^{1}$, M.J. van Belzen ${ }^{2}$, C.M.R. Weemaes ${ }^{2}$, D. Smeets ${ }^{3}$, B.G.M. van Engelen ${ }^{4}$, F.J.M. Gabreels ${ }^{4}$ and L.P. van den $\mathrm{Heuvel}^{2}$

${ }^{1}$ Department of Neurology, St. Joseph Hospital, P.O. Box 7777, Veldhoven, the Netherlands

${ }^{2}$ Departments of Pediatrics, ${ }^{3}$ Human Genetics and ${ }^{4}$ Neurology, Academic Hospital Nijmegen, P.O. Box 9101, 6500 HB Nijmegen, the Netherlands

Ataxia telangiectasia (AT) is an autosomal recessive multisystem disorder characterized by progressive cerebellar ataxia with onset in childhood, oculocutaneous telangiectasia, high levels of alpha-foetoprotein, variable immunodeficiency, chromosomal instability (especially of chromosomes 7 and 14) and cancer predisposition. AT cells are hypersensitive to ionizing radiation and radiomimetic chemicals. The gene responsible for AT was recently identified by positional cloning on chromosome 11q22-23 and designated ATM, AT mutated [1,2]. The ATM gene, which has a major transcript of 13 kilobases, spans approximately $150 \mathrm{~kb}$ of genomic DNA and consists of 66 exons. The initiation codon falls within exon 4. The last exon is 3.8 kilobases and contains the 3 'untranslated region of about 3600 nucleotides. The ATM gene product is a putative $350 \mathrm{kDa}$ protein with a phosphatidylinositol-3'-kinase-like domain, presumably involved in mitogenic signal transduction, meiotic recombination, and cell cycle control.

The term AT variants is used for syndromes that exhibit only some of the hallmarks of AT. They usually represent milder forms of the classical AT phenotype, with no additional features. Age of the onset of the clinical signs is later, progression of the disease is slower, life span is longer and extent of chromosomal instability and cellular radiosensitivity is less. We recently described two patients with AT variant belonging to one family [3]. They presented with a juvenile resting tremor at adult age. Genomic DNA of this family was available for linkage analyses. Markers flanking the previously described locus 
for the ATM gene on chromosome 11q22-23 will be chosen. Linkage analyses will be performed to elucidate the possible involvement of the ATM gene as disease causing gene in these AT variants.

\section{References}

[1] Savitsky et al. Science 268, (1995) 1749-1753.

[2] Savitsky et al. Hum. Mol. Genet. 4, (1995) 2025-2032.

[3] Hiel et al. Movement Disorders 9, (1994) 460-462.

\section{Signalling pathways downstream of $A T M$ and $A T R$}

Merl F. Hoekstra ${ }^{1}$, Gail Flaggs ${ }^{1}$, Kathy Keegan ${ }^{1}$, Erik R. Christenson ${ }^{1}$, Dan Herendeen ${ }^{1}$, Tony Carr ${ }^{2}$, Annemieke Plug ${ }^{3}$, Terry Ashley ${ }^{3}$, Christoph Westphal ${ }^{4}$ and Phil Leder ${ }^{4}$

${ }^{1}$ ICOS Corporation, Bothell, Washington, USA

${ }^{2}$ MRC Cell Mutation Unit, University of Sussex, Falmer, Brighton, UK

${ }^{3}$ Department of Genetics, Yale University School of Medicine, New Haven, Connecticut, USA

${ }^{4}$ Department of Genetics, HHMI, Harvard University, Cambridge, Massachusetts, USA

Cell cycle checkpoint responses involve a series of genetically-defined steps that result from a response to a specific lesion, the amplification of a signal, and the activation of specific effectors. Based on model systems like $S$. cerevisiae and $S$. pombe, the detectors could include homologues of human ATR and ATM protein kinases and signalling could proceed through effectors such as $\operatorname{Rad} 1^{\mathrm{sp}}$, Rad $17^{\mathrm{sp}}$, $\mathrm{Cds} 1 \mathrm{sp} / \mathrm{Rad} 53^{\mathrm{sc}}$, and $\mathrm{Rad} 27 \mathrm{sp} / \mathrm{Chk} 1^{\mathrm{sp}}$. In order to understand in greater detail the process of checkpoint signalling, we have isolated and characterized components of the human and mouse cascades that respond to ATR and ATM and have examined the activities of specific effectors to alterations in ATR and ATM activity.

The best characterized system to examine ATR and ATM regulation is during the process of meiosis. Here, a germ cell proceeds through a well-defined set of chromosome interactions that include programmed DNA strand interruptions and genetic recombination, chromosome condensation and pairing, and chromosome segregation.

We have previously shown that ATR associates with asynapsed arms of pairing chromosomes. Furthermore, consistent with the meiotic defects in $\mathrm{A}^{-} \mathrm{T}^{-} / \mathrm{A}-\mathrm{T}^{-}$patients and $\mathrm{atm}^{-} / \mathrm{atm}^{-}$mice, ATM also associates with meiotic chromosomes. One of the potential downstream signalling molecules for Atm and Atr is human/mouse Chk1. HuChk1 and MmChk1 is most highly expressed in testes, particularly during meiosis I (MI). Immunoprecipitation experiments confirm protein kinase activity for Chk1 and cytological analysis shows that Chk1 associates with meiotic chromosomes at a phase of MI temporally and spatially later than Atr and Atm. While not a direct or genetic interaction, Chk1 appears downstream in a signalling cascade.

A second potential downstream target for Atm and Atr is $\mathrm{p} 53$. We have investigated this in $\mathrm{atm}^{-} \mathrm{p} 53^{-}$ mice and find that testicular apoptosis in double mutants is similar to atm ${ }^{-}$mice, suggesting that the elevated lesions that initiate MI recombination do not require p53 for maintaining viability but do require Atm for preventing cell death. Further, Atr is severely affected in $\mathrm{atm}^{-}$mice. In a p53-independent, Atmdependent fashion, we find that Atr show normal chromosome interactions on asynapsed arms and is 
present at normal levels in $\mathrm{atm}^{-}, \mathrm{p} 53^{-}$and $\mathrm{atm}^{-} \mathrm{p} 53^{-}$mice. Significantly, Atr is hypophosphorylated in $\mathrm{atm}^{-}$testes and shows little, if any, protein kinase activity. These data suggest two roles for Atr in MI: a structural and chromosome-associating role that does not require Atm or p53 for its role in early MI and a protein kinase active-role later in MI that is Atm-dependent. Furthermore, we find little possible important role for $\mathrm{p} 53$ in the normal meiotic process.

Finally, a third potential effector for Atr and Atm is Brcal. The Brcal protein associates with meiotic chromosomes in a fashion similar to Atr. Brcal shows cell cycle- and DNA damage-dependent phosphorylation. The phosphorylation at G1-S and after damage is neither DNA-PK- nor Atm-dependent and neither protein kinase phosphorylates Brcal with high efficiency. In contrast, Atr co-localizes with Brcal on meiotic chromosomes, co-immunoprecipitates with Brcal and phosphorylates Brca1 in vitro. In total, these data suggest complex signalling cascades downstream of Atr and Atm that include the Brca1 tumor suppressor and a new human checkpoint gene product, Chk1.

\title{
Elevated frequency of p53-independent programmed cell death after irradiation increases levels of DNA breaks in ataxia telangiectasia lymphoblasts
}

\author{
Bostjan Humar, Hansjakob Müller and Rodney Scott
}

Human Genetics, Department Research, University Hospital, CH-4031 Basel, Switzerland

Ataxia telangiectasia (AT) is a recessive genetic disease featuring cerebellar degeneration, developmental abnormalities, high cancer risk, immunodeficiency, and radiosensitivity. Increased levels of unrepaired DNA breaks have been observed in irradiated AT cells compared to normal cells, however, no specific DNA break rejoining rate deficiency has been defined. Alterations in radiation-induced p53dependent programmed cell death (PCD) have been reported for AT cells.

We investigated the radiation response of AT lymphoblastoid cells using the comet assay, an electrophoretic technique, which allows for the quantitation of DNA breaks in individual cells. Early after exposure to $\gamma$-rays, AT lymphoblasts exhibit an elevated frequency of cells harbouring highly fragmented DNA (highly damaged comets or HDCs), which increase the apparent number of DNA breaks relative to controls during post irradiation incubation. Apart from HDCs, AT lymphoblasts have an identical capacity to rejoin radiation-induced DNA breaks as controls.

The number of HDCs after irradiation can be substantially reduced by high serum levels, indicating a protective role of serum towards this type of DNA fragmentation. Further, HDCs represent living and not necrotic cells as shown by FACS analysis. Since the increase in HDCs with radiation dose correlates with an increase of pyknotic nuclei in AT cells after irradiation, we propose that HDCs, at least in part, are cells undergoing PCD. The PCD involved appears to be independent of $\mathrm{p} 53$, as we did not observe radiation-induced $\mathrm{p} 53$ activation at studied time points in AT-lymphoblasts.

We propose that in addition to $\mathrm{p} 53$-dependent PCD, a p53-independent PCD response to radiation is likewise altered in AT lymphoblasts. Importantly, the elevated PCD that we observed early after exposure to $\gamma$-rays may explain the occurence of residual unrepaired DNA breaks detected in AT cells. Furthermore, these results suggest that p53-independent PCD may contribute to the radiosensitivity and some of the immune defects observed in AT patients. 


\title{
Management of children with Ataxia-Telangiectasia
}

\author{
Nada Jabado, Mariane Debré and Alain Fischer
}

Unité d'immunologie et d'hématologie pédiatrique, Hôpital Necker Enfants Malades, 149 rue de Sèvres, 75015 Paris, France

Ataxia-Telangiectasia (A-T) is an autosomal recessive multisystem disease characterized by neurodegeneration, immunodeficiency, predisposition to cancer, radiosensitivity and genetic implications ( $1 \%$ heterozygotes for A-T). There is no curative treatment for this disease, however, symptomatic treatment help improve quality of life and survival of children with A-T.

Neurodegeneration is responsible of a progressive unremitting loss of all major motor functions.

The delay and the pace of this loss vary with children, however, most lose the capacity to walk by 10 years. Later on, capacity to draw or write, speech and reading are impaired further limiting their contacts with a normal environement. Symptomatic treatment is based on individualized physical therapy which should be instaured early. It doesn't prevent or delay the degeneration, however it can prevent or lessen muscular retractions, and counsel on the possible physical activity the child may have. Pharmacological agents have little impact and should be assessed individualy. Immunodeficiency is present in 50 to $70 \%$ of children. Severe recurrent sinopulmonary infections partly due to immunoglobulin deficiencies (various combinations of $\operatorname{IgA}, \operatorname{IgE}, \operatorname{IgG} 2$ and 4 deficiency) are observed. Pneumonitis and the evolution to bronchiectasia are also majored by the swallowing problems these children have. Treatment is based on regular Ig substitution, with a major role for physical therapy and a wide use of antibiotics when an infection is suspected. All obligatory and recommended vaccinations should be performed in children with A-T who, excluding the response to polysaccharidal antigens, may have normal vaccinal responses. Patients with A-T have a higher incidence of cancer than the rest of the population. Lymphomas and leukemias represent $75 \%$ of all cancers, with a five-fold increase in T cell tumours as compared to B cell tumours, and epithelial carcinomas represent $25 \%$. The treatment of these malignancies should be individualized: patients with A-T are highly sensitive to chemotherapeutic agents which can be severely toxic. Also, there is a potential for disease control using low doses of chemotherapy and avoiding, if possible, radiotherapy and radiomimetic agents. Genetic counselling is another major hallmark of the disease. Implications on the family and siblings are high. The possibility of a pre-natal diagnosis in a family with a previously affected child opens new hopes. However, the necessity as to the detection of heterozygotes in A-T families remains an unsolved question.

In summary the management of children with A-T calls for an individualized care with the help of the general practician or peadiatrician in charge of the child. However, disease rarity and the multisystem character of this disorder also call for a multidisciplinary care in specialized centers where ideally a neurologist, an immunologist, an oncologist, a physiotherapist and a genetic counsellor regularly see the children with A-T. This care will help us improve the quality of life and survival of children, gather data on the evolution of these patients with a rare disease and possible new unforseen complications, and lastly, ensure for the families a continuous quality information on the advances made in this disease. 


\section{Breast cancer risk in AT heterozygotes from 34 french families with an AT affected child}

Nicolas Janin ${ }^{1}$, Nadine Andrieu ${ }^{2}$, Katia Ossian ${ }^{1}$, Anthony Laugé ${ }^{3}$, Marie-Françoise Croquette ${ }^{4}$, Claude Griscelli $^{5}$, Marianne Debré ${ }^{5}$, Brigitte Bressac de Paillerets ${ }^{1}$, Alain Aurias ${ }^{3}$ and Dominique StoppaLyonnet $^{3}$

${ }^{1}$ Institut Gustave Roussy, Villejuif, France

${ }^{2}$ U351 Inserm, Institut Gustave Roussy, Villejuif, France

${ }^{3}$ Institut Curie, Paris, France

${ }^{4}$ Hôpital Saint-Antoine, Lille, France

${ }^{5}$ Hôpital des Enfants Malades, Paris, France

Epidemiological studies in AT families have suggested that AT heterozygotes (HetAT) could have an increased cancer risk especially for breast cancer in women (relative risk: 3.9, 95\%CI 2.1-7.2 in Easton 1994). However, this finding is still controversial. As the previously suggested genetic heterogeneity of the four AT complementation groups has been rejected by the identification of the ATM locus, it is now possible to examine the segregation of AT linked haplotypes in families with an AT affected child to identify heterozygotes with a sensitivity close to $100 \%$. This approach should permit the risk of cancers associated with ATM heterozygosis to be better estimated. Since the ATM protein is involved in the repair pathway of radio-induced DNA alterations, this estimate may be an important goal for screening and management of breast cancer of HetAT women, whose frequency may be as high as $1 \%$ in the general population.

An epidemiological study of cancer risks associated with AT heterozygosis is being conducted. Heterozygotes are identified through segregation of AT linked haplotypes in families with an AT affected child. Information on ionizing radiation exposures is also collected. At present, 34 French families have been recruited from pediatricians and cytogeneticists who are clinically following the AT children or who have contributed to the diagnoses of AT. All contacted families, except one, consented to participate. Participation of families (grandparents, uncles and aunts, parents and siblings of the AT subject plus the AT subject) consists of providing a blood or buccal cells sample and answering a physician-administrated questionnaire on medical history and exposures to medical and occupational radiation. DNA samples from 401 individuals have been studied so far. Eight microsatellite markers of the ATM gene were analyzed, including seven flanking markers [two centromeric (D11S1817, D11S1819), five telomeric (D11S1294, D11S2180, D11S2178 D11S1300, D11S1391), one intragenic (D11S2179)]. Haplotype construction identified 201 HetAT. Confirmation of declared neoplasm status and statistical analysis of cancer associations in the families are currently being conducted. Association with breast and other cancers will be examined and discussed.

\section{Interaction between the Ataxia-telangiectasia gene product (ATM) and the cyclin dependent kinase inhibitor p21 (WAF1), post-irradiation}

Padmini Kedar, Shaun Scott, Sergei Kozlov and Martin Lavin

The human disease ataxia-telangiectasia (A-T) results from a mutation of the ATM gene [1]. An autosomal recessive disease, A-T has a complex phenotype involving the nervous, immune and 
reproductive systems. Ataxia is the presenting symptom in this syndrome and is primarily due to progressive cortical cerebellar degeneration, which involves primarily Purkinje and granular cells but basket cells are also affected. Telangiectasia, (dilated blood vessels in the conjunctiva and occasionally in the facial skin) another clinical manifestation of the disease, has a later onset.

Absence or abnormal development of the thymus is a consistent feature of A-T [2]. AT cells are approximately four times more sensitive to ionizing radiation than any other human cells. Exposure of mammalian cells to ionizing radiation causes a delay in progression of cells from G1 into $\mathrm{S}$ phase, inhibition of DNA synthesis and a delay in progression from G2 phase to mitosis [3]. The DNA damage leads to the rapid and dose dependent inhibition of DNA synthesis. The ATM gene is a member of the family of phosphatidylinositol-3-kinase related to enzymes that are involved in cell cycle control, meiotic recombination and response to DNA damage.

In order to understand the unique functions of ATM, it is necessary to identify interacting proteins and to determine its specific substrates. The yeast two hybrid system was used to identify the protein partners for ATM. We have previously documented protein-protein interactions between ATM and p53, and between ATM/c-Abl [4,5]. A $4.01 \mathrm{~Kb}$ fragment from the 3' end of ATM was isolated from the full-length complementary DNA, and subcloned in frame into pAS2 vectors fused to the Gal4 DNA binding domain (4.01ATMpAS2). This construct failed to activate reporter b-galactosidase expression by itself. A human heart cDNA library (MATCHMAKER), cloned into pGAD10 vector and 4.01 ATMpAS2 were co transformed into yeast strains y190 to express the pair of hybrid proteins. Two hybrid interaction analysis revealed binding of WAF1 (p21) to ATM.

In order to substantiate further the interaction between WAF1 and ATM, control and A-T lymphoblastoid cells were exposed to 6 Gy of ionizing radiation, and after eight hours of incubation, lysates were prepared and subjected to immunoprecipitation with WAF1 antibody. Immunoblot analysis of anti p21 immunoprecipitates with an anti ATM peptide antibody (ATM-3BA) [5] showed the association of WAF1 and ATM in control cell lines but not in the A-T cell lines. The association of p21 with Gadd45, PCNA, and cyclin/ Cdks has previously been demonstrated $[6,7,8,9]$. To test our hypothesis that ATM is present in this complex, p21 immuno-precipitated lysates were immunoblotted with antibodies to PCNA, Gadd45, cyclin A, cyclin E, Cdk 2, and c-Abl. Our results confirm that ATM and $\mathrm{p} 21$ are present in a complex with all of these proteins.

To further confirm the interaction between ATM and $\mathrm{p} 21$, in vitro binding assays were performed using a GST-p21 full lengths wild type construct. Cell lysates were prepared from A-T and control cell lines as above. GST beads with full length $\mathrm{p} 21$ were incubated with lysates, the product was analysed on SDS-PAGE and the gel was immunoblotted with ATM 3BA antibody. The results show that ATM from control cells was bound to $\mathrm{p} 21$ whereas binding was not observed in the A-T cell lines. In vitro transcribed and translated ${ }^{35} \mathrm{~S}$ labelled $5.7 \mathrm{~kb}$ ATM, partial length cDNA was incubated with full length GST-p21 or mutated GST-p21 on the beads. ATM did not bind to the "N" terminal (a.a. 1-90) and "C" terminal (a.a. 87-164) ends of p21, neither did it bind to the middle construct (a.a.55-150), indicating that full length $\mathrm{p} 21$ is required to bind to ATM.

To determine which region of ATM is involved in binding to p21, 13 overlapping GST-ATM constructs were used for in vitro binding assays with full length $\mathrm{p} 21$. ATM fusion proteins were bound to GST beads, the beads were incubated with in vitro labelled ${ }^{35} \mathrm{~S}$ full length $\mathrm{p} 21$. The bound proteins were analysed by SDS-PAGE. GST ATM containing the nearly full length PI3 kinase domain was bound to the labelled full length $\mathrm{p} 21$. This interaction shows that $\mathrm{p} 21$ protein specifically binds to the PI3 kinase domain of ATM.

To examine whether phosphorylation is involved in the association of ATM and p21, we conducted the kinase reaction with full length baculoviral ATM and full length GST-p21 and its mutants. It was observed that ATM phosphorylated full length p21 and the C- terminal p21 GST- fusion protein, and the middle p21M (a.a.55-150). The C-terminal GST-p21 construct and the p21M construct has overlapping 
amino acid residues from 87 to 150 . The $\mathrm{N}$ terminal fragment of $\mathrm{p} 21$ did not show any phosphorylation. Since the baculovirus preparation of ATM is not entirely pure, it is not possible to comment on whether ATM acts alone or in combination with an adaptor protein in this phosphorylation reaction.

From the above experimental analysis it is seen that WAF1 and ATM proteins bind and interact with each other, post irradiation. This appears to play an important role in the cell cycle control and needs to be further investigated.

\title{
References
}

[1] Savitsky, K., Bar-Shira, A., Gilad, S., Rotman, G., Ziv, Y., Vanagaite, L., Tagle, D.A., Smith, S., Uziel, T., Sfez, S. et al. Science 268, (1995) 1749-1753.

[2] McFarlin, D.E., Strober, W. and Waldmann, T.A. Medicine 51, (1972) 281-314.

[3] Konig, K. and Baish, H. Radiation Envirnm. Biophys. 18, (1980) 257-265.

[4] Shafman, T., Khanna, K.K., Kedar, P., Spring, K., Kozlov, S., Yen, T., Hobson, K., Gatei, M., Zing, N., Watters, D., Egerton, M., Shiloh, Y., Kharbanda, S., Kufe, D. and Lavin, M.F. Nature 386, (1997) 520-523.

[5] Watters, D., Khanna, K.K., Beamish, H., Birrell, G., Spring, K., Kedar, P., Gatie, M., Stenzel, D., Hobson, K., Kozlov, S., Zing, N., Farrell, A., Ramsay, J., Gatti, R. and Lavin, M. Oncogene (1997) 1911-1921.

[6] Zhang, H., Hannon, G. and Beach, D. Genes and Development 8, (1994) 1750-1758.

[7] Xiong, Y., Zhang, H. and Beach, D. Genes and Development 7, (1993) 1572-1583.

[8] Flores-Rozas, H., Kelman, Z., Dean, F. et al. PNAS, 91, (1994) 8655-8659.

[9] Kearsey, J.M., Coates, P.J., Prescott, A.R., Warbrick, E. and Hall, P.A. 11, (1993) 1675-1683.

\section{Radiation induction of p53 in cells from Nijmegen Breakage Syndrome and functional mapping of the underlying gene at $8 \mathrm{q} 21$}

\author{
K. Komatsu ${ }^{1}$, K. Matsuura, S. Matsuura, N. Kondo, H. Tauchi, M. Oshimura ${ }^{2}$, D. Smeets ${ }^{3}$ \\ and C. Weemaes ${ }^{3}$ \\ ${ }^{I}$ Department Radiation Biology, Hiroshima University, Hiroshima 734, Japan \\ ${ }^{2}$ Tottori University, Yonago 683, Japan \\ ${ }^{3}$ Nijmegen University Hospital, Nijmegen, 6500HB, the Netherlands
}

p53-mediated signal transduction after exposure to ionizing radiation was examined in cells from patients with Nijmegen breakage syndrome (NBS), an autosomal recessive disease characterized by microcephaly, immunodeficiency, predisposition to malignancy and a high sensitivity to ionizing radiation. NBS cells accumulated p53 protein in a dose dependent fashion, with a peak level $2 \mathrm{hrs}$ after irradiation with 5 Gy. However, the maximal level of p53 protein in NBS cells was constantly lower than in normal cells. Moreover, this attenuation of p53 induction was confirmed by decreased levels of p21WAF1 protein, which is transcriptionally regulated by p53 protein. This defective induction of p53 protein in NBS is similar to that in ataxia-telangiectasia (AT), although the induced levels of p53 protein in NBS appeared to be the intermediate between normal cells and AT cells. This moderate p53 induction in NBS cells is consistent with the relatively mild radiation sensitivity and the abnormal cell cycle regulation post irradiation, as present in NBS. Furthermore, all NBS cell lines used here exhibited time courses of p53 induction similar to normal cells, which is in contrast with p53 induction in AT cells, where the maximum induction shows a delay of approximately $2 \mathrm{hrs}$ compared with normal cells. These 
evidences suggest a different function of each gene product in an upstream p53 response to radiationinduced DNA damage.

To identify the disease-bearing chromosome, microcell-mediated chromosome transfer was performed. An immortalized fibroblast cell line, GM7166VA7 (from an NBS-V2 patient), was used as a recipient for microcell fusion. A library of murine A9 hybrid cell lines containing a single human chromosome tagged with a neo gene was used as a chromosome donor. Microcells were produced from the murine A9 hybrid cells and were fused to the GM7166VA7 cells. After G418 selection, the resulting microcell hybrids were isolated and were used for complementation assays based on radiation sensitivity at $4 \mathrm{~Gy}$. Since NBS shows autosomal recessive inheritance, all autosomal chromosomes, except for chromosome 9, were tested. Chromosome 9 donor cells tagged with neo were not available. In each experiment, 1-12 clones of the microcell hybrids were obtained. Complementation studies demonstrated that none of the microcell hybrids containing human chromosomes 1-7 or 1022 showed restoration of radiation resistance. In contrast, 9 of 12 microcell hybrid clones with a transferred human chromosome 8 were rescued, since radiation resistance was normalized. To confirm this, we performed a second transfer of a chromosome 8 and generated an additional six microcell hybrids. All six hybrids showed normal levels of radiation sensitivity. Chromosome painting of these complemented hybrids was performed by use of mouse genomic DNA as a probe. No signals were detected, excluding the possibility of the presence of mouse DNA and, thus, of a cotransfer of mouse chromosomes. In addition, when a chromosome 8 was transferred into 1022QVA8N cells (from an NBS-V1 patient), six clones of microcell-hybrid cells were obtained. Four of the six microcell-hybrid clones showed the restoration of radiation sensitivity. These data clearly demonstrate that only human chromosome 8 complements the sensitivity to ionizing radiation in NBS cell lines.

To narrow the NBS candidate region, we generated a new series of murine A9 hybrid cell lines, which contained a deleted human chromosome 8. Microcells from A9 (neo8)-1 cells were irradiated with 5 Gy of \$B\&C (B-rays) and we re-fused back to murine A9 cells. After G418 selection, 50 colonies were isolated and were analyzed for their human chromosome content. These hybrids initially were screened by use of 17 selected STS primers from chromosome 8 . Of the 50 clones, 30 hybrid clones showed several patterns of deletions. Four of these hybrid clone (Rm15, Rn33, Rm33-1, and Rm46) showed a large contiguous deletion. By use of STS markers in chromosome 8, a more precise deletion mapping was performed. Clone Rm15 was negative for the markers surrounding the centromeric region of chromosome 8, whereas the Rm33, Rm33-1, and Rm46 cells were negative for markers in the short arm. Hybrid Rm33-1 also had a microdeletion around locus D8S1832. We then introduced the reduced chromosomes into GM7166VA7 cells via microcell fusion, and we analyzed the radiosensitivity of the resultant microcell hybrids. Rm15 cells generated six microcell-hybrid clones, which showed restoration of radiation resistance. The clones of microcell hybrids obtained from Rm33, the clones of the hybrids from Rm33-1, and the clones of hybrids from Rm46 all showed restoration of radiation resistance. These data indicate that the NBS gene is located neither in the short arm nor in the centromeric region of chromosome 8 . Considering the results obtained from the hybrids of clones, we conclude that the NBS gene resides in the distal long arm of chromosome 8-most probably in the region 8q21. Furthermore, this functional mapping is in good agreement with our results from the homozygous mapping of Dutch patient with consanguinity, demonstrating 2-3 cM around D8S1811 as a candidate region. 


\section{ATM mutation screening in Norwegian and Danish AT families and evaluation of cancer risk in relatives}

Kirsten Laake ${ }^{1}$, Laila Jansen ${ }^{1}$, Gry A. Geitvik ${ }^{1}$, Siri Jansen ${ }^{1}$, Johanne Hanemann², Karen Brøndum Nielsen ${ }^{2}$, Milhan Telatar ${ }^{3}$, Richard Gatti ${ }^{3}$, Arvid Heiberg ${ }^{4}$, Jørgen Olsen ${ }^{5}$, Steinar Trætli ${ }^{6}$ and Anne-Lise Børresen-Dale ${ }^{1}$

${ }^{I}$ Department of Genetics, Institute for Cancer Research, The Norwegian Radium Hospital, Oslo, Norway

${ }^{2}$ Kennedy Institute, Denmark

${ }^{3}$ Department of Pathology, UCLA School of Medicine, Los Angelos, CA USA

${ }^{4}$ The National Hospital of Norway, Norway

${ }^{5}$ Danish Cancer Society, Denmark

${ }^{6}$ Norwegian Cancer Registry, Norway

Eleven Norwegian and 8 Danish AT families were examined for mutations in the ATM gene by using PTT and perpendicular DGGE. Both RNA and genomic DNA were used as source. Mutations have been identified in 21 out of the 22 Norwegian and 15 out of 16 Danish ATM alleles. A total of 18 different mutations, spread all over the gene, predominantly deletions and insertions leading to a frameshift and subsequent truncation of the protein were found. A mutation 3245 delATC insTGAT in exon 24 was found in 12 of 22 proband alleles in the Norwegian families [1]. The mutations were found in 12 of 22 proband alleles in 11 Norwegian families: five patients were homozygotes and two heterozygotes. Haplotype analyses were performed using eight microsatellite markers, within and flanking the ATM gene. All carriers of the mutation described were found to have a common haplotype of the five closest CA-repeat microsatellite markers. Some of the Norwegian A-T families were known to have originated from Østerdalen, a valley in the south-east part of Norway; so a founder mutation was anticipated. No A$\mathrm{T}$ patients have been identified in the northern parts of Norway. Genealogical investigations identified a common ancestor, born in 1684, for three of the families. This woman was born in Rendalen which is located north in Østerdalen, and hence the mutation was designated the "Rendal mutation".

Two other Norwegian AT parents form different families carried the same mutation in exon 58 on a common haplotype. This mutation has also been described in an American AT patient by Wright et al [2]. In one family a de novo seems likely although not proven. The AT patient and her healthy 25 years old brother had the same haplotypes and both were carrying the 3245 delATCinsTGAT mutation. In the total cohort 7 of 19 probands were found to be homozygote for an ATM mutation. These findings allow a major subset of AT heterozygotes in Norway and Denmark to be identified so that their cancer risk can be evaluated.

A rapid screening analyses using the restriction enzyme HphI that recognize the wildtype sequence but not the mutant sequence with the "Rendal" mutation was used to screen to larger cohorts of breast cancer. In a cohort of 302 consecutive cases admitted to the Norwegian Radium Hospital no carriers of the mutation were found. In another series of 145 cases admitted to the City Hospital of Oslo, which is the regional hospital for Rendalen, one mutation carrier was found.

Previous investigations of 8 of the Norwegian AT families had revealed an elevated breast cancer risk of 3.9 in first and second degree relatives [3].

Updating of these data have been performed. Investigations of cancer in 290 first, second and third degree relatives of 13 Norwegian AT patients gave a RR of 1.71 (95\% CI 1.06-2.61) for all type of cancers in females and $1.63(1.03-2.45)$ in males. The RR for all types of cancer in both genders was 1.67 (1.21-2.24). The RR for breast cancer in females was 2.38 (0.95-4.98). 
In 360 first and second degree relatives of 16 Danish AT patients the RR for all types of cancer was 1.22 (0.78-1.82). The RR for breast cancer was $1.30(0.26-3.80)$.

Genotyping of these relatives as well as relatives from Swedish and Finnish patients will be performed to more accurately estimate the risk of cancer, particular breast cancer in ATM mutation carriers in the Scandinavian cohort.

\section{References}

[1] Laake, K., Telatar, M., Geitvik, G.A., Hansen, R.Ø., Heiberg, A., Andresen, A.M., Gatti, R. and BørresenDale, A.-L., Identical mutation in $55 \%$ of the $A T M$ alleles in 11 Norwegian A-T families; evidence for a founder effect. Europ. J. Genetics (1997), in press.

[2] Wright, J., Teraoka, S., Onengut, S., Tolun, A., Gatti, R., Ochs, H.D., Concannon, P. A high frequency of distinct ATM gene mutations in ataxia-telangiectasia. Am. J. Hum. Genet. 59, (1996) 839-846.

[3] Børresen, A.-L., Andersen, T.I., Tretli, S., Heiberg, A. and Møller, P. Breast cancer and other cancers in Norwegian families with Ataxia-telangiectasia. Genes Chromosom Cancer 2, (1990) 339-340.

\section{Chromosome 11q22.3-q25 LOH in ovarian cancer}

Virpi Launonen ${ }^{1}$, Frej Stenbäck ${ }^{2}$, Ulla Puistola ${ }^{3}$, Risto Bloigu ${ }^{4}$, Pia M. Huusko ${ }^{1}$, Soili Kytölä ${ }^{1}$, Antti Kauppila $^{3}$ and Robert Winqvist ${ }^{1,5}$

Departments of ${ }^{1}$ Clinical Genetics, ${ }^{2}$ Pathology, ${ }^{3}$ Obstetrics and Gynaecology, ${ }^{4}$ Mathematical Sciences/Statistics and ${ }^{5}$ Oncology and Radiotherapy, University of Oulu/Oulu University Hospital, Kajaanintie 50, FIN-90220 Oulu, Finland

\section{Introduction}

High incidences of LOH for the chromosome 11q22-qter region have been seen in ovarian cancer [1] as well as in breast [2] and cervical cancer [3] and in malignant melanoma [4]. In tumours, LOH for specific chromosome regions may indicate the presence of tumour suppressor genes. One of the candidate genes on chromosome 11q is the ATM gene located at 11q22.3-q23.1 [5]. Mutations in the ATM gene cause the recessively inherited disorder ataxia-telangiectasia. Heterozygote carriers of the mutated ATM gene have been indicated to have an increased risk of developing cancer [6].

Here we have examined epithelial ovarian cancer (EOC) material from 49 patients for loss of heterozygosity (LOH) using 9 microsatellite markers on 11q22.3-q25, and evaluated the effect of observed deletions with regard to clinicopathological variables.

\section{Materials and methods}

Sections of paraffin-embedded tumour and corresponding normal tissue were obtained from 49 randomly chosen females from Northern Finland, diagnosed with EOC between 1983 and 1994. DNA was extracted from archival tumour and matched control tissue material according to standard methods. The PCR amplification of target DNA was performed using the inclusion of $\left[\alpha_{-}^{32} \mathrm{P}\right]-\mathrm{dCTP}$. For the LOH analysis, PCR products were resolved by electrophoresis on $7 \%$ polyacrylamide sequencing gels. The $\mathrm{LOH}$ analysis of 11q22.3-q25 was performed using 9 microsatellite marker loci. 


\title{
Results and discussion
}

$\mathrm{LOH}$ was detected in $61 \%$ of the patients. $\mathrm{LOH}$ on $11 \mathrm{q} 22.3-\mathrm{q} 25$ could be assigned mainly to two chromosomal regions, A (11q22.3-q23.2) and B (11q23.2-q25). The LOH region A includes the ATM gene. LOH for the markers in the A region showed no particular effect on clinical behaviour of the tumours. Therefore, it appears that deletions of ATM gene would not be crucial for determining the outcome of ovarian cancer. The $\mathrm{LOH}$ region $\mathrm{B}$ appeared to be associated with a more aggressive disease course e.g. reduced survival times, a higher tumour stage and finding of residual tumour. These results support the possibility that the 11q23.2-q25 region located distal to ATM gene contains one or more genes involved in the progression of ovarian cancer [7].

\section{References}

[1] Gabra, H. et al. Cancer Res. 56, (1996) 950-954.

[2] Winqvist, R. et al. Cancer Res. 55, (1995) 2660-2664.

[3] Hampton, G.M. et al. Proc. Natl. Acad. Sci. USA 91, (1994) 6953-6957.

[4] Herbst, R.A. et al. Cancer Res. 55, (1995) 2494-2496.

[5] Savitsky, K. et al. Science 268, (1995) 1749-1753.

[6] Swift, M. et al. New. Eng. J. Med. 316, (1987) 1289-1294.

[7] Launonen, V. et al. (1997) Submitted.

\section{Nature of the cell cycle defect in Ataxia-Telangiectasia}

\author{
Martin F. Lavin ${ }^{1,2}$ and Kum Kum Khanna ${ }^{1}$ \\ ${ }^{I}$ The Queensland Institute of Medical Research, PO Royal Brisbane Hospital, Herston, Brisbane, \\ Australia \\ ${ }^{2}$ The Department of Surgery, The University of Queensland, PO Royal Brisbane Hospital, Herston, \\ Brisbane, Australia
}

Ataxia-telangiectasia cells are characterized by a failure to activate either the $\mathrm{Gl} / \mathrm{S}$ or $\mathrm{G} 2 / \mathrm{M}$ checkpoints at short times after radiation exposure and they exhibit radioresistant DNA synthesis.

The inability of A-T cells to activate these checkpoints efficiently ultimately leads to the accumulation of irradiated cells in G2/M phase where they die. The molecular nature of the defect in cell cycle control in A-T cells has been extensively studied and it is evident that a pathway mediated by the ATM gene functioning through p53 is defective in A-T cells.

The defect is evident not only at the level of radiation-induced stabilization of p53 but also at the level of its downstream effectors WAF1, gadd 45 and mdm2. Increased WAF1, as a consequence of exposure of control cells to radiation leads to an inhibition of cyclin-dependent kinase activity (cyclinE-cdk2 at the G1/S transition point). Inhibition of cyclinE-cdk2 activity prevents phosphorylation of substrates required for entry into S phase causing G1 arrest. Failure to inhibit cyclin-dependent kinase is also observed at the other checkpoints post-irradiation. The defect at the G1/S checkpoint may be more complex than first envisaged. The product of the c-Abl gene, a non-receptor tyrosine kinase, has been shown to be activated by ionizing radiation and overexpression induces WAF1, downregulates cyclin-dependent kinase cdk2 
and blocks cells in G1 phase. Cells lacking c-Abl are impaired in their ability to downregulate cdk2 activity or undergo G1 arrest in response to ionizing radiation exposure. Since these results with c-Abl paralleled what was observed in A-T cells post-irradiation the possibility that ATM and c-Abl might interact was explored. Constitutive binding of c-Abl to ATM was observed in control cells but not in A-T cells. This failure to bind ATM in A-T cells resulted in diminished levels of c-Abl tyrosine kinase activation in irradiated cells. In support of a role for ATM in direct activation of c-Abl kinase, phosphorylation of c-Abl using a recombinant protein corresponding to the PI3-kinase domain was recently observed in irradiated A-T cells. These studies and other levels of regulation of the cell cycle in A-T will be discussed.

\title{
Sporadic breast cancer as a model of genotype phenotype correlation
}

\author{
G. Lesec ${ }^{1}$, E. Richard-Coulet ${ }^{1}$, R. Salmon ${ }^{2}$ and Y. Remvikos ${ }^{2}$ \\ ${ }^{1}$ Laboratoire d'anatomie et de cytologie pathologiques, 4 avenue Victoria, 03200 Vichy, France \\ ${ }^{2}$ Institut Curie, UMR 147 CNRS, 26 rue d'Ulm, 75231 Paris, France
}

The high frequency of cytogenetic aberrations observed in breast carcinomas has led Dutrillaux to develop a model of cytogenetic evolution including unbalanced translocation followed by endoreduplication and whole chromosome losses.

The important number of rearranged chromosomes explains the difficulty to localise or identify the genes involved in neoplastic transformation. But it remains possible to correlate genetic desorders with loss of differenciation and de novo oncogenic expression potentialy with loss of heterozygoty. So the phenotype can be interpreted in terms of underling genetics modifications correlated with prognosis.

This approach is founded on cytogenetic, quantitative DNA, ploidy, phenotype and oncogenes phenotyping.

\section{The Ataxia-Telangiectasia gene product as a tumour suppressor: is there an epigenetic inactivation of atm in sporadic t-cell prolymphocytic leukaemia?}

L. Luo, F.-M. Lu, M.J.S. Dyer, D. Catovsky, M.A.R. Yuille and I. Vorechovsky

Karolinska Institute at NOVUM, Huddinge, Sweden

Institute for Cancer Research, Sutton, Surrey, UK

Abnormal patterns of DNA methylation have been described in a number of tumours, including both widespread genomic hypomethylation and regions with abnormally increased methylation. These changes have been proposed to contribute to oncogenesis by affecting the expression levels of protooncogenes and tumour suppressor genes. Hypermethylation of DNA in tumour cells, especially if it occurs in normally unmethylated $\mathrm{CpG}$ islands associated with gene promoter regions, has the capacity to decrease gene expression and alter chromatin structure. Evidence to support hypermethylation of CpG 
islands in tumour cell exists for a growing number of tumour suppressor genes, including the $R B 1$ gene, $V H L$, E-cadherin, $p 16$, and $p 15[2,3,7]$.

The ATM gene was previously shown to be altered in a large proportion of tumour DNA samples from patients with T-cell prolymphocytic leukaemia [4,6,8], a malignancy exhibiting phenotypic similarities to that seen in excess in ataxia-telangiectasia. The mutation pattern in this gene in T-PLL was different from that in the germ-line of patients with ataxia-telangiectasia [6]. The presence of loss-of-function mutations and regional clustering of missense mutations in conserved regions of the gene suggested that ATM acts as a tumour suppressor. We have now analyzed the putative ATM promoter region for methylation in normal and T-PLL DNA using a bisulphite method, a technique which allowed us, unlike methylation sensitive restriction enzymes, to assess each cytosine in a continuous stretch of DNA. Sodium bisulphite converts unmethylated cytosines to uracils while leaving methylated cytosines intact.

The bisulphite conversion reaction was carried out according to the combined protocols of Clark et al. (1994) and Zeschnigk et al. (1997) [1,9]. For primer design, we used the GenBank sequence desposited under the acc. number D83244. The amplified fragments were sequenced directly or subcloned into Teasy vector (Promega). Individual clones were sequenced either manually using Sequenase v 2.0 DNA sequencing kit or automated 373A DNA Sequencer.

By analyzing 5 control samples, we found that the whole region covering positions 325 to 1010 was completely unmethylated in lymphocytes, consistent with the active transcription of ATM in these cells. The complete absence of methylated cytosines was observed in both strands, which were analyzed separately using bottom and top primers as bisulphite-treated DNA is no longer complementary. Methylated cytosines were found only occassionally in few subclones. We have also analyzed 6 tumour DNA samples, in which no mutation has been identified in an exon by exon SSCP analysis. Most tumours exhibited the same pattern as seen in normal cells, ie. there was no methylation of CpGs. No tumour DNA sample was found with an extensive hypermethylation involving all or most $\mathrm{CpG}$ dinucleotides as previously observed for the $R B 1$ gene [5]. Occassional findings of unconverted or potentially methylated cytosines within $\mathrm{CpG}$ correlated to the rate of unconverted cytosines outside $\mathrm{CpG}$, suggesting incomplete bisulphite conversion reaction. The finding of a higher number of methylated cytosines within $\mathrm{CpG}$ as compared to those outside $\mathrm{CpG}$ observed in two tumour samples may suggest that random methylation errors may be present at presentation of T-PLL and contribute to a decreased expression of ATM. This will, however, require further investigation.

In conclusion, we have developed a technique for detecting methylated cytosines in about $0.7 \mathrm{~kb}$ region of the $\mathrm{CpG}$ island associated with the $A T M$ promoter. This method can be used for the analysis of DNA methylation in just about hundred cells and assist in studying the regulation of ATM expression/methylation of ATM mutation hot spots in different cell types.

\section{References}

[1] Clark, S. et al. High sensitivity mapping of methylated cytosines. Nucleic. Acids Res. 22, (1994) 2990.

[2] Gregor, V. et al. Epigenetic changes may contribute to the formation and spontaneous regression of retinoblastoma. Hum Genet. 83, (1989) 155.

[3] Saikai, T. et al. Allele-specific hypermethylation of the reginoblastoma tumor-suppressor gene. Am. J. Hum. Genet. 48, (1991) 880.

[4] Stilgenbauer, S. et al. Biallelic mutations in the ATm gene in T-prolymphocytic leukemia. Nat. Medic. 3, (1997) 1155.

[5] Stirzaker, C. et al. Extensive DNA methylation spanning the Rb promoter in retinoblastoma tumours. Cancer Res. 57, (1997) 2229.

[6] Vorechovsky, I. et al. Clustering of missense mutations in the ataxia-telangiectasia gene in a sporadic T-cell leukaemia. Nat. Genet. 17, (1997) 96. 
[7] Yoshiura, K, et al. Silencing of the E-cadherin invasion-suppressor gene by $\mathrm{CpG}$ methylation in human carcinomas. Proc. Natl. Acad. Sci. USA 92, (1995) 7416.

[8] Yuille M. et al. ATM is usually rearranged in T-cell prolymphocytic leukemia. Oncogene (1997) in press.

[9] Zeschnigk M. et al. Imprinted segments in the human genome: different DNA methylation patterns in the Prader-Willi/Angelman syndrome region as determined by the genomic sequencing method. Hum. Mol. Genet. 6, (1997) 387.

\title{
ATM-/- mice express increased in vivo spontaneous and radiation-induced apoptosis
}

\author{
M. Stephen Meyn ${ }^{1,2}$, Yang $\mathrm{Xu}^{3}$, David Baltimore ${ }^{3}$ and Nancy Uhrhammer ${ }^{1}$ \\ ${ }^{I}$ Departments of Genetics and ${ }^{2}$ Pediatrics, Yale School of Medicine, New Haven, CT, USA \\ ${ }^{3}$ Department of Biology, Massachusetts Institute of Technology, Cambridge, MA, USA
}

ATM, the gene mutated in ataxia-telangiectasia, is a member of a family of protein kinases thought to be involved in DNA damage detection and cycle checkpoint control. We previously demonstrated that cultured fibroblasts and lymphoblasts from A-T homozygotes were abnormally sensitive to radiation and streptonigrin-induced apoptosis. We now report loss of ATM function is associated with increased in vivo apoptosis in response to programmed and environmentally-induced DSBs. By studying mice homozygous for an ATM kinase domain mutation we find that:

Atm-/- spermatocytes die via spontaneous apoptosis: Atm- -1 males are sterile due to early pachytene arrest of spermatocytes. We find, by morphologic analysis and FISEL labeling, that Atm-/spermatocytes die via apoptosis. The distribution of apoptotic cells within Atm-/- seminiferous tubules indicates that apoptosis does not affect all cell types, but is uniformly triggered as primary spermatocytes traverse pachynema, shortly after ATM normally associates with synaptonemal complexes and at a time when DSBs are thought to be present.

p53 expression in spermatocytes is ATM-dependent: Using immunohistochemical staining, we find that p53 is highly expressed in normal spermatocytes but is not detectable in Atm-/- spermatocytes, suggesting that ATM normally triggers p53 expression in meiotic cells and that Atm-/- spermatocyte apoptosis may be p53-independent.

$\mathrm{X}$-irradation induces increased apoptosis in some tissues of the Atm-/- mice:

When analyzed 3 days post-irradiation, 5 Gy induces proportionally more apoptosis in the skin, gut and testes of Atm-/- mice than in normal controls.

Increased apoptosis is selective, preferentially affecting skin fibroblasts, gut epithelial stem cells, spermatogonia and spermatocytes.

Our results support the hypothesis that an unusually low threshold for the activation of apoptosis by DSBs is a major factor in the in vivo mutagen-sensitivity and the chronic spontaneous loss of cells from the tissues of A-T homozygotes [1]. Our observations suggest that ATM-dependent functions are normally activated in meiotic cells in response to the creation of ds breaks during meiotic recombination. The data support the idea that ATM may serve a similar function in both meiotic and mitotic cells: it acts as a sensor for a signal transduction network that promotes survival in the presence of DSBs by coordinating genetic recombination, cell cycle checkpoints and other responses to DNA damage. 
References

[1] Meyn, M.S. Cancer Res. 55, (1995) 5991.

Intermediate sensitivity of ATM heterozygote cells after streptonigrin and etoposide exposure

D. Pernin, J.-O. Bay, M. Grancho and Y.-J. Bignon

Laboratoire d'Oncologie Moléculaire, INSERM CRI 9402 et EA 2145, Centre Jean Perrin, 58 Rue Montalembert, 63000 Clermont-Ferrand, France

Ataxia-Telangiectasia (A-T) is a rare autosomal recessive disease characterized by cutaneous telangiectasia, cerebellar ataxia, immunodeficiency, high sensitivity to ionizing radiation, chromosomal instability and an increased risk of cancer. A-T heterozygote cells show an intermediate radiosensitivity ranged between normal cell lines and A-T homozygote cell lines using colony survival assay (CSA). Furthermore, hypersensitivity to chemical agents causing DNA damage, has been found in A-T homozygote cell lines. Therefore, we investigated the effects of two drugs (etoposide and streptonigrin) on 4 normal cell lines, 10 A-T heterozygote cells lines and 12 A-T homozygote cell lines. All lymphoblastoid cell lines were exposed to drugs for 24 hours and then cultivated in media free of drugs. Apoptotis was quantify using the TUNEL method on samples collected between 0 and 72 hours after exposure to chemotherapy. Our results suggest that, as observed after ionizing radiation, A-T heterozygote cell lines show an intermediate response to chemical agents.

Meiotic arrest in spermatocytes of $A T M-/-$ mice: fragmentation of synapsed axes and proteins associated with ends of fragments

\author{
Annemieke W. Plug ${ }^{1}$, Yang $\mathrm{Xu}^{2}$, David Baltimore ${ }^{2}$, Steve Meyn ${ }^{1}$ and Terry Ashley ${ }^{1}$ \\ ${ }^{I}$ Department of Genetics, Yale University School of Medicine, 333 Cedar Street, New Haven, CT 06510, \\ USA \\ ${ }^{2}$ Whitehead Institute, MIT, Boston, MA, USA
}

Mice homozygous for disruption of the ATM gene within the kinase domain are sterile due to arrest of primary spermatocytes during meiotic prophase. Autosomes begin to pair normally and synaptonemal complexes (SCs) begin to form, then the SCs begin to fragment, followed by arrest and apoptosis. The variability in the amount of synapsis that occurs before fragmentation and arrest most likely reflects the normal amount of synaptic asynchrony within nuclei. As in normal prophase spermatocytes, both the asynapsed axial elements and synapsed SCs have early recombination nodules (early RNs) associated with them. Early RNs are thought to be nucleoprotein complexes involved in the check for homology preceding, or accompanying synapsis. There is a change in protein composition in early RNs on synapsed vs asynapsed axes and a further change as a subset of synapsed early RNs is converted into late RNs, structures involved in reciprocal recombination. Using a series of antibodies that has previously 
been shown to be components of early RNs, we find that fragmentation occurs at the sites of some synapsed early RNs. Only RPA, a protein found on fully synapsed SCs occur at the ends of the fragments. RPA is also often found at sites along the synapsed axes that have not fragmented. RAD51 is infrequent at sites on synapsed axes, consistent with our observations that it disappears from SCs shortly after synapsis. However, RAD51 often is observed at "off axes" locations in the nucleoplasm of Atm-/spermatocytes, a location not observed in normals and that we associate with degradation of the chromatin as nuclei undergo apoptosis in these $\mathrm{Atm}-1-$ mice.

\title{
Temporal and spacial distribution of atm and other proteins in meiotic prophase nuclei of mouse spermatocytes
}

Annemieke W. Plug and Terry Ashley

Department of Genetics, Yale University School of Medicine, 333 Cedar Street, New Haven, CT 06510, USA

During mammalian meiosis homologous chromosome synapsis and recombination is facilitated by several meiotic-specific structures: the synaptonemal complex (SC) and early and late recombination nodules (RNs). Early RNs are thought to be nucleoprotein complexes involved in the check for homology preceding, or accompanying synapsis. A subset of early RNs are converted into late RNs that are involved in reciprocal recombination. This conversion involves a change in the protein composition of the nodules. Early RNs can be further subdivided into presynaptic RNs and postsynaptic RNs found on asynapsed and synapsed axes respectively, and the change in the synaptic state of the RNs is likewise accompanied by a change in protein composition. The $\mathrm{X}$ chromosome in mammalian spermatocytes has no homologue and never synapses. Nonetheless, early RNs on the X are eventually "processed" by undergoing the same changes in protein composition that occur during homologous synapsis of the autosomes. Both ATM and RPA become components of early RNs as homologous chromosomes synapse and both are involved in the "processing" of early RNs on the X chromosome axis. RPA and, by inference, ATM are also components of late RNs involved in reciprocal recombination. In Atm-/- mice, the SCs fragment at the sites of some early RNs. RPA is found at the ends of these fragments.

\section{Mutation of the $A T M$ gene in Italy recovered through different methodological approaches}

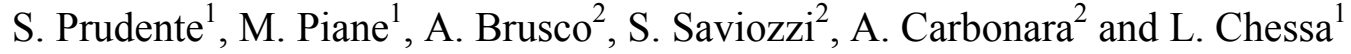 \\ ${ }^{1}$ Department of Experimental Medicine and Pathology, University "La Sapienza”, Roma, Italy \\ ${ }^{2}$ Department of Genetics, Biology and Medical Chemistry, University of Torino, Torino, Italy
}

\section{Introduction}

Ataxia Telangiectasia (AT) is a rare disease but not infrequent in Italy; 110 families are recorded in the Italian Registry and a total of 373 lymphoblastoid cell lines (LCLs) were established from peripheral blood of AT patients, parents and relatives. 
Since the ATM gene was cloned [3], more than 300 different mutations were detected in the AT patients all over the world using different methodological approaches including REF, SSCP, PTT and direct sequencing. Twenty-five mutations were found in 46 Italian AT patients from 37 different families $[1,4,5$, personal data]. The extensive structure of the ATM gene and the large size of its transcript call for different methods in detecting mutations. REF methods was succesfully utilized in identifying a number of mutations due to the possibility to analyze fragment more than $1 \mathrm{~Kb}$ [2]. Also the PTT represents an efficient method to search mutation in ATM gene, considering that the large majority of AT mutations leads to protein truncation. However, about $20 \%$ of the mutations do not lead to protein truncation; in these cases SSCP offer an efficient alternative in exon scanning mutations. In our laboratory, we optimized non isotopic SSCP and PTT to identify new mutations and more simple and faster methods, such as Heteroduplex and Restriction analyses, to perform segregation analysis in the families whose mutation was identified.

\section{Materials and Methods}

DNA and RNA were mostly extracted from the LCLs of the AT patients and their relatives and analyzed with the following techniques:

- Non Isotopic SSCP: PCR products of each of the 65 ATM exons were obtained using specific primers. Seven $\mu 1$ of sample mixed with $15 \mu 1$ of stop solution was boiled for 5', cooled on ice and immediately run on MDE gel (0.5-1X) overnight in TBE 0.6X buffer. Gel was stained with silver stain (Biorad Silver Stain Kit) and photographed.

- PTT: Primers for six overlapping segments of $A T M$ cDNA were designed. After RT-PCR agarose gel electrophoresis was performed to determine yield and size of the products. In a single tube, both in vitro transcription and translation was performed using TnT T7 Quick System (Promega). Protein detection was performed on 14\% SDS-PAGE.

- DNA Heteroduplex: In order to obtain PCR products directly resolvable on $12 \%$ PAGE, specific primers were designed for each small deletion or insertion. Each sample, alone and mixed with normal control, was boiled for 5', cooled 30' $\left(25^{\circ} \mathrm{C}\right)$. Electrophoresis was performed running the samples 16-20 hrs to $10-15 \mathrm{~mA}$, depending on specific fragments lenght. Gels were stained with EtBr and photographed by UV transilluminator.

- Restriction analysis: For each point mutation or small deletion involving a restriction site, specific primers were designed to obtaine PCR products and digested products to analyze on agarose gel. Digestion was performed for all used enzymes (New England Biolabs) overnigth. The digested products were analyzed on $2 \%$ Separide gel matrix (Life Technologies).

- RT-PCR: Extraction was performed on RNA samples obtained from lymphoblastoid cell lines using an ULTRASPEC protocol (Biotech). Reverse transcription was performed according to RT-PCR Kit protocol (Stratagene). Specific primers were designed for each large deletion to analyze the PCR products on agarose gel.

\section{Results}

\section{Molecular Screening}

Molecular screening for all but two identified mutations on 58 AT Italian patients by means of DNA Heteroduplex and Restriction analysis showed:

- the mutation 7517de14 (previously identified in 6 AT patients) in 3 unrelated patients: AT2RM (compound heterozygote), AT72RM (compound heterozygote) and AT76RM (homozygote);

- the mutation $128 \mathrm{C}->\mathrm{T}$ (previously identified in the 2 related patients AT15RM and AT16RM, both compound heterozygotes) in the patient AT37RM (compound heterozygote);

- the mutation IVS12+G->T (1407 del 201 on cDNA previously identified in patient AT44RM homozygote) in the patient AT39RM (homozygote); 
- the new mutation $8708 \mathrm{C}->\mathrm{T}$, involving the same restriction site of the mutation $8711 \mathrm{~A}->\mathrm{G}$ (previously identified in patient AT41 homozygote), in the patient AT67RM (compound heterozygote);

-three different mutations non yet sequenced, the first at exon 63 in the patients AT45RM and AT49RM, the second at exon 42 in patients AT61RM and AT62RM and the third at exon 53 in the Japanese patient TAT.

\section{Identification of New Mutations}

Exon scanning mutations was performed by non isotopic SSCP on 58 AT Italian patient and 3 Japanese patients for the exons $60,61,62,63,64$ and 65 . The analysis showed the presence of a new mutation (also identified by Heteroduplex analysis) in both patients AT45RM and AT49RM at exon 63 (sequence is still in progress). One new polymorphism was detected in both patients AT3RM and AT8RM in exon 64 (IVS64-44G->A).

PPT performed on 11 unrelated AT Italian patients showed the presence of new mutation in patients AT32RM (3802delG at exon 28), AT40RM (3226delTT at exon 27), AT17RM and AT18RM (3894insT at exon 28), AT12RM (mutation resulting in a stop at fr2) and A(-T)5RM (mutation resulting in a stop at fr4). The sequencing for the last two mutations is still in progress.

\section{Acknowledgment}

This work was partially supported by Telethon grant E.337 and by the Associazione Nazionale AT "Davide De Marini" - Fondazione Cassa di Risparmio di Fano.

\section{References}

[1] Gilad, S. et al. Predominance of null mutations in ataxia-telangiectasia. Hum. Mol. Genet. 5, (1996) 433-439.

[2] Liu, Q. and Sommer, S. Restriction Endonuclease Fingerprinting (REF): a sensitive method for screening mutations in long, contigous segments of DNA. Biotechniques 18, (1995) 470-477.

[3] Savitsky, K. et al. A single Ataxia Telangiectasia Gene with a product similar to PI-3 Kinase. Science 268, (1995) 1794-1753.

[4] Telatar, M. et al. Ataxia Telangiectasia: Mutations in cDNA detected by protein truncation screening. Am. $J$. Hum. Genet. 59, (1996) 40-44.

[5] Vorechovsky et al. Exon scanning mutation analysis of the ATM gene in patients with Ataxia Telangiectasia. Eur. J. Hum. Genet. 4, (1996) 352-355.

[6] Vorechovsky et al. The ATM gene susceptibility to breast cancer: Analysis of 38 breast tumors reveals no evidence for mutation. Canc. Res. 56, (1996) 2776-2732.

\section{ATM mutation testing in radiosensitive cancer patients}

J. Ramsay, G. Birrell and M. Lavin

Queensland Radium Institute Laboratory, Queensland Institute of Medical Research-, Herston, Brisbane QLD 4029, Australia 


\section{Introduction}

Successful radiotherapy is mainly dependent on the total dose that can be administered safely. Excessive dose will result in severe damage to the surrounding normal tissue which can cause substantial morbidity and in some anatomical areas can be fatal. For many tumours there is a fine balance between giving sufficient dose to control the tumour without an excessive morbidity. The rationale for genetic radiosensitivity testing is that there is a sensitive subgroup of individuals who limit the dose that is delivered to the other patients; in other words the minority of sensitive patients may comprise the majority of complications. If these can be identified prior to treatment there would be scope to treat the remaining radioresistant individuals to a higher dose with no increased rate of complications and improved tumour control [1]. The radiosensitive individuals might be treated with alternative modalities or with lower doses of radiotherapy.

Much of the interest surrounding identification of a sensitive subgroup has been associated with the condition ataxia telangiectasia (A-T). This is an autosomal recessive disorder with affected individuals having unusual susceptibility to injury by radiation. While A-T patients presenting for radiotherapy are very uncommon A-T heterozygotes who are phenotypically normal may comprise $1 \%$ of the general population. Epidemiological studies of A-T families have suggested that A-T heterozygotes may be cancer prone with a particular risk of breast cancer [2].

Cells from obligate A-T heterozygotes also show a significant increase in radiosensitivity which is intermediate between A-T homozygotes and normal individuals [3]. Our own studies over the last few years on normal tissue radiosensitivity in breast cancer patients has established considerable variation in radiosensitivity with patients exhibiting a severe reaction being significantly more sensitive in vitro than normal controls and breast cancer patients not developing complications. With the cloning of the gene for ataxia telangiectasia designated ATM we have now carried out mutation analysis using a protein truncation assay (PTT) on a group of patients exhibiting a severe reaction to standard radiotherapy.

\section{Materials and methods}

Blood samples were obtained from consenting volunteers, A-T patients and cancer patients exhibiting a severe reaction to a standard radiotherapy schedules. Lymphoblastoid cell lines (LCLs) were derived by Epstein-Barr transformation of peripheral blood mononuclear cells. Differences in intrinsic radiosensitivity were measured using the MTT based colorimetric growth assay [1]. Mutation analysis was performed using the PTT [4]. This involves RT-PCR followed by a transcription - translation reaction after which the protein products are analyzed for size by SDS-PAGE. 8PCR reactions were used to amplify 8 overlapping regions of the ATM open reading frame ORF.

\section{Results}

Significant differences in radiosensitivity were observed between the A-T patients, A-T heterozygotes and normal volunteers. The patients with a severe reaction to radiotherapy were as a group significantly more sensitive than the normal controls ( $\mathrm{p}=0.01)$. Using the PTT we were able to identify mutations in 11 of 14 A-T patients $(79 \%)$. Mutations were located along the whole length of the ORF. Mutation analysis of the 21 radiosensitive cancer patients showed no evidence of truncated proteins.

\section{Conclusions}

Testing for the ATM gene using the protein truncation assay is unlikely to be useful for identifying clinically radiosensitive individuals prior to radiotherapy. Direct measuring of cellular radiosensitivity is likely at present to be the most useful assay in predicting response to radiotherapy. 


\section{References}

[1] Ramsay, J.R. and Birrell, G.W. Normal tissue radiosensitivity in breast cancer patients. Int. J. Radiat. Oncol. Biol. Phys. 31, (2) (1995) 339-344.

[2] Swift, M., Morrell, D., Massay, R.B. et al. Incidence of cancer in 161 families affected by ataxiatelangiectasia. New Engl. J. Med. 325, (1991) 1831-1836.

[3] Chen, P.C., Lavin, M.F. and Kidson, C. Identification of ataxia-telangiectasia heterozygotes, a cancer prone population. Nature 274, (3) (1978) 484-486.

[4] Ramsay, J., Birrell, G. and Lavin, M. Breast cancer and radiotherapy in ataxia-telangiectasia. Lancet 347, (1996) 1627.

\section{Analysis of allelic losses of $B R C A 1, B R C A 2$ and $A T M$ genes in sporadic invasive ductal breast carcinoma}

Pascale Rio ${ }^{1,2}$, David Pernin ${ }^{1}$, Fabrice Kwiatkowski ${ }^{1}$, Monique De Latour ${ }^{1}$, Dominique Bernard-Gallon ${ }^{1}$, Jacques-Olivier Bay ${ }^{1}$ and Yves-Jean Bignon ${ }^{1}$

${ }^{1}$ Laboratoire d'Oncologie Moléculaire, INSERM CRI 9502, Centre Jean Perrin BP 392, 63011 ClermontFerrand Cedex 1, France

${ }^{2}$ INSERM U71, BP 184, 63005 Clermont-Ferrand, France

To study genetic changes and the respective involvement of the three genes $B R C A 1, B R C A 2$ and $A T M$ in sporadic breast cancer, we assayed for loss of heterozygosity (LOH) in 59 sets of invasive ductal carcinoma, compared to matched normal control DNA. Microsatellite markers which are intragenic to BRCA1 (D17S1323, D17S1322, D17S855), BRCA2 (D13S1699, D13S1701, D13S1695) and ATM (D11S2179) were simultaneously used. In addition, one marker, telomeric to BRCA2 (D13S1694) and four more markers centromeric and telomeric to $A T M$ were analysed (D11S1816, D11S1819, D11S1294, D11S1818).

Thirty-one per-cent of the informative cases showed loss of heterozygosity for the BRCAl gene (17/54), $22.8 \%$ for the $B R C A 2$ gene (8/35) and $40 \%$ for the $A T M$ gene (14/35). The incidence of allelic loss per informative patient in the other microsatellite markers was as follows: D11S1816: 9/32; D11S1819: 15/42; D11S1294: 11/31; D11S1818: 7/24. None of our samples but one was informative for the D11S1699 marker.

The total number of $\mathrm{LOH}$ per tumor correlated with higher grade $(\mathrm{p}=0.0005 ; \mathrm{H}=13.9, \mathrm{df}=2) \mathrm{LOH}$ were found in larger tumors ( $\mathrm{p}=0.01$; Spearman's ranks test: $\mathrm{r}=0.38, \mathrm{df}=56$ ).

LOH of BRCA1 significantly correlated with high grade tumors $(\mathrm{p}=0.0005)$ and negative hormone receptors $(\mathrm{p}=0.01$ for estrogen receptor and $\mathrm{p}=0.01$ for progesterone receptor).

LOH across the region of $B R C A 2$ were not correlated with any of the studied clinicopathological parameters. However, $\mathrm{LOH}$ of the D13S1694 marker, telomeric to BRCA2, was correlated with negative estrogen receptors $\left(\chi^{2}=4.08\right.$, Yates' correction; $p<0.05$; $\left.R R=6.4\right)$. They were found in larger size tumours ( $\mathrm{t}$ test: $\mathrm{t}=2.21, \mathrm{df}=21,0.02<\mathrm{p}<0.05$ ). Therefore, it may be hypothesised that another gene, telomeric to BRCA2, would be responsible for the correlations which have been previously registered between negative hormone receptors, tumor grade and $\mathrm{LOH}$ of the BRCA2 region.

Loss of heterozygosity of the D11S2179 marker, which is intragenic to ATM was found in high grade tumours: grade III versus grade I and grade II ( $p$ Fisher= 0.0278). 
Significant correlations were found between LOH of D11S1818 and LOH of any of the four other markers in the $A T M$ region $\left(\mathrm{p}=0.01 ; \chi^{2}>6.6, \mathrm{df}=1\right)$. The strongest correlation appeared between $\mathrm{LOH}$ of D11S1819 and D11S2179, the latter being intragenic to $A T M\left(\mathrm{p}=0.001 ; \chi^{2}=12.13, \mathrm{df}=1\right)$. This would imply that the loss of the most telomeric marker is frequently associated with the absence of a larger part of the chomosome.

In conclusion, $\mathrm{LOH}$ of $B R C A 1$ have been found correlated with the grade of the tumors as well as negative hormone receptors. None of the classical clinicopathological parameters was correlated with the LOH of BRCA2. Grade III tumors showed an increased incidence of ATM LOH.

These results may indicate that ATM, BRCA1 and BRAC2 genes alterations do not occur in the same pathways in the pathogenesis of breast carcinomas.

\title{
Phenotypical and functional characterization of herpes virus saimiri-immortalized $t$ cells from Ataxia-Telangiectasia patients
}

\author{
M.E. Rivero ${ }^{1}$, O. Porras ${ }^{2}$, I. Leiva ${ }^{2}$, A. Pacheco ${ }^{1}$ and J.R. Regueiro ${ }^{1}$ \\ ${ }^{1}$ Inmunología, Facultad de Medicina, Universidad Complutense, E-28040 Madrid, Spain \\ ${ }^{2}$ Inmunología, Hospital Nacional de Niños, San José, Costa Rica
}

\section{Introduction}

Ataxia-Telangiectasia (AT) is an autosomal recessive disease characterized by progressive cerebelar ataxia, oculocutaneous telangiectasia, immunodeficiency, radiosensitivity and predisposition to lymphoid malignancies [1]. The responsible gene (ATM) has been shown to encode a protein containing a phosphatidylinositol 3-kinase domain with possible signaling capacities [2], which may be involved in ab $\mathrm{T}$ lymphocyte selection (thymic tissue and peripheral CD4+ cell numbers are frequently reduced in AT patients) and function (low responses to skin tests and grafts, and to mitogenic stimuli are common) [1].

We have explored the role of the ATM protein in T lymphocytes by transforming with Herpesvirus saimiri (HVS, 3) T cells from 11 AT patients with proven T cell dysfunctions (low PHA response) [4].

\section{Materials and methods}

\section{Patients}

Blood was obtained from 11 patients, aged 4 to 16 years, with the clinical picture of classical AT.

\section{Immortalization procedures}

PBMC isolated from these patients were immortalized as described [3]. Briefly, they were exposed to HVS supernatant and resuspended in CG/RPMI medium containing human rIL-2 (with or without PHA). An immortalized phenotype was indicated by death of control cultures (i.e. non-HVS-exposed) vs sustained growth as described $[5,6]$.

\section{Phenotypical analyses}

The expression of different surface markers (TCRab, CD3, CD4 and CD8) was studied by flow cytometry in a Coulter Elite cytometer as described [5].

\section{Functional analyses}

Intracellular calcium release, an immediate activation event after TCR/CD3 engagement, was induced in cells loaded with the fluorescent dye Fluo-3AM (Sigma) according to a standard procedure [7]. Proliferation, a comparatively late event, was tested in response to anti-CD3 and human rIL2, by standard 
3H-thymidine uptake assays [7]. Intracellular IL-2 induction after stimulation with anti-CD3 was measured by flow cytometry using commercial reagents (R\&D systems) essentially as described [8].

\title{
Results and discussion
}

The resulting $\mathrm{T}$ cell lines were $\mathrm{TCRab}+\mathrm{CD} 8+$ (ten lines) and TCRab $+\mathrm{CD} 4+$ (one line). The functional analyses performed to date (proliferative response to anti-CD3 and IL-2, IL-2 production and intracellular calcium mobilization in response to anti-CD3) indicate that immortalized AT T lymphocytes, both CD4 (one tested line) and CD8 (five tested lines), are indistinguishable from their normal controls. Therefore, the ATM gene product is not required for such T cell functions in this model, and the observed defects ex vivo may be secondary. These results can help to understand the biological role of ATM.

\section{References}

[1] Lavin, F.M. and Shiloh, Y. The genetic defect in Ataxia-Telangiectasia. Annu. Rev. Immunol. (1997) 15, 177202.

[2] Savitsky, K., Bar-Shira, A., Gilad, S., Rotman, G., Ziv, Y., Vanagaite, L., Tagle, D.A., Smith, S., Uziel, T., Sfez, S., Ashkenazi, M., Pecker, I., Frydman, M., Harnik, R., Patanjali, S.R., Simmons, A., Clines, G.A., Sartiel, A., Gatti, R.A., Chessa, L., Sanal, O., Lavin, M.F., Miki, T., Weissman, S.M., Lovett, M., Collins, F.S. and Shiloh, Y. A single Ataxia-Telangiectasia gene with a product similar to PI-3 kinase. Science 268, (1995) 1749-1753.

[3] Biesinger, B., Müller-Fleckenstein, I., Simmer, B. et al. Stable growth transformation of human T lymphocytes by Herpesvirus saimiri. Proc. Natl. Acad. Sci. 89, (1992) 3116-3120.

[4] Porras, O., Arguedas, O., Arala, M., Barrantes, M., Gonzalez, L., Sáenz, E. Epidemiology of AtaxiaTelangiectasia in Costa Rica. NATO ASI, Subs.H Cell Biology 77, (1993) 199-207.

[5] Pacheco Castro, A., Marquez, C., Toribio, M.L, Ramiro, A.R., Trigueros, C. and Regueiro, J.R. Herpesvirus saimiri immortalization of ab and gd human T-linage cells derived from CD34+ intrathymic precursors in vitro. Int. Immunol. 8, (1996) 1797-1805.

[6] Meinl, E., Hohfeld, R., Wekerle, H. and Fleckenstein, B. Immortalization of human T cells by Herpesvirus saimiri. Immunol. Today 16, (1995) 55-58.

[7] Alvarez-Zapata, D., de Miguel Olalla, S., Fontán, G., Ferreira, A., García-Rodriguez, M.C., Madero, L., van den Elsen, P. and Regueiro, J.R. Phenotypical and functional characterization of Herpesvirus saimiriimmortalized human MHC class II-deficient T lymphocytes. Tissue Antigens (1997) in press.

[8] Assenmacher, M., Schmitz, J. and Radbruch, A. Flow cytometric determination of cytokines in activated murine $\mathrm{T}$ helper lymphocytes: expression of interleukin-10 in interferon-g and in interleukin-4-expressing cells. Eur. J. Immunol. 24, (1994) 1097-1101.

\section{Nijmegen- and Berlin Breakage Syndromes are caused by mutations in the same gene mapping to chromosome 8q21}

Kathrin Saar ${ }^{1,2}$, R. Varon ${ }^{1}$, K.H. Chrzanowska ${ }^{3}$, M. Platzer ${ }^{4}$, G. Beckmann ${ }^{5}$, M. Stumm ${ }^{1}$, T.F. Wienker ${ }^{2}$, E. Seemanova ${ }^{6}$, R.D. Wegner ${ }^{1}$, M. Digweed ${ }^{1}$, A. Rosenthal ${ }^{4}$, K. Sperling ${ }^{1}$ and A. Reis ${ }^{1,2}$

\author{
${ }^{1}$ Institut für Humangenetik, Virchow-Klinikum, Humboldt University, 13353 Berlin, Germany \\ ${ }^{2}$ Mikrosatellitenzentrum, Max-Delbrück-Centrum, 13122 Berlin, Germany \\ ${ }^{3}$ Department of Medical Genetics, Childrens Memorial Health Institute, Warsaw, Poland \\ ${ }^{4}$ Institut für Molekulare Biologie, Jena, Germany
}


${ }^{5}$ Abt. Bioinformatik, Max-Delbrück-Centrum, 13122 Berlin, Germany

${ }^{6}$ Department of Medical Genetics, Charles University, Prague, Czech Republic

Nijmegen Breakage Syndrome (NBS) and Berlin Breakage Syndrome (BBS), also known as ataxia telangiectasia variants, are two clinically indistinguishable autosomal recessive familial cancer syndromes that share similar cellular, immunological and chromosomal but not clinical findings with ataxia telangiectasia (AT). NBS/BBS patients are characterized by a progressive microcephaly, immunodeficiencies, a typical face and a high incidence of lymphoreticular malignancies. They have no ataxia or telangiectasia. On the cellular level, though, they are indistinguishable from AT patients showing chromosomal instability, 7/14 translocations and a particular chromosomal and cellular sensitivity to irradiation. The original classification of the two variants was based on cellular complementation of radioresistant DNA synthesis of NBS and BBS cells in fusion experiments.

Recent investigations have questioned the former classification into two different disease entities, suggesting that NBS/BBS is caused by mutations in a single radiosensitivity gene. After the localization of the ATM gene we tested AT-Variant patients for linkage to chromosome 11q23, and this locus was clearly excluded from linkage. More recently, we identified a NBS patient carrying a chromosomal translocation involving the chromosomes 3 and 7. The translocation breakpoints were tested for linkage, but they were also excluded for linkage.

We have performed a whole-genome screen in 14 NBS/BBS families and localized the gene for NBS/BBS to a $1 \mathrm{cM}$ interval on chromosome 8q21 between markers D8S271 and D8S270, with a peak lod-score of $\mathrm{z}=6.86$ at $\mathrm{q}=0$ at $\mathrm{D} 8 \mathrm{~S} 1811$. This marker also shows strong allelic association to both Slavic (NBS) and German (BBS) patients suggesting the existence of a single major mutation of Slavic origin. The same allele is seen in both former complementation groups, and through the identification and analysis of novel polymorphisms we have identified a common haplotype which was found in all patients tested so far, including the BBS patients. Therefore genetic homogeneity of NBS/BBS can be considered as proven.

In an attempt to clone the NBS gene we are currently refining the gene region. The haplotype analysis allowed us to reduce the critical region A BAC contig spanning the critical region has been constructed, and our large restriction map indicates that this contig spans more than $1 \mathrm{Mb}$ of DNA. Over $500 \mathrm{~kb}$ DNA have been sequenced to date revealing so far more than 20 ESTs. The expressed sequences are being scored for homologies to known proteins in order to find positional and functional candidates for NBS. Also, they are being tested for mutations in NBS patients and assayed in cellular complementation studies measuring radiosensitivity as a genetic endpoint.

\section{Heterogeneity in Ataxia-Telangiectasia: various laboratory features of 56 cases}

O. Sanal, D. Smeets, Y. Aksoy, A.Y. Berkel, F. Ersoy, S. Gariboglu, A. Metin, H. Ogus, N. Ozer, Y. Tezcan, C. Weemaes and L. Yel

Although the clinical features of classical ataxia-telangiectasia (A-T) patients are rather homogeneous, heterogeneity is common at the laboratory level.

The following tests were done in 56 patients with classical phenotype (ages between 4-20) and in 5 variant cases (ages between 11-30) in various combinations.

Spontaneous chromosomal aberrations in 32 , 
Radiation induced chromosomal damage in 32 ,

Radioresistant DNA synthesis in 29,

Serum Igs in 56 and IgG subclasses in 41,

Antibody response to serotype specific polysaccharides of S.Pneumonia in 29,

Antibody response to tetanus toxoid in 14 ,

Superoxide production from monocytes in 7 , and

Enzymes involved in anti-oxidant metabolism (SOD, catalase,G6PD) in lymphocytes in 15 patients.

\section{Results}

The ranges for the percentage of cells with chromosomal aberrations after irradiation were $36-92 \%$ for patients and 3-44\% for controls. The level of induced breakage overlapped with the normal range in 3 patients. These three patients with lower chromosomal radiosensitivity showed $7 / 14$ translocation and RDS typical for A-T.

The clinical features and chromosomal radiosensitivity results for variant cases studied are summarized below.

* Slow progression of ataxia

*Absence of typical telangiectasia

*Normal serum AFP levels

*Normal Igs

*Normal IgG subclasses

*No 7 and/or 14 aberration

*Intermediate radiosensitivity

RDS pattern similar to controls

*In all patients except one (in different patients for each feature)

Serum AFP level was normal $(<2 \mathrm{ng} / \mathrm{ml})$ in $1 / 45(2.2 \%)$ and slightly increased in 6/45 $(6-18 \mathrm{ng} / \mathrm{ml})$ classical patients. The rest of the classical patients' AFP levels were 35-369 ng/ml).

The patterns of serum Igs of classical patients were as follows;

Low IgA 33/56 (59\%)

Low IgG2 16/41 (39\%) Low normal IgG2 7/41 (17\%)

Low IgA+ Low IgG2 11/41 (27\%)

Low IgA-normal IgG2 12/41 (29\%)(12\% low normal IgG2)

Normal IgA-low IgG2 5/41(12\%) (5\% low normal IgA)

Normal IgA-normal IgG2 13/41 (32\%)(2.4\% low normal IgG2)

Serum Ig pattern of HIM (hyper IgM; very low IgG, IgA and normal or high IgM) in 6 patients

Except patients with serum Ig pattern of HIM there seems to be minimal relationship between serum Ig (IgA, IgG2) levels and susceptibility to infections.

Antibody production to pneumococcal polysaccharides were studied in 25 classical and 4 variant cases by ELISA.

The antibody titers were determined before and 3-4 weeks after polyvalent pneumococcal vaccine (Pneumo-23).

Antibody response to pnemococcal serotypes of 3, 6 A, 7F, 14, 19F, 23F were studied. The antibody titers were expressed as $\%$ of reference serum

The response was considered to be positive;

-when post vaccine $\mathrm{Ab}$ titer is higher than $20 \%$

-when post vaccine $\mathrm{Ab}$ titer is between $10-20 \%$ and there is a four fold rise (weak response)

Anti pneumococcal $\mathrm{Ab}$ responses (Total $\mathrm{IgG}$ ) were as follows: 


\section{IN CLASSICAL CASES}

Complete negative response: $22 / 25(88 \%)$

Positive response to one serotype: $2 / 25(8 \%)$

Positive response to 4 serotypes (two were weakly positive): 1/25 (4\%)

\section{IN VARIANT CASES}

Positive responses to $2,4,5$ and 5 serotypes in individual cases

There was no correlation between IgG2 level and antibody response.

Antibody production studied by RIA gave different results. Eleven out of 14 patient produced protective levels of antibodies against more than half of the serotypes studied (Dr. S. Fikrig, State Univ. of Newyork at Brooklyn).

All 14 patients studied produced antibody to tetanus vaccine.

Superoxide production of monocytes were studied by SOD inhibitable cytochrome-c reduction by $\mathrm{O}_{2}^{-}$in seven patients. Two patients had increased $\mathrm{O}_{2}^{-}$production. One of these patients had serum $\mathrm{IgG}$ pattern of HIM and developed lymphoma, the other patient is a classiccal case without increased susceptibility to infection.

We determined only basal levels of SOD, catalase and G6PD in lymphocytes of A-T patients and controls. In general the enzyme activities of A-T patients were within normal values, few patients showed low or high values without any consistent pattern. Some patients showed variation on repeated determinations.

\section{Conclusions}

The laboratory features were heterogeneous, and failure of $\mathrm{IgG}$ antibody production to pneumococcal polysaccharides in classical cases in general; no correlation between serum IgG2 level and antibody response to pneumococcal polysaccharides; no clear correlation between serum IgA, IgG2 levels, antibody production and susceptibility to infections; no consistent pattern in $\mathrm{O}_{2}^{-}$production or basal antioxidant enzyme level were observed.

\section{ATM is a putative tumor-suppressor gene in T-prolymphocytic leukemia}

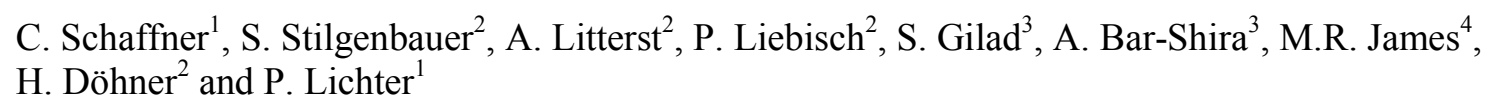

${ }^{1}$ Abteilung "Organisation komplexer Genome", Deutsches Krebsforschungszentrum, Heidelberg, Germany

${ }^{2}$ Medizinische Klinik und Poliklinik V, University of Heidelberg, Germany

${ }^{3}$ Sackler School of Medicine, Tel Aviv, Israel

${ }^{4}$ The Wellcome Trust Centre for Human Genetics, University of Oxford, United Kingdom

Ataxia telangiectasia (AT) is an autosomal recessive disease characterized by cerebellar ataxia, oculocutaneus telangiectasia, immune deficiency, chromosomal instability and a high susceptibility to develop malignancies. Although the responsible gene, designated ataxia telangiectasia mutated (ATM), is considered to be a tumorigenic factor in several human cancers, it has not yet been found recurrently mutated in tumors of non-AT patients. Homozygous ATM mutations predispose AT patients to cancer 
with some individuals suffering from multiple malignancies. The cancers most commonly observed are neoplasms of the lymphoid system, in particular T-lymphoblastic leukemia in AT children and Tprolymphocytic leukemia (T-PLL) in adult AT patients. T-PLL is also observed as a sporadic disease in non-AT individuals and is the most common T-cell leukemia with a mature (postthymic) phenotype in Western countries.

In the current study, we analyzed a series of T-PLL tumors in non-AT patients to search for genomic changes that play a pathogenic role in the development of this disease. Chromosome banding analysis of 10 T-PLLs revealed complex abnormalities, most commonly of chromosomes 11,8, 14 and 6 . The most frequent aberration was deletion of the chromosome arm 11q with the commonly deleted region of 11q21-23 (7 out of 10 tumors). Subsequent cytogenetic analyses by FISH with individual probes of a YAC contig spanning the chromosomal region 11q14.3-23.3 detected deletions of 11q in 13 of 24 T-PLL tumors. A commonly deleted segment of $1.2 \mathrm{Mb}$ size was identified at 11q22.3-q23.1. Since this critical region contained ATM, we investigated the ATM locus by FISH with cosmids from this gene and detected two additional tumors which exhibited small monoallelic deletions within the ATM locus.

In seven T-PLLs that had a deletion affecting one ATM allele, mutation analysis of the remaining copy of the gene was completed. Molecular analyses of the ATM transcript were performed by RT-PCR amplification of a set of overlapping fragments along the entire 9.4-kb coding region of the cDNA sequence and subsequent SSCP and sequence analysis of the respective fragments. The promoter region and defined genomic sequences of the gene (containing exons 1a-3, 29-30, 56-57) were analyzed by PCR. In one tumor, ATM transcript was absent due to a disruption of the 5' region of the gene. Another T-PLL showed deletion of 120 nucleotides in exon 28 of the remaining ATM allele resulting in the loss of 40 amino acids in close vicinity of the c-Abl binding domain of the ATM gene product. In a third tumor a nonsense mutation was identified in exon 37 resulting in a truncated translation product (Ser1770ter) which lacks the functionally important phosphatidylinositol-3 kinase domain. This kinase domain was found to be affected by mutations in other four T-PLLs: in one case 15 nucleotides were deleted in exon 58 leading to an amino acid substitution and the loss of five amino acids (Arg2746Ser, Del Lys2747Thr2751), three cases showed missense mutations resulting in amino acid substitutions (Asp2725Gly, Ala3006Pro, Arg3008Cys). Whether the mutations were already present in the germline and thus caused a putative predisposition to T-PLL could not be assessed because no non-tumor DNA was available from our series of patients. Such extended investigations will be addressed to another group of patients.

In our study, we analyzed genetic alterations in T-PLL tumors of non-AT patients moving stepwise from the cytogenetic level down to the level of point mutations. We detected biallelic disruption of the ATM gene in tumor cells: deletion of one allele and mutation of the second resulting in the absence, premature truncation or alteration of the ATM gene product. The identified aberrations of the ATM gene follow the classic pattern of tumor-suppressor gene inactivation: deletion of one allele and mutation of the other, or vice versa. This argues for a role of ATM as a tumor-suppressor gene in tumors of non-AT individuals.

\section{Lymphocytes in patients with Ataxia Telangiectasia constantly undergo apoptosis}

R. Schubert, N. Kappenhagen, N. Royer, I. Bühring and S. Zielen

Department of Pediatrics, J.W. Goethe Universität, Theodor Stern Kai 7, 60596 Frankfurt, Germany 
Ataxia Telangiectasia (AT) is a genetic disorder, characterized by cerebellar degeneration, immunodeficiency and increased incidence of cancer. Apart from the neurological abnormalities, one main feature of the disease is the defect in both the humoral and cellular immune systems. Most patients exhibit defective IgE, IgA and IgG2-subclass production [1]. Previous investigations have demonstrated a marked loss of B- and T-lymphocytes, combined with an increased rate of activated cells [2]. A defect in the "cell surveillance network" to explain the chronic cell loss in AT has been proposed [3], suggesting that the damaged AT-gene product is responsible for a default in the cell cycle control and DNA repair. Moreover, the inability controlling life and death leads to an increased rate of spontaneous and induced apoptosis. Proving this hypothesis, we investigated blood lymphocytes from 11 patients and 15 healthy controls. Flow cytometry was used for the characterization of lymphocytes, the cell-activation state (CD45RO) as well as the apoptotic level of the cells (CD95). For the apoptotic resistance of the cells the proto oncogene Bcl-2 was detected. Bcl-2 was stained intracellular after permeabilisation with Fix \& Perm (An der Grub, Austria).

Additionally, spontaneous apoptosis of the lymphocytes, the apoptotic level after a $24 \mathrm{~h}$-stimulation with phytohaemagglutinin (PHA), and an oxygen-producing-system (Hypoxanthine- Xanthine-system) was investigated by the DNA dye 7AAD.

According to previous investigations the number of B- and T-cells, especially CD4-cells, in patients was significantly decreased (CD3-cells: median 837 cells/ $\mu 1$, CD4-cells: median 453 cells $/ \mu 1$; B-cells: median 50 cells/ $\mu 1$ ) compared to healthy controls (CD3-cells: 2354 cells/ $\mu 1$, CD4-cells: 1326 cells $/ \mu 1$; Bcells: 216 cells $/ \mu 1)$.

Simultaneously, the level of activated CD4 cells was increased vs. controls (CD45RO: $93.24 \%$ vs. $28.45 \% ; \mathrm{p}<0.0001)$. Furthermore patients showed a 3-fold higher expression of the pre-apoptotic marker CD95 (Fas/APO-1) in the CD4-cell population $(90.10 \%$ vs. $27.34 \%$; $<<0.0001)$ and a decreased number of Bcl-2 protected cells $(78,25 \%$ vs. $88,97 \% ; \mathrm{p}<0.05)$. In culture, cells of patients showed a higher amount of spontaneously programmed cell death. In contrast applying the Hypoxanthine/Xanthinesystem the result of apoptosis was lower in patients cell population compared to controls. No difference was shown after PHA stimulation.

The amount of activated cells reflects the higher risk of apoptosis in blood lymphocytes of patients with AT. The result was confirmed by the decreased level of Bcl-2 protected cells. In agreement with previous investigations [3] cells of patients with AT showed a higher rate of spontaneous apoptosis.

However it appears that oxidative stress does not cause programmed cell death as has been shown for ionizing radiation or radiomimetic drugs [4]. In our culture system patients cells are more resistant to oxygen radicals than control lymphocytes.

Our data underline the hypothesis that AT lymphocytes show an imbalance between life and death in the control of the cell cycle. Further studies will help to clarify exactly the position of the ATM-gene product in the cell cycle cascade.

\section{References}

[1] Oxelius, V.A., Berkel, A. and Hanson, L.A. IgG2 deficiency in ataxia telangiectasia. N. Engl. J. Med. 281, (1982) 469-474.

[2] Paganelli, R., Scala, E. et al. Selective deficiency of CD4+/CD45RA+ lymphocytes in patients with ataxia telangiectasia. J. Clin. Immunol. 12, (1992) 84-91.

[3] Meyn, M.S. Ataxia-telangiectasia and cellular responses to DNA damage. Cancer Res. 55, (1995) 5991-6001.

[4] Beamish, H.and Lavin, M. Radiosensitivity in ataxia telangiectasia: anomalies in radiation-induced cell cycle delay. Int. J. Radiat. Biol. 65, (1994) 175-184. 


\title{
Absence of germline $A T M$ mutations in breast cancer patients with severe responses to radiotherapy
}

\author{
D. Scott ${ }^{1}$, J.M. Appleby ${ }^{1}$, J.P.B. Barber ${ }^{1}$, E. Levine ${ }^{1}$, J.M. Varley ${ }^{1}$, A.M.R. Taylor ${ }^{2}$, T. Stankovik ${ }^{2}$, \\ J. Heighway ${ }^{1}$ and C. Warren ${ }^{1}$ \\ ${ }^{1}$ Paterson Institute for Cancer Research, Manchester, UK \\ ${ }^{2}$ CRC Institute for Cancer Studies, Birmingham, UK
}

The estimate of $4 \%$ of breast cancer cases being heterozygous for ATM mutations is intriguingly close to the figure of $5 \%$ of patients who show adverse reactions to standard radiotherapy treatments. Since known A-T heterozygotes and severely reacting (SR) breast cancer patients both show a modest degree of cellular radiosensitivity in vitro, it has been suggested that a high proportion of the latter may indeed be carriers of $A T M$ mutations. We have, therefore, screened 16 SR breast cancer patients (and 7 other SR patients with other cancers) for $A T M$ mutations using the restriction endonuclease fingerprinting (REF) technique. No mutations were detected. In our hands the efficiency of the REF system in detecting ATM mutations in A-T patients is at present $70 \%$.

Our results suggest either that $A T M$ mutations do not confer clinical radiosensitivity or that the figure of $4 \%$ for the frequency of A-T heterozygotes amongst breast cancer patients is an overestimate, or both.

\section{Ataxia-Telangiectasia: from the disease to the gene - and back}

Yosef Shiloh

Department of Human Genetics, Sackler School of Medicine, Tel Aviv University, Ramat aviv 69978, Israel

Gene mutations causing genetic disorders provide valuable clues to cellular metabolism. The expression of such mutations at the clinical, cellular and molecular levels often discloses novel physiological pathways. Ataxia-telangiectasia (A-T) stands out as a prime example of a human genetic disorder whose research has led to new insights into basic processes such as cellular senescence, cell cycle control, and cellular defense against DNA damaging agents, as well as developmental processes in specific tissues and genetic predisposition to cancer.

The cellular phenotype of A-T cells indicates that the A-T defect touches upon multiple, apparently unrelated cellular functions. While no clear DNA repair defect has been observed in A-T cells, the processing of certain DNA breaks is defective or lacks the necessary fidelity. A major abnormality of A$\mathrm{T}$ cells is defective activation of cell cycle checkpoints by ionizing radiation. A notable example is the delayed stabilization of the p53 protein which is implicated in the G1/S checkpoint. Several other signal transduction pathways that are induced by environmental stress or normal stimuli were found defective in A-T cells.

The identity of the protein involved in all these functions remained elusive until the discovery of the A$\mathrm{T}$ gene. The A-T locus was mapped to chromosome 11q22-23, and the gene responsible for the disease was identified within this locus using a positional cloning approach. The gene, designated ATM (A-T, mutated), spans $150 \mathrm{~kb}$ of genomic DNA and encodes several transcripts of about $13 \mathrm{~kb}$ representing 66 
exons. All of these transcripts share the same open reading frame (ORF) predicting a protein of 3,056 amino acids, but differ in their untranslated regions. While disruption of the mouse Atm gene created an animal model closely related to the human disorder, ectopic expression of recombinant ATM complemented the cellular A-T phenotype, indicating that this gene is indeed responsible for the disease manifestations.

A plethora of ATM mutations was identified in A-T patients, most of which are unique to single families. The great majority of these mutations truncate the ATM protein or lead to its complete absence or inactivation. Milder A-T variants are characterized by residual amounts of ATM which might be partly active.

A basic clue to the function of the ATM protein was furnished by its sequence homology to other proteins. The carboxy terminal region of this protein, spanning about 350 amino acids, shows high similarity to the catalytic domain of the signal transduction enzyme phosphatidylinositol 3-kinase (PI 3kinase). This homology places ATM within a family of large proteins, identified in various organisms that share the PI 3-kinase-like domain. Importantly, most of these proteins are involved in cellular responses to genotoxic damage and/or cell cycle control. A notable member of this family is the DNAdependent protein kinase (DNA-PK), which is involved in the processing of DNA breaks and signals the presence of this type of damage to various cellular systems via protein phosphorylation. This protein family demonstrates evolutionary conservation of physiological junctions that receive signals from sensors of DNA damage or replication arrest, and convey them to different signal transduction pathways.

The ATM protein is a $370 \mathrm{kDa}$ phosphoprotein which is constitutively expressed in all tissues. ATM is localized predominantly in the nucleus, but some is present also in the cytoplasm, in the microsomal fraction. Interestingly, its cellular level is not altered by treatment with ionizing radiation. Size fractionation chromatography reveals several high molecular weight protein complexes in which ATM is involved. Direct association of this protein with meiotic chromosomes has been demonstrated. It is not clear whether ATM is directly involved in recombinational events in meiotic chromosomes, or in signalling such events to other systems; but, these observations probably do signify that ATM or ATMcontaining complexes sense specific DNA structures by direct physical association. Immuno precipitates obtained with anti-ATM antibodies exhibit an associated protein kinase activity. One target of this activity is the c-Abl protein, whose tyrosine kinase activity is stimulated by DNA damaging agents and triggers a number of signal transduction pathways. Purification of endogenous and recombinant ATM is technically challenging due to their low cellular amounts and association with other protein kinases.

ATM thus appears to play a pivotal role in protein complexes responsible for activating an intricate web of signal transduction pathways. It may do so by associating dynamically with numerous other proteins, and at times with the cellular genome. Current research focuses on identifying additional ATMinteracting proteins, fine tuning the A-T cellular phenotype, and functional dissection of the huge ATM molecule. These studies should yield valuable information about how our cells maintain the delicate balance between perpetuating the normal life cycle and coping with hazardous by-products of their own metabolism and environmental stress. Complete understanding of the A-T phenotype will provide important clues to the link between these processes and specific developmental processes, as well as genetic predisposition to cancer.

\section{Inactivation of the $A T M$ gene in T-cell prolymphocytic leukemias}

Dominique Stoppa-Lyonnet, Jean Soulier, Anthony Laugé, Hélène Dastot, Richard Garand, François Sigaux and Marc-Henri Stern 
Unité I.N.S.E.R.M. U462, Hôpital Saint Louis, Paris, France

Unité de Génétique Oncologique, Institut Curie, Paris, France

Laboratoire d'Hématologie, Nantes, France for the Groupe Français d'Hématologie Cellulaire

T-cell prolymphocytic leukemia (T-PLL) is an adult T-cell mature leukemia also occurring in younger patients suffering an hereditary condition, ataxia telangiectasia (AT). The gene mutated in AT, ATM, is located in the 11q22-23 chromosomal region. The strong predisposition of AT patients to develop T-PLL and the high frequency of $\mathrm{T}$ cell lymphomas observed in atm deficient mice, together with the known functions of the ATM protein, led us to evaluate the ATM gene as a potential tumor suppressor gene involved in T-PLL. Loss of heterozygosity $(\mathrm{LOH})$ of the 11q22-23 region was detected in 10 of these 15 (67 percent) paired leukemic and non-leukemic cell DNAs of patients suffering sporadic T-PLLs. The minimal deleted region was an approximately $2.5 \mathrm{Mb}$ interval containing the ATM gene. No ATM rearrangement or bi-allelic deletion was detected by Southern blotting in this T-PLL series. However, in 5 T-PLLs with LOH of the 11q22-23 region, western blot analysis revealed either undetectable (3 cases) or decreased levels (1 case) of ATM protein, whereas ATM was present at high levels in cases without LOH. The Protein Truncation Test (PTT) revealed mutations in the ATM gene (one nonsense, two aberrant splicings and one missense) in four patients with $\mathrm{LOH}$, and in no patients without $\mathrm{LOH}$ of the region. The acquired character of these ATM mutations was demonstrated in three patients by comparing DNA and RNA obtained from EBV-transformed B lymphoblastic cell lines and from tumoral cells. Allelic ATM inactivations were thus found in approximately two thirds of T-PLL. ATM is thus a tumor suppressor gene whose inactivation is a key event in the development of T-cell prolymphocytic leukemias.

\title{
Acknowledgment
}

Supported by l'INSERM, la Fondation contre la Leucémie, le Comité National, le Comité de Paris et le Comité des Hauts de Seine de la Ligue Nationale Contre le Cancer, and Electricité de France.

Cytogenetic and molecular-cytogenetic investigations in cells from Ataxia-telangiectasia- and Nijmegen breakage syndrome homozygotes and heterozygotes

\author{
M. Stumm ${ }^{1}$, S. Neubauer ${ }^{2}$, R. Sauer ${ }^{2}$, P.F. Wieacker ${ }^{1}$ and R.D. Wegner ${ }^{3}$ \\ ${ }^{I}$ Institut für Humangenetik, Universitätsklinikum, Leipziger Str. 44, 39120 Magdeburg, Germany \\ ${ }^{2}$ Klinik für Strahlentherapie, Universität Erlangen-Nürnberg, Universitätsstraße 27, 91054 Erlangen, \\ Germany \\ ${ }^{3}$ Institut für Humangenetik, Virchow-Klinikum, Augustenburger Platz 1, 13353 Berlin, Germany
}

Ataxia telangiectasia (AT) and Nijmegen breakage syndrome (NBS) are radiosensitivity syndromes caused by mutations in different genes [1,2]. The phenotype of AT and NBS patients are clearly distinguishable from each other. However, cellular findings as chromosome instability, hypersensitivity to ionizing radiation or to radiomimetic drugs, and radioresistant replicative DNA-synthesis (RDS) are common for both diseases $[3,4]$. 
We have focused our cytogenetic investigations on lymphoblastoid cell lines (LCLs) of AT and NBS patients. In EBV-positive immortalized B-lymphocytes we analyzed chromosomal instability after treatment with different clastogenic agents (ionizing radiation, Bleomycin, Trenimon, Mitomycin C). Induced chromosomal breakage demonstrates similar hypersensitivities in AT- and NBS-LCLs after treatment with ionizing radiation or with the radiominetic agent Bleomycin. This feature clearly separates AT- and NBS from normal cells. So far controversial results concerning hypersensitivity of AT and NBS cells to alkylating agents have been published. Exposition to Diepoxybutane (DEB) (bifunctional) [5], UV-activated Psoralen (bifunctional) and Angelicin (monofunctional) [6] induced an increased rate of chromosomal aberrations and sister chromatid exchanges (SCEs) in AT cells. On the other hand after Mitomycin $\mathrm{C}$ (bifunctional) treatment similar chromosomal instability could be observed in normal controls and AT cells [7,8]. In NBS only few data from case reports are available. Seemanova et al. [9] found weak evidence for an increased chromosomal sensitivity after DEB treatment in one of two patients. In contrast, normal DEB sensitivity has been reported for the patient described by Der Kaloustian et al. [10]. Because of these contradictory results, we have performed more systematic investigations using the trifunctional alkylating agent Trenimon (TRE) and Mitomycin C (MMC) for chromosomal aberration tests. After treatment with TRE and MMC respectively, an individual sensitivity spectrum for AT- and NBS- patients can be detected, showing an up to a 10-fold increase of aberration rates in comparison to controls. This finding could be important for the chemotherapy of AT and NBSpatients. Therefore, a predictive in vitro sensitivity-test of AT- and NBS- patients, examinating their cellular response to chemotherapeutical agents, should be considered. This might reduce the risk of known therapeutical side effects. Furthermore, these results indicate that the damage processing pathways induced by ionizing radiation and alkylating agents are different.

Additionally we present data from chromosomal aberration analysis on AT- and NBS- homozygotes and heterozygotes using a three-color chromosome painting analysis assay. The aim of this study was the development of a new method, enabling fast and reliable cytogenetic diagnosis of these probands. This technique was shown to be suitable for the detection of radiation induced chromosomal aberrations [11]. Whole chromosome paints of chromosome 1,2 and 4 were used as specific probes. Lymphocytes and lymphoblastoid cell lines of 5 AT patients, 6 obligate AT-heterozygotes and 2 NBS heterozygotes were analyzed for chromosomal aberrations after irradiation with 0,7 and 2,0 Gy. The quantity and quality of cytogenetic aberrations in AT-homozygotes and AT- and NBS-heterozygotes are different in all tested probands and in controls. Therefore, these preliminary results suggest, that this assay might become a reliable cytogenetic method for the diagnosis of AT- and NBS- homozygotes and heterozygotes.

\section{References}

[1] Savitsky et al. Science $\mathbf{2 6 8}$ (1995)

[2] Saar et al. Am. J. Hum. Genet. 60 (1997)

[3] Shiloh et al. Eur. J. Hum. Genet. 3 (1995)

[4] Wegner et al. Primary immunodeficiency diseases (Ochs, Puck and Smith, eds.) (1997) in press

[5] Auerbach and Wollman Cancer Genet. Cytogenet. 1 (1979)

[6] Natarajan et al. Ataxia telangiectasia (Bridges and Harnden, eds.) Wiley \& Sons (1982)

[7] Cohen et al. Cancer Res. 41 (1981)

[8] Cohen and Simpson Mutat. Res. 112 (1983)

[9] Seemanova et al. Am. J. Med. Genet. 20 (1985)

[10] Der Kaloustian et al. Am. J. Hum. Genet. 65 (1996)

[11] Neubauer et al. Int. J. Oncol. 8 (1996) 


\section{ATM mRNA levels are reduced in sporadic breast carcinomas}

Chris Sturne ${ }^{1}$, Andreas Waha ${ }^{2}$, Astrid Kessler ${ }^{1}$, Anke Koch ${ }^{2}$, Ellen Kreyer ${ }^{1}$, Otmar D. Wiestler ${ }^{2}$, Andreas von Deimling ${ }^{2}$, Dieter Krebs ${ }^{1}$ and Rita K. Schmutzler ${ }^{1,2}$

Department of Obstetrics and Gynecology ${ }^{1}$ and Department of Neuropathology ${ }^{2}$, University of Bonn Medical Center, 53105 Bonn, Germany

The gene mutated in ataxia telangiectasia patients (ATM) is located on chromosome 11q22-23, a region frequently altered in mammary tumors. Patients homozygous for ATM mutations are prone to develop a variety of different tumors. Female carriers are reported to have a 5 to 8 fold increased risk for mammary tumors. However mutations in the ATM gene are rare in sporadic mammary tumors. Most of the alterations described in A-T patients lead to a functional inactive ATM protein. Moreover, it has been suggested that mutations of the ATM gene in A-T patients influence the amount of ATM mRNA and that this may affect the severity of the disease. In this study we analyzed ATM expression in a series of 39 breast carcinomas, 14 benign breast lesions and 12 normal breast tissue samples. ATM mRNA levels were measured by semiquantitative competitive RT - PCR. Competitor RNA molecules for the ATM gene and the housekeeping gene $\beta-2$-microglobuline (B2M) were generated by PCR mutagenesis. Low concentrations of ATM transcripts were detected in breast carcinomas, intermediate levels in benign lesions and highest levels in normal breast tissue specimens $(\mathrm{F}$-test $\mathrm{p}=0.0013)$. Mutational analysis of the phosphatidylinositol-3 kinase (PI-3 kinase) functional domain of the ATM gene did not reveal alterations in this region indicating that reduced expression is not associated with alterations in the PI3 kinase region. These results suggest that reduced expression of the ATM gene may contribute to the development and/or malignant transformation of breast carcinomas.

\section{High frequency of mis-rejoining of double-strand breaks in plasmid DNA by ataxia-telangiectasia cell extract}

Akira Tachibana and Masao S. Sasaki

Radiation Biology Center, Kyoto University, Kyoto 606-01, Japan

Ataxia-telangiectasia (AT) is a human autosomal recessive disorder that exhibits neurological deterioration, immunodeficiency, high incidence of lymphoreticular malignancy and an increased sensitivity to ionizing radiation. Cells from AT patients are hypersensitive to cell killing by ionizing radiation and radiomimetic agents, and demonstrate chromosomal instability. AT cells were shown to be defective in the induction of p53 following irradiation, which would cause the defect in the G1-S checkpoint after irradiation, resulting in the reduction of the efficiency of DNA repair. However, premature chromosome condensation studies have shown that AT cells exhibit higher level of chromosome damage than normal cells in G1 phase. The fact that radioresistant DNA replication did not conform to increased chromosomal aberrations in AT cells also suggested certain involvement of the $A T M$ gene in DNA repair process.

The DNA double-strand break (dsb) has been implicated as the critical lesion induced by ionizing radiation leading to chromosome aberrations, mutations and cell death. We have attempted to clarify the 
measurement and analysis of the rejoining of dsbs with the use of nuclear extracts applied to defined plasmid molecules carrying specific enzymatically-induced dsb, and applied this method to AT cells to examine the efficiency and the fidelity of rejoining of dsbs in AT cells.

The plasmid pZErO-2 (Invitrogen Co.) containing the $c c d B$ gene under the control of the lac gene promoter was used as a substrate. The $c c d B$ gene is lethal to E. coli when it is overexpressed [1]. A dsb was introduced at a specific site within the $c c d B$ gene using restriction endonuclease BsrGI, and the plasmid was treated with nuclear extracts from human cells. The fidelity of rejoining was assessed by expression of the $c c d B$ gene after bacterial transformation with the treated plasmid. Simple re-ligation of $\mathrm{dsb}$ will form a complete plasmid with no alteration in the $c c d B$ gene, but a mis-rejoining process of dsb will cause a certain alteration in the gene. E. coli cells bearing a plasmid with the wild-type $c c d B$ gene would not form colonies on plates containing IPTG, an inducer for the lac promoter, because of the overexpression of the $c c d B$ gene from the lac promoter. On the contrary, those bearing a plasmid with the mutated $c c d B$ gene would form colonies on the same plates, which makes it easy to select plasmids containing mutations caused by mis-rejoining.

Nuclear extracts were prepared from an AT cell line, AT2KYSV, and from a normal cell line, N2KYSV. Plasmid molecules linearized by the digestion with BsrGI were treated with either the AT2KYSV extract or the N2KYSV extract. After several hours of incubation, plasmid DNA was purified from the reaction and subjected to Southern blot analysis. Although most of the input DNA remained as linear monomer molecules, substantial amount of linear dimer and linear trimer molecules appeared after incubation. The intensity of each band was measured by Ultroscan XL (Pharmacia Biotech), and the time courses of both the decrease of monomer molecules and the increase of dimer and trimer molecules were examined. The amount of dimer and trimer molecules increased with the time of incubation with the N2KYSV extract, and saturated around $16 \mathrm{hr}$. The AT2KYSV extract showed the similar amount of rejoined molecules as the N2KYSV extract at all the time points examined. Both extracts also gave very similar bacterial transformation frequencies. Thus, the activity of rejoining of dsbs in the AT2KYSV extract was comparable to that in the N2KYSV extract, in agreement with studies of rejoining of dsbs in cellular DNA.

Fidelity of rejoining of digested plasmids was measured as the fraction of pZErO-2 plasmids yielding colonies on IPTG-containing plates. The fractions of mis-rejoined plasmids without incubation with nuclear extracts were indistinguishable from those of untreated plasmids. The fractions of mis-rejoined plasmids increased with time of incubation with the N2KYSV nuclear extract, and saturated around $16 \mathrm{hr}$, as the rejoining of reaction. The fraction of mis-rejoined plasmids resulted from the exposure to the nuclear extract from AT2KYSV were much higher than that from N2KYSV extracts at all the time points examined. The fraction of mis-rejoined plasmids by the AT2KYSV extract was about 3 times higher than that by N2KYSV after incubation for $8 \mathrm{hr}$. The fraction of mis-rejoining by AT2KYSV increased with time of incubation, and was about 5 times higher than that by N2KYSV after $24 \mathrm{hr}$ incubation. Thus it appears that the AT nuclear extract lacks fidelity in rejoining of dsbs.

Bacterial colonies on IPTG-containing plates resulting from mis-rejoining of dsbs were isolated. Most of the mis-rejoined plasmid molecules showed small reduction in length of $<500 \mathrm{bp}$. Particularly, significant number of mis-rejoined molecules after exposure to the AT2KYSV extracts showed relatively small reductions in length comparing to the plasmids exposed to the N2KYSV extracts.

Sequence changes in the plasmid molecules were analysed. All of the sequenced molecules from extract treatments showed deletions of DNA around the initial break-site, and all except one showed short direct repeats at the deletion breakpoints. Thus, in each case, at the deletion site one of a pair of short repeats remains in the mis-rejoined molecules and one is lost in the deletion. Deletions were found to be associated with a variety of direct repeats of varying length from 1-9 bp. The numbers of molecules with a given deletion are listed in Table 1. Mis-rejoined molecules after exposure to the N2KYSV extracts showed varying sizes of deletions from 44-615 bp without any particular hot spots for breakpoints. 
However, mis-rejoined plasmids after the treatment with the AT2KYSV extracts showed a strong preference of the deletion of 46 bp between GCCG as approximately 80\% (13/16) of mis-rejoined molecules had this deletion.

Thacker and his colleagues performed similar analysis of the nuclear extract from an AT cell line by using the plasmid pUC18 digested at a specific site within the lacZ gene as a substrate $[2,3]$. They showed that the AT nuclear extracts had reduced fidelity of rejoining dsbs, and that the AT extract produced relatively smaller deletions at a common site. The repeats found at the breakpoint junctions are interpreted in terms of a model of deletion formation involving single-strand exposure and repair. Our results confirmed their data by using another gene as the target for dsb, and both data indicate that AT cells have certain deficiencies in processing strand breaks. We speculate that normal cells have a mechanism for suppressing mis-rejoining of dsbs but AT cells lack this suppressing mechanism, resulting in increased mis-rejoined molecules.

Table 1

Size and frequency of deletions

\begin{tabular}{ccccc}
\hline & & & \multicolumn{2}{c}{ Cell Extracts } \\
Deleted region & Size of deletion (bp) & Sequence of the repeat & N2KYSV & AT2KYSV \\
\hline $619-663$ & 44 & GAT & 1 & \\
$599-645$ & 46 & GCCG & 2 & 13 \\
$607-682$ & 75 & CGTCTG & 3 & 1 \\
$564-654$ & 90 & ACGG & & \\
$568-675$ & 107 & CAGT & 1 & \\
$552-675$ & 123 & CAG & 3 & 2 \\
$529-663$ & 134 & GATCGCCCT & & \\
$520-679$ & 159 & GC & 1 & \\
$605-932$ & 327 & none & 1 & \\
$133-642$ & 509 & CAC & 1 & \\
$58-648$ & 590 & GG & 1 & \\
$44-659$ & 615 & T & & \\
\hline
\end{tabular}

\section{References}

[1] Ogura, T. and Hiraga, S. Proc. Natl. Acad. Sci. USA 80, (1983) 4784-4788.

[2] North, P., Ganesh, A. and Thacker, J. Nucl. Acids Res. 18, (1990) 6205-6210.

[3] Thacker, J., Chalk, J., Ganesh, A. and Thacker, J. Nucl. Acids Res. 20, (1992) 6183-6188.

\section{Predominance of mutations with extensive deletions in Ataxia Telangiectasia lymphoblastoid cells treated with ionizing radiation}

Kouichi Tatsumi ${ }^{1}$, Akira Tachibana ${ }^{2}$, Yuko Houki-Fujimori ${ }^{1}$, Akira Fujimori ${ }^{1}$, Ikuko Furuno-Fukushi ${ }^{1}$, Masao Sasaki ${ }^{2}$ and Takesi Kato ${ }^{3}$

${ }^{I}$ Division of Biology and Oncology, National Institute of Radiological Sciences, Chiba 263, Japan

${ }^{2}$ Radiation Biology Center, Kyoto University, Kyoto 606-01, Japan

${ }^{3}$ Department of Radiation Biology, Faculty of Medicine, Osaka University, Suita, Osaka 565, Japan 
Ataxia telangiectasia (AT) is an autosomal recessive hereditary disease distinguished by a high incidence of lympho-reticular malignancy, cerebellar ataxia, defects in the immune system, and a hypersensitivity to cell killing by ionizing radiation. Earlier studies with primary fibroblasts from AT patients suggested that AT cells were extremely hypomutable or even immutable to ionizing radiation (Arlett, 1980). As far as 6-thioguanine resistant (TGr) marker is concerned, however, EBV-immortalized lymphoblastoid cells from an AT patient (GM2783) are, in fact, mutable by gamma-rays in a dosedependent manner but are significantly less sensitive to the mutagenic effect of gamma-rays than those from normal controls when plotted against survival [6]. We confirmed afterwards this hypomutability of AT cells as a function of lethal hit with another AT lymphoblastoid cell line, AT1-1 [2]. With regard to the mutability by ionizing radiation, AT cells are dissimilar to LX830, which is a subline of mouse leukemia L5178Y cells and extremely hypersensitive to both cytotoxic and mutagenic effect of gammarays [4].

We examined the structural change of the hypoxanthine-guanine phosphoribosyltransferase (HPRT) gene in TGr mutant clones from GM2783, by employing the multiplex enzymatic amplification of all exons. Twelve out of $15(80 \%)$ gamma-ray-induced TGr mutants from GM2783 showed loss of at least some exons, implying deletions in the HPRT gene. Moreover, 8 of these 12 deletion mutant clones lacked all the exons examined. Five mutants had even lost both DXS79 and DXS86, flanking markers of the HPRT locus. In contrast, only 38\% (18/48) of gamma-ray-induced TGr mutants from a control cell line, TK6, showed deletions, and very small number of total deletion of the HPRT gene was detected for TK6 cells (6.3\%). Thus, prevailing mutations induced by gamma-rays in AT cells seem to be extensive deletions, presumably leading to the poor recovery of mutants induced by ionizing radiation at the hemizygous HPRT gene from AT cells.

In an attempt to isolate from AT cells a clone that had been heterozygously inactivated at the adenine phosphoribosyltransferase gene on the autosome 16 (APRT+/-), AT1-1 cells were treated with 0.5 microgram/ml of ICR-191, a frame-shift mutagen, for $24 \mathrm{~h}$. Following this treatment, APRT deficient mutants resistant to 100 micromolar of 2,6-diaminopurine (DAP) were found to have been generated at the frequency of $4.9 \times 10^{-6}$, much higher than expected for a 2-hit event, i.e., APRT $+/+>$ APRT $-/-$ or APRT o/-. Southern blot analyses revealed that AT1-1 cells were heterozygous for TaqI RFLP at the APRT gene, and that all of the 11 mutant clones examined lost either a TaqI-site-(+) or a TaqI-site-(-) allele. When the mutagenic effectiveness of ICR-191(2 $\left.\times 10^{-5}\right)$ to the other APRT $+/-$ human lymphoblastoid cells (WR10 cells) at the same concentration employed was taken into account, these results collectively implied that the AT1-1 cell population had accumulated APRT hemizygous cells (APRTo/+) at an extremely high frequency prior to the ICR-191 treatment, possibly reflecting an excessive genome instability of AT cells. Finally we succeded in obtaining an APRT $+/-$ tester clone, and again all of spontaneous and X-ray induced DAPr mutants were associated with allelic losses. Dosage analysis of those mutants revealed that $90 \%$ was represented by one copy, implying deletion. Regardless of treatment with irradiation, for radiation-normosensitive APRT $+/-$ tester cell line WR10 the proportion of DAPr mutants due to deletions was approximately 50\% (Fujimori et al., 1992), while virtually all of DAPr mutants from APRT $+/-$ subline of TK6, that is recombination repair deficient, have been recently reported to be attributable to mitotic recombinations [5].

In conclusion, for both HPRT locus and APRT locus deletion mutations prevail in AT lymphoblastoid cells.

\section{References}

[1] Arlett, C.F. Mutagenesis on repair-deficient human cell strains. J. Progress in Environmental Mutagenesis (1980) J. ed. M. Alacevic 161-174. 
[2] Arita, I., Fujimori, A., Takebe, H. and Tatsumi, K. Evidence for spontaneous conversion of Mex- to Mex+ as cellular phenotype in a human lymphoblastoid cells line. Carcinogenesis 11, (1990) 1733-1738.

[3] Fujimori, A., Tachibana, A. and Tatsumi, K. Allelic losses in mutations at the APRT locus of human lymphoblastoid cells. Mutation Res. 269, (1992) 55-62.

[4] Furuno-Fukushi, I. and Matsudaira, H. Mutation induction by different dose rates of gamma-rays in radiation sensitive mutants of mouse leukemia cells. Radiat. Res. 120, (1989) 370-374.

[5] Pongsaensook et al. Isolation of an APRT heterozygote from TK6 human lymphoblasts: Predominance of multi-locus loss of heterozygosity among spontaneous APRT- mutants. Mutation Res. 377, (1997) 27-36.

[6] Tatsumi, K. and Takebe, H. Gamma-irradiation induces mutation in ataxia-telangiectasia lymphoblastoid cells. Gann 75, (1984) 1040-1043.

\section{Correlations between the ATM genotype and phenotype}

A.M.R. Taylor, T. Stankovic, A. Sutcliffe, G.M. McGuire, P. Robinson, P. Weber, T. Bedenham, D.F. Easton and P.J. Byrd

CRC Institute for Cancer Studies, The Medical School, University of Birmingham, Birmingham, B15 2TA, U.K.

The classical clinical and cellular phenotype of ataxia telangiectasia is associated with the presence of two null mutations in patients. An important question is what range of phenotypes, including the presence of different tumours, is associated with different types of ATM mutations. Of 51 ATM mutations we have identified in families native to the British Isles 11 were founder mutations and 2/11 of these conferred a milder clinical phenotype with respect to both cerebellar degeneration and cellular features.

A-T patients in the British Isles with the first of these two founder mutations showed a less severe clinical and cellular phenotype including a later onset and slower progression of the cerebellar ataxia, an intermediate cellular radiosensitivity and possibly decreased susceptibility to leukaemia or lymphoma compared with classical A-T. All these patients carried the 5762 ins 137 insertion caused by a point mutation in intronic sequence resembling a splice donor site. Although this mutation will result in protein truncation, the less severe phenotype appeared to be caused by some degree of normal splicing which occurred as an alternative product from the insertion containing allele. The presence of normal ATM protein could also be demonstrated and it is possible, therefore, that the expression of a low level of normal ATM protein can ameliorate the phenotype of A-T [1,3].

A second founder mutation in the British Isles associated with a slower rate of progress of cerebellar ataxia and intermediate cellular radiosensitivity was the 7271T- $>\mathrm{G}$ mutation observed in two A-T families. In one family the affected siblings were heterozygous for this mutation (having a different ATM mutation in the second allele) and in the second family they were homozygous for this missense mutation. The severity of the cerebellar ataxia appeared to be less in the family with the homozygous mutation and these patients were longer lived. The mutation may, however, be associated with an increased risk of breast cancer in both female homozygotes and heterozygotes in the two families. This mutation (7271T$>$ G) also allowed expression of a high level of full length ATM protein when compared with unaffected individuals [2].

Something can also be said about the relationship between the presence of leukaemia or lymphoma in A-T patients and ATM mutations. Twenty different ATM mutations were identified in 15 families (18 patients) with leukaemia, lymphoma or T-cell preleukaemic clonal proliferations. Mutations were 
scattered across the ATM gene suggesting that a single location within the ATM coding sequence was not associated with the occurrence of lymphoid tumours. A spectrum of missense, in frame deletions and null mutations was observed in patients with lymphoid tumours with no particular ATM mutation attributable to any specific type of malignancy. However, more than half of the leukaemia and lymphoma patients (in $8 / 15$ families) showed the presence of either missense mutations, or in frame deletions, all resulting in protein expression. In addition, we observed concordance for tumour type within families where two A-T patients developed a lymphoid tumour. Between families, with no expression of ATM, tumour types were different and occurred at different ages. Possible explanations for this difference between families, with no expression of ATM, include either the influence of modifying genes, the differential expression of redundant genes, and/or environmental factors which may affect predisposition to the leukamia or lymphoma phenotype.

Clearly a proportion of ATM mutations can give rise to recognisably less severe clinical and cellular phenotypes. The least severe phenotype appeared to result from an equal affect on all the features of A-T rather than selective improvements in particular features. Even amongst patients with two null mutations there were significant differences in the phenotype which appear to be influenced by other genes and/or environmental influences.

\section{References}

[1] McConville, C.M., Stankovic, T., Byrd, P.J., McGuire, G., Yao, Q.-Y., Lennox, G.G. and Taylor, A.M.R. Mutations associated with variant phenotypes in ataxia telangiectasia. Am. J. Hum. Genet. 59, (1996) 320-330.

[2] Stankovic, T., Kidd, A.M.J, Sutcliffe, A, McGuire, G.M., Robinson, P., Weber, P., Bedenham, T., Bradwell, A.R., Easton, D.F., Lennox, G.G., Haites, N., Byrd, P.J. and Taylor, A.M.R. ATM mutations and phenotypes in A-T families in the British Isles; expression of mutant ATM and the risk of leukaemia, lymphoma and breast cancer. Am J. Hum. Genet. in press.

[3] Taylor, A.M.R., Hernandez, D., McConville, C.M., Woods, C.G., Stacey, M., Biggs, P., Byrd, P.J. et al. Malignant disease and variations in radiosensitivity in ataxia telangiectasia patients In: Eeles, R.A., Ponder, B.A.J., Easton, D.F., Horwich, D. (eds). Genetic Predisposition to Cancer. Chapman and Hall, London, (1996) $138-151$.

\section{Study of radiation-induced chromatid aberrations in Ataxia-Telangiectasia patients and carriers}

Andrei Tchirkov ${ }^{1}$, Jacques-Olivier Bay ${ }^{2}$, David Pernin ${ }^{2}$, Yves-Jean Bignon ${ }^{2}$, Pascale Rio ${ }^{2}$, Maria Grancho ${ }^{2}$, Fabrice Kwiatkowski ${ }^{3}$, Michel Giollant ${ }^{1}$, Paul Malet ${ }^{1}$ and Pierre Verrelle ${ }^{4}$

${ }^{1}$ Laboratoire de Cytogénétique Médicale, Faculté de Médecine, Clermont-Ferrand, France

${ }^{2}$ Laboratoire d'Oncologie Moléculaire et INSERM CRI 9502, Clermont-Ferrand, France

${ }^{3}$ Service Statistiques et Communication Médicales, Clermont-Ferrand, France

${ }^{4}$ Département de Radiothérapie et INSERM U71, Centre Jean Perrin, Clermont-Ferrand, France

In ataxia-telangiectasia (A-T) patients, mutations in a single gene, ATM, result in an autosomal recessive syndrome embracing a variety of clinical features and manifesting an extreme radiosensitivity and a strong predisposition to malignancy. Heterozygotes for the ATM gene have no clinical expression of A-T but may be cancer prone with a moderate increase in in vitro radiosensitivity. Cytogenetically, this abnormal response to radiation manifests as enhanced chromatid breakage when the cells are exposed 
during G2 phase of the cell cycle. The G2 irradiation technique with skin fibroblasts was able to distinguish blindly A-T heterozygotes from normal controls by higher frequencies of induced chromatid breaks [1]. In addition, this cytogenetic assay was adapted to phytohemagglutitin(PHA)-stimulated blood lymphocytes [2,3]. Several reports, however, indicated that G2 chromosomal radiosensitivity of blood lymphocytes was not a reliable indicator of A-T heterozygosity because of substantial overlaps between the values of radiation-induced chromatid aberrations for A-T heterozygous and normal cells $[4,5]$. We performed blindly chromosome analysis on G2 phase lymphocytes from 7 unrelated A-T patients, 13 obligate A-T heterozygotes (parents of the patients), and 14 normal controls following X-irradiation with $1 \mathrm{~Gy}$ in order to evaluate this cytogenetic method as a tool for ATM carrier detection. Both the lymphocytes from A-T homozygotes and heterozygotes showed an enhanced chromosomal response to G2 irradiation compared to the control. The increased chromatid breakage in cells from A-T carriers ranged from 1.50 to 2.29 breaks/metaphase, while in controls the levels of breaks were between 0.62 and 0.94 per metaphase cell. Thus, neither A-T heterozygote showed normal chromosomal radiosensitivity. Occasional overlaps of chromatid break frequencies were observed only between homozygotes and heterozygotes. Frequencies of induced chromatid breaks in cells from A-T heterozygotes were significantly higher than in those from normal donors but significantly lower than in A-T lymphocytes (chi2 $=27.5$, d.f. $=2, P<0.0001)$. Similarly, the increase in total chromatid aberration frequencies was significant between the 3 groups (chi $2=27.7$, d.f. $=2, \mathrm{P}<0.0001$ ). There were no significant differences in mean frequencies of occasional chromatid exchanges. The average age for A-T heterozygotes was not significantly different from that for controls $(\mathrm{chi} 2=2.8$, d.f. $=1, \mathrm{NS}, \mathrm{P}>0.09$ ). In addition, we did not found any correlation between the age and the level of induced chromatid breakage neither within A-T carrier and normal control groups nor within the whole population examined. Both individual and mean aberration frequencies observed in unirradiated lymphocytes were not notable in each group.

Enhanced G2 chromosomal radiosensitivity observed in A-T cells is directly related to the molecular defect of the disease. ATM protein is presumably required for DNA repair and particularly for the ability of cells to arrest the mitotic cycle in response to DNA damage. Thus, elevated chromatid breakage observed in A-T cells after G2 irradiation reflects the progression of cells with damaged chromosomes into mitosis. Intermediate cytogenetic response of cells from A-T heterozygotes to G2 irradiation relative to that of A-T homozygous and normal cells may be viewed as a consequence of a partial ATM deficiency and a dose-response relationship for ATM protein.

Apart from A-T heterozygotes, an abnormal cytogenetic response to G2 phase irradiation was observed in peripheral lymphocytes of clinically healthy carriers of genes for other cancer-prone genetic disorders such as displastic nevus syndrome [6] and xeroderma pigmentosum [7]. Furthermore, an increased G2 radiation-induced chromatid damage in lymphocytes associated with a high risk of cancer has been reported in families not affected with genetic disorders predisposing to malignancy [8]. Therefore, the cytogenetic assay alone may be used for the rapid detection of heterozygotes for the ATM gene only within A-T families. In studies aimed to identify the patients with cancer who are carriers of the ATM gene, the $\mathrm{G} 2$ chromosomal radiosensitivity analysis could be proposed as a pre-screening test for mutated ATM gene.

\section{References}

[1] Shiloh et al. Human Genet. 84, (1989) 15.

[2] Sandford et al. J. Natl. Cancer Inst. 82, (1990) 1050.

[3] Chen et al. Cancer Genet. Cytogenet. 76, (1994) 43.

[4] Bender et al. Mutat. Res. 152, (1985) 39.

[5] Wiencke et al. Cancer Causes Control 3, (1992) 237.

[6] Sandford et al. Lancet 2, (1987) 1111. 
[7] Parshad et al. J. Clin. Invest. 85, (1990) 135.

[8] Knight et al. Int. J. Cancer 54, (1993) 589.

\section{Common ATM mutations and shared haplotypes}

M. Telatar ${ }^{1}$, L.-Q. Tai ${ }^{1}$, Z. Wang ${ }^{1}$, S. Castellvi-Bel ${ }^{1}$, S. Shiekhavandi ${ }^{1}$, S. Teraoka ${ }^{2}$, P. Concannon ${ }^{2}$ and R.A. Gatti ${ }^{1}$

${ }^{I}$ Department of Pathology, UCLA School of Medicine, Los Angeles CA, USA

${ }^{2}$ Virginia Mason Research Center, Seattle, WA, USA

The spectrum of ATM mutations now includes over 250 mutations, from a wide variety of ethnic backgrounds. Almost all common mutations are found on shared haplotypes, as defined by microsatellite typing across the ATM chromosomal region, and these are considered as founder effect mutations. The markers we are presently using include: D11S1817, D11S1343, D11S1819, D11S2179, NS22, D11S1778, D11S1294, and D11S1818. The alleles for these markers have been standardized by size. Some common founder mutations include: NORAT [A], CRAT [A-D], BRAT [FM1-11(including FM7="418" and FM10=7636de19]), IAT [A= 7517del4], IAT [B=3403G $>$ Adel174], IAT [SARD], ISAT [A=MorJew], AAT [AMISH], AAT [MENN], POLAT [A-E] and TAT [A]. Some shared cDNA defects derive from different gDNA mutations. Very few shared mutations have been observed in patients who do not also share a haplotype across this region, e.g., IVS62+1G $>$ A(codon2891del115). In view of this finding, it is unlikely that testing for just a small number of known ATM mutations will identify a significant proportion of mutations in new patients from other ethnic backgrounds, or in American patients who derive from many diverse ethnicities. We now have sufficient data to examine whether identifying a new patient's ATM haplotypes might be more efficient than trying to identify both mutation sites. By this approach, shared haplotypes would suggest shared mutation sites.

\section{ATM, cell cycle control and radiosensitivity in lymphoid and solid tumors}

Nancy Uhrhammer ${ }^{1}$, Fatih Uckun ${ }^{2}$, Carla Wood ${ }^{2}$ and M. Stephen Meyn ${ }^{1,3}$

Departments of ${ }^{1}$ Genetics and ${ }^{3}$ Pediatrics, Yale University School of Medicine, New Haven, Connecticut; USA

${ }^{2}$ Hughes Institute, Saint Paul, Minnesota, USA

The ataxia-telangiectasia (A-T) protein, ATM, appears to initiate a signal transduction network in response to DNA strand breaks, leading to cell cycle arrest, the prevention of apoptosis, and the facilitation of homologous recombination. Targets of ATM include p53, c-Abl, and RPA. To assess the role of defects in this network in sporadic cancers, we transfected an ATM antisense vector $(A T M \alpha)$ into a variety of malignant cell lines, and analyzed their radiation response. This vector has been shown previously to infer an A-T-like radiosensitivity phenotype on normal cells [1], including increased apoptosis, decreased survival, abnormal cell cycle response, and the failure to induce radiation-response 
proteins including p53 following treatment with ionizing radiation. The malignant cell lines Raji, RS4;11, LC1;19, REH, Nalm6, SKOV3, and MCF7 were included in this study.

Western blotting was performed on each of the cell lines with four antibodies to ATM. No ATM was detectable in SKOV3, a finding that was confirmed by Southern blots showing deletion of the 3' portion of the gene. In addition to the normal $350 \mathrm{kD}$ band; a $\sim 150 \mathrm{kD}$ band was detectable in REH with two antibodies raised against peptides from the N-terminal half of ATM, but not with the two antibodies raised against more $\mathrm{C}$-terminal peptides. The remaining cell lines all exhibited the normal ATM band at $350 \mathrm{kD}$.

Mutations in genes that control cell cycle checkpoints are common in malignant cells, so the induction of several DNA damage response proteins was studied in the panel of tumor cell lines. P53 induction in response to 3 Gy was defective in Raji, RS4;11, LC1;19, REH, Nalm6, and SKOV3, in keeping with the known p53 defects in these cell lines, but was normal in MCF7. Three growth-arrest-DNA-damage (gadd) proteins were studied, including two involved in the G2 cell cycle checkpoint (gadd34 and gadd153), and one involved in the G1/S checkpoint (gadd45). Only RS4;11 pre-B cell lymphoma cells induced all three of these gadd proteins normally following $3 \mathrm{~Gy}$. Each of the other cell lines, plus an AT lymphoblastoid cell line, GM11253, exhibited dysregulation of one or more gadd proteins.

Excessive apoptosis is thought to be responsible for the poor survival of A-T cells after treatment with ionizing radiation or radiomimetic drugs [2]. In many cell types apoptosis in response to irradiation is p53-dependent. In addition, the degree to which normal cells are sensitive to the killing effect of ionizing raditation may be dependent on their type and stage of development. Moderately radiosensitive RS4;11 (a pre-B cell) and radioresistant Raji (a more mature B cell) both became extremely radiosensitive with the introduction of $A T M \alpha$; The increased radiosensitivity of RS4;11 and Raji when ATM expression was impaired suggests that these cell lines maintain at least part of the ATM damage response network in spite of the apparent p53 defects in these two cell lines. Protein blots showed that less than $10 \%$ of the level of ATM present in the parental cells remained in the $A T M$-antisense derivatives. In contrast, the ovarian cancer cell line SKOV3 was found to be null for both p53 and ATM protein. SKOV3 was radioresistant in a clonogenic survival assay, and did not undergo apoptosis following $3 \mathrm{~Gy}$, which may suggest that radiation-induced apoptosis is p53-dependent in this cell type. This lack of apoptosis cannot be explained as a defect in the apoptosis process itself, as these cells have been reported to undergo widespread apoptosis in response to cisplatin. As might be expected, introduction of $A T M \alpha$ into SKOV 3 did not affect its radiation response.

Three cell lines, REH, Nalm6, and LC1;19, all representative of pre-pre-B or pre-B cells, underwent high levels of apoptosis in response to $3 \mathrm{~Gy}$ ionizing radiation. These sensitive cell lines failed to become stably transfected with ATM $\alpha$ after four attempts, using different electroporation and selection protocols. MCF7 breast cancer cells exhibited no increase in apoptosis following $3 \mathrm{~Gy}$, but isolated subclones stably transfected with $A T M \alpha$ did not have substantially reduced levels of ATM protein, and were not studied further.

Cell cycle was studied at 15 and 18 hours following 3 Gy. RS4;11 and Raji initially had relatively normal cell cycle profiles, while their ATM $\alpha$ derivatives showed the prolonged G2 block characteristic of A-T cells [3]. SKOV3, with constitutional mutations in both p53 and ATM, exhibited minimal changes in cell cycle distribution following $3 \mathrm{~Gy}$, suggesting that it is insensitive to irradiation at all stages of the cell cycle. Although defects in the G1/S, S-phase, and immediate G2 checkpoints might be expected given the known defect in ATM, the late G2 checkpoint responsible for permanently arresting A-T cells before apoptosis is also defective in this cell line. The study of cell cycle checkpoints in the radiosensitive cells that have thus far not been successfully transfected with ATM antisense is underway, although preliminary results indicate that MCF7 undergoes prolonged G1/S phase checkpoint, such that only $5 \%$ of the cells are replicating their DNA after 15 hours, but that the cells are then cycling normally at 24 hours. 
Further analysis of the behavior of this panel of malignant cells before and after interference with ATM expression, as well as the identification of mutations in or amplification of genes downstream in the cascade of ATM signalling (e.g. c-Abl), should allow independent components of cell cycle control, DNA damage survival, and apoptosis control to be separated in vivo. For example, a wild-type copy of p53 and a fragment of ATM that complements the A-T phenotype in cultured cells [4] could be introduced into SKOV3, together and singly, to ascertain whether these two genes are sufficient to reconstitute the DNA strand-break damage cell cycle checkpoints, and if not, to study what additional checkpoint genes have been mutated in this cell line.

\section{References}

[1] Uhrhammer, N., Fritz, E., Boyden, L. and Meyn, M.S. ATM antisense confers an A-T phenotype on normal fibroblasts. Am. J. Hum. Genet. 59, (1996) 10.

[2] Meyn, M.S., Strasfeld, L. and Allen, C. Testing the role of p53 in genetic instability in ataxia-telangiectasia. Int. J. Rad. Biol. 66, (1994) 141-149.

[3] Beamish, H. and Lavin, M.F. Radiosensitivity in ataxia-telangiectasia: anomalies in radiation-induced cell cycle delay. Int. J. Rad. Biol. 66, (1994) 175-184.

[4] Morgan, S.E., Lovly, C., Pandita, T.K., Shiloh, Y.and Kastan, M.B. Fragments of ATM which have dominantnegative or complementing activity. Mol. Cell Biol. 17, (1997) 2020-2029.

\section{Linkage analyses in ataxia telangiectasia variants}

M.J. van Belzen ${ }^{1}$, J.A.P. Hiel ${ }^{3,5}$, C.M.R. Weemaes ${ }^{2}$, D. Smeets ${ }^{4}$, B.G.M. van Engelen ${ }^{3}$, M.W.I.M. Horstink ${ }^{3}$, F.J.M. Gabreels ${ }^{3}$ and L.P. van den Heuvel ${ }^{1}$

Laboratory of Pediatrics and Neurology ${ }^{1}$, Departments of Pediatrics ${ }^{2}$, Neurology $^{3}$, and Human Genetics ${ }^{4}$, University Hospital Nijmegen, the Netherlands

Department of Neurology, St Joseph Hospital, Veldhoven, the Netherlands

Ataxia is an autosomal recesive multisystem disorder characterized by progressive cerebellar ataxia with onset in childhood, oculocutaneous telangiectasia, high levels of alphafetoprotein, variable immunodeficiency, chromosomal instability (especially of chromosomes 7 and 14) and cancer predisposition. AT cells are hypersensitive to ionizing radiation and radiomimetic chemicals. The gene responsible for AT was recently identified by positional cloning on chromosome 11q22-23 and designated ATM, AT mutated [1,2].

The term AT variants is used for syndromes that exhibit only some of the hallmarks of AT. They usually represent milder forms of the classical AT phenotype, with no additional features. Age of the onset of clinical signs is later, progression of the disease is slower, life span is longer and extent of chromosomal instability and cellular radiosensitivity is less. We recently described two patients with AT variant belonging to one family [3]. They presented with a juvenile resting tremor at adult age. Genomic DNA of this family was available for linkage analysis.

Figure 1 shows the pedigree of a family with AT-variants. Three of the four male sibs are affected (II4, II6 and II7). The three female sibs are healthy. The parents said not to be consanguineous. Two of the three affected brothers (II6 and II7) were described in Movement Disorders (see above). They presented with a resting tremor at young adult age. Although ataxia was not unequivocally present and 
ocular telangiectasia was minimal, typical rearrangements of chromosomes 7 and 14, and increased alphafoetoprotein levels indicated the presence of AT. Immunological tests and radiosensitivity were close to normal. The other affected brother (II4) showed the same features.

For genotyping we obtained DNA samples from blood of AT-variants, who are the index individuals, and their unaffected family members (see pedigree). Using standard procedures DNA was extracted from the blood lymphocytes. Genotyping was done through CA repeat markers (table 2) closely flanking the AT-gene locus on 11q22-23. The CA strand primer was end-labeled with (gamma-32P) ATP and polymerase chain reaction (PCR) was performed using standard conditions. The PCR products were analyzed on a $6 \%$ polyacrylamide sequencing gel and autoradiograms were read after 2 to 4 hours of exposure. Haplotype analyses were performed with different microsatellite markers on chromosome 11. Five of these markers were informative. For all of these markers the affected sibs had a unique genotype not shared by unaffected family members.

In conclusion, linkage analyses did not exclude the ATM gene as being the disease-causing gene in our family with AT-variant patients. Mutation detection studies are in progress to identify and characterize mutations that may be present.

\section{References}

[1] Savitsky et al. Science 268, (1995) 1749-1753.

[2] Savitsky et al. Human Mol. Genet. 4, (1995) 2025-2032.

[3] Hiel et al. Movement Disorders 9, (1994) 460-462.

\section{Novel mutations in the ATM gene in the Dutch population}

M.J. van Belzen ${ }^{1}$, J.A.P. Hiel ${ }^{3,5}$, C.M.R. Weemaes ${ }^{2}$, D. Smeets ${ }^{4}$, B.G.M. van Engelen ${ }^{3}$, M.W.I.M. Horstink ${ }^{3}$, F.J.M. Gabreels ${ }^{3}$ and L.P. van den Heuvel ${ }^{1}$

Laboratory of Pediatrics and Neurology ${ }^{1}$, Departments of Pediatrics ${ }^{2}$, Neurology $^{3}$, and Human Genetics ${ }^{4}$, University Hospital Nijmegen, the Netherlands

Department of Neurology, St Joseph Hospital, Veldhoven, the Netherlands

Ataxia telangiectasia (AT) is an autosomal recessive multisystem disorder characterized by progressive cerebellar ataxia, oculocutaneous telangiectasia, high levels of alpha-fetoprotein, cellular and humoral immunodeficiency, chromosomal instability, sensitivity to ionizing radiation, and prediposition to lymphoreticular malignancies. AT heterozygotes are moderately cancer prone and cultured cells of these individuals are moderately radiosensitive. The gene responsible for AT is localized on chromosome 11 at position q22-23. This gene, designated ATM (AT mutated), extends over $150 \mathrm{~kb}$ of genomic DNA and contains 66 exons. In this report we describe new mutations found in Dutch AT patients.

In five classical Dutch AT patients $(2 \mathrm{M}, 3 \mathrm{~F})$ mutation detection was performed on RNA level according to established procedures. The ATM cDNA was divided in 22 fragments of approximately $500 \mathrm{bp}$. These fragments were amplified by PCR and were screened for mutations by direct DNA sequencing. Fragment 1 is located at the $3^{\prime}$ end of the cDNA while fragment 22 is located at the $5^{\prime}$ end.

Direct sequencing of ATM cDNA revealed four mutations in the ATM gene (Table 1). Of these mutations three were not previously reported. The TG $\varnothing \mathrm{GC}$ mutation in patients 2,3 and 4 is described in 
Human Genetics (in press). One mutation, namely delTCT in patient 4, has been previously described in a patient from Dutch origin (Savitsky et al. 1995a). It is unclear however, whether this patient is the same patient as patient 4 .

The TG $\varnothing$ GC mutation, in patient 2,3 and 4, results in the substitution of two conserved amino acids: an aspartic acid to a glutamic acid (codon 2625) and an alanine to a proline (codon 2626). This mutation was present in a homozygous state, on cDNA as well as genomic DNA level, in two patients of one family. Furthermore this mutation was also present, in a heterozygous state, in another patient of an unrelated family (patient 4). Screening of 90 control alleles revealed one individual who is heterozygous for this mutation.

Table 1

Mutations detected in the ATM gene of Dutch AT patients

\begin{tabular}{|c|c|c|c|c|c|c|}
\hline Mutation & $\begin{array}{l}\text { cDNA } \\
{ }_{1} \\
\text { position }\end{array}$ & Exon & Codon & Consequence & Patient & $\mathrm{Ho} / \mathrm{He}^{2}$ \\
\hline DelGAAA & $1027-1030$ & 10 & 343 & Frameshift & 1 & $\mathrm{He}$ \\
\hline $\mathrm{TG} \varnothing \mathrm{GC}^{3}$ & $7875-7876$ & 55 & $2625-2626$ & $\begin{array}{l}\text { Asp } \varnothing \text { Glu }+ \\
\text { Ala } \varnothing \text { Pro }\end{array}$ & $\begin{array}{c}2,3^{4} \\
4\end{array}$ & $\begin{array}{l}\mathrm{Ho} \\
\mathrm{He}\end{array}$ \\
\hline $\operatorname{DelTCT}^{5}$ & 8578 & 60 & 2860 & DelSer & 4 & $\mathrm{He}$ \\
\hline $\mathrm{T} \varnothing \mathrm{G}$ & 8633 & 61 & 2878 & Ile ØArg & 5 & $\mathrm{He}$ \\
\hline
\end{tabular}

${ }^{1}$ cDNA position according to Savitsky et al. $1995 \mathrm{~b}$ with the first nucleotide of the ORF designated as +1 ; Genbank accession number U33841

${ }^{2}$ Ho means homozygous, He means heterozygous

${ }^{3}$ This mutation is described in Human Genetics (in press)

${ }^{4}$ Patients 2 and 3 are a brother and a sister

${ }^{5}$ This mutation is already described by Savitsky et al. 1995a

Secondary structure prediction according to Chou-Fasman demonstrated a conformational change of the mutated ATM protein.

The fragment that contained the delTCT mutation in patient 4 (fragment 2) has been amplified twice and sequenced three times. Every time, the first 250 bases of the forward sequence were present as a unique signal. After that, the spectrum contained two signals that were mixed up, indicating that a deletion or an insertion was present in one allele. The reverse sequences showed a similar spectrum. No restriction sites are present in the mutant or wild type sequence on the position of the mutation. This mutation results in an in-frame deletion of a conserved serine residue. The deleted amino acid is located in the conserved PI-3 kinase domain and is conserved between most proteins of the PI-3 kinase family. Chou-Fasman secondary structure prediction demonstrated a conformational change of the ATM protein containing this deletion. In the mutant protein a beta-turn formed by codons $2858-2861$ is missing and replaced by a beta-sheet. These findings suggest that this mutation is pathogenic. 
The fragment that contained the delGAAA mutation in patient 1 (fragment 20) has been amplified once and sequenced twice. The forward and reverse sequences of this fragment showed a similar spectrum as the spectrum that contained the deletion in patient 4 , namely in the beginning a unique signal that became mixed up after 235 bases. This spectrum also indicated that a deletion or an insertion was present in one allele. The delGAAA mutation results in frameshift in the ATM protein which would lead to a truncated protein product.

The fragment that contained the $T \varnothing \mathrm{G}$ transversion in patient 5 (fragment 2) was amplified once and sequenced once. In the sequence spectrum the mutant base $\mathrm{G}$ is present together with the wildtype base $\mathrm{T}$, indicating that this mutation is present in heterozygous state. This mutation was confirmed on cDNA level by PCR-PIRA analysis with XhoI. This enzyme cleaves the mutant PCR-PIRA amplimer of $164 \mathrm{bp}$ into two fragments of $18 \mathrm{bp}$ and $146 \mathrm{bp}$ and does not cleave the normal amplimer. After digestion with XhoI, the normal fragment of $164 \mathrm{bp}$ was present together with the smaller fragment of $146 \mathrm{bp}$, again indicating that the mutation is heterozygous. This mutation still has to be confirmed on genomic DNA level. The missense mutation results in an amino acid substitution from an isoleucine to an arginine. Secondary structure analysis according to Chou-Fasman demonstrated that a piece of a $\beta$ sheet that is present in the normal ATM protein is replaced by an a-helix in the mutant protein. This suggests that the $\mathrm{T} \varnothing \mathrm{G}$ transversion is a pathogenic mutation.

In conclusion, we found four mutations in the ATM gene of the Dutch population. Three of these mutations were not previously described. Our findings suggest that all four mutations may be disease causing mutations.

\title{
A different histologic spectrum of breast cancer in AT gene carriers
}

\author{
Sandra R. Wolman ${ }^{1}$, Fattaneh A. Tavassoli ${ }^{2}$, Peter J. Dawson ${ }^{3}$ and Michael Swift ${ }^{4}$ \\ ${ }^{I}$ SRW at Uniformed Services University of the Health Sciences, Bethesda, MD, USA \\ ${ }^{2}$ FAT at Armed Forces Institute of Pathology, Washington, DC, USA \\ ${ }^{3}$ PJD at Department of Pathology and Laboratory Medicine, University of South Florida and James A. \\ Haley Veterans Administration Hospital, Tampa, FL, USA \\ ${ }^{4}$ MS at New York Medical College, Valhalla, NY, USA
}

An increased risk of breast cancer $(\mathrm{RR}=3.8)$ has been found in heterozygous gene carriers of the AT gene. Gene-determined differences in the origin and developmental sequence of these tumors could be reflected in unusual or unique pathologic characteristics. Breast cancer patients were identified from known A-T families and tissue blocks and histologic sections of the resected breast lesions were retrieved for review. Although unknown to the reviewers, the carrier status of many of these patients was determined, either by family history or by genotyping based on tightly linked markers to the AT gene. Of the 50 lesions reviewed, 43 invasive cancers were identified, 4 showed only in situ cancer (CIS), and 3 did not contain tumor.

The tumors were classified as: 26 ductal (IDC), 5 lobular, 1 medullary, 5 lobular/ductal, 2 colloid, 1 colloid/ductal, 1 papillary, 1 colloid/lobular and 1 pleomorphic (bone-forming). Thus, 17/43 (40\%) were of non-ductal morphology. Moreover, significant morphologic variation was observed within the IDC, 6 cases with apocrine features and many with prominent myxoid stroma. The genotypes of 32 patients were known, either from obligate heterozygote status or from linkage-based genotyping. Among 24 tumors from 23 gene carriers (one bilateral), over 50\% were morphologically unusual, including 5 
lobular, 2 lobular/ductal, 2 colloid, and 2 mixed colloid cancers. In the entire patient group as well as the gene carriers, the frequencies of nodal involvement (19/40) and associated atypias (32 with CIS, 20 with hyperplasia) were high. Comparison with published data on other heritable (BRCA1 and BRCA2) breast tumors [1,2], indicates that lobular histology $(28 \%)$ and colloid changes $(20 \%)$ may distinguish cases in AT heterozygotes from other forms of heritable breast cancer syndromes and possibly aid in detection of gene carriers.

Acknowledgment
Grant Support is acknowledged from CA14235, CA61217, and CA70923.

References

[1] Marcus et al. Cancer 77, (1996) 697.

[2] Consortium Study, Lancet 349, (1997) 1505.

\section{Frequency of loss of heterozygosity at the $A T M$ and the $B R C A 1$ loci in women with Stage III and IV breast cancer}

Maria J. Worsham, Sandra R. Wolman, Usha Raju, Nandita Barnabas, S. David Nathanson

and Gerard Pals

Henry Ford Hospital, Detroit, Uniformed Services University of the Health Sciences, Bethesda, MD, USA Vrije Universiteit, Amsterdam, the Netherlands

Five to ten percent of all breast cancers are attributable to hereditary predisposing genes. Mutations in the $B R C A 1$ and $\mathrm{LOH}$ from chromosome 17q (BRCA1 locus) in both familial and sporadic tumors support the hypothesis that BRCAI is a tumor suppressor gene. $\mathrm{LOH}$ in this region is observed in $30-70 \%$ of sporadic breast cancers examined as well as in sporadic ovarian cancers. The ATM (ataxia telangiectasia, mutated) gene may contribute to or account for risk in $8 \%$ of all breast cancers, with cancer predisposition in heterozygotes estimated to be three to fourfold that of the general population. In the heterozygote, the mutant ATM may also play a tumor suppressor role in the development of breast cancer. We evaluated 31 women with stage III and IV breast cancer using flanking and intragenic markers in the ATM gene and intragenic markers for BRCA1. Archival specimens from 31 women were the source of DNA obtained from normal breast and nodal tissue, and primary tumor tissue microdissected from 4 micron paraffin sections. The mean age at diagnosis was 61. Tumor stage, type and grade included: 21 stage 3, 9 stage 4, and 1 undefined; 23 invasive ductal carinomas, 3 invasive lobular and 5 undefined; and 17 grade 3, 8 grade 2, 1 grade 1, and 4 undefined. LOH for BRCA1 employed intragenic markers D17S855 and D17S1323, and for the $A T M$ gene, markers D11S1818, D11S1819, and D11S2719. Using these markers both LOH and microsatellite instability (MI) could be determined simultaneously. LOH/MI for any one of the two markers for BRCAI and for any one the three markers for the ATM gene was scored as an LOH/MI. The frequency of LOH/MI instability for BRCA1 was $45 \%(14 / 31)$ and for the ATM gene $32 \%$ $(10 / 31)$. The similarity of results support an interpretation that both these genes function as tumor 
suppressors. Correlation with tumor stage, grade, hormonal status, survival, and other parameters will be reported.

Acknowledgment

Supported by NIH RO1 CA70923 \& ACS EDT\#116

\section{ATM is usually rearranged in T-cell prolymphocytic leukemia}

M.A.R. Yuille ${ }^{1}$, L.J.A. Coignet ${ }^{1}$, S.M. Abraham ${ }^{1}$, F. Yaqub ${ }^{1}$, L. Luo ${ }^{2}$, N.D. Lakin ${ }^{3}$, E. Matutes ${ }^{1}$, V. Brito-Babapulle ${ }^{1}$, S.P. Jackson ${ }^{3}$, I. Vorechovsky ${ }^{2}$, M.J.S. Dyer ${ }^{1}$ and D. Catovsky ${ }^{1}$

${ }^{1}$ Academic Department of Haematology and Cytogenetics, Institute of Cancer Research - Royal Marsden Hospital NHS Trust, London SW3, UK

${ }^{2}$ Department of Biosciences at NOVUM, Karolinska Institute, 14157 Huddinge, Sweden

${ }^{3}$ Wellcome-CRC Institute, Tennis Court Road, Cambridge CB2 1QR, UK

T-prolymphocytic leukemia (T-PLL) is a sporadic leukaemia of cells with a mature T-cell phenotype that is highly aggressive (mean survival: 7 months) and that we have shown responds well to a monoclonal antibody, CAMPATH-1H, directed at the cell surface antigen, CD52. A striking similarity exists between this sporadic disease and a mature T-cell leukaemia reported in Ataxia Telangiectasia (AT) patients. T-PLL is a rare disease, while the mature T-cell leukaemia occurs occasionally in A-T. ATM sequence mutations have been found by PCR-SSCP exon-scanning in $46 \%$ of sporadic T-PLL cases, but some cases also have karyotypic abnormalities at 11q, including 11q23 (our unpublished observations).

This led us to initiate an investigation of a panel of twenty T-PLL cases by Southern blotting using probes from 11q23. While there was no indication of the involvement of PLZF and MLL, two probes closer to ATM (D11S384 and BOB-1) revealed, in different cases, a nearby rearrangement. However, with ATM cDNA probes, rearrangements were identified in about a quarter of cases. Some were clearly complex rearrangements, so we examined seven T-PLL cases by Western blotting, by PCR-SSCP exon scanning, by RT-PCR and by Fibre FISH. DNA fibres were released from tumour cells on glass slides and the fibres stretched out by gravity prior to hybidization using four fluorochrome-labeled cosmids (cos B10, $\cos \mathrm{A} 12, \cos \mathrm{A} 1$ and $\cos \mathrm{A} 4)$ spanning the ATM locus. RT-PCR showed two ATM mRNAs in TPLL: with and without exon 2.

Case 2: One fibre type was normal and two abnormal fibre types were interpreted as an allele having undergone firstly an inversion between the telomeric end of the cos A4 region and a location close to the telomeric end of the cos A12 region and secondly a translocation or insertion within the cos A4 region. Western blotting showed no $350 \mathrm{kDa}$ band.

Case 3: One type of stained DNA fibre was identified consistent with the deletion of an entire parental ATM allele. The cos A1 region was probably transposed. The cos A12 region was longer than normal, suggesting a duplication. Western blotting with antibody to a peptide derived from exons in both cos A1 and cos A4 region identified a ca $350 \mathrm{kDa}$ polypeptide. A nucleotide change leading to L2890V was observed in the tumour but not in a CAMPATH-1H-induced remission sample.

Case 4: A single type of DNA fibre was observed like that in case 3, but with a centromeric region deleted. A ca $350 \mathrm{kDa}$ polypeptide and $\mathrm{R} 3008 \mathrm{C}$ were detected. 
Case 5: Four different types of DNA fibre were detected, consistent with a translocation on one allele and a transposition of the cos A1 region from the other. No $350 \mathrm{kDa}$ polypeptide was detected. PCRSSCP identified a 31 base pair deletion removing the 5' splice site and 9 bases of exon 41 .

Case 6: Three types of stained DNA fibre were identified, one normal and two consistent with transposition of the cos A1 region. Western blotting showed a $350 \mathrm{kDA}$ band but E2139G was detected with loss of wildtype allele from the tumour sample. There was no mutation in a CAMPATH-1Hinduced remission sample.

Case 7: One allele had a translocation. There was no $350 \mathrm{kDa}$ band.

Case 8: Both alleles had translocations. There was no $350 \mathrm{kDa}$ band. RT-PCR identified two mRNAs: with and without exon 40 .

At least one structural lesion at ATM was present in every sample. Of three cases with one intact ATM allele, two had no ATM polypeptide. Case 6 had polypeptide and an intact allele, but it also had a point mutation that was absent from germline. Overall, inactivation of ATM is usual in T-PLL tumourigenesis and thus the gene acts as a type of tumour suppressor.

The presence and location of nucleotide changes was consistent with our report [4] of a clustering of missense mutations in the ATM kinase domain. The pattern of mutations in T-PLL compared with that in A-T suggests ATM may play two roles in T-PLL tumourigenesis. The presence of more than one structural lesion on a single allele may be explained in a number of ways (e.g. a second unknown nearby T-PLL gene) but the most intriguing is that there is a defect in DNA repair at the time the lesions are fixed. The absence of wildtype allele from all tumour samples with nucleotide changes may be due to a gene conversion event.

\section{Acknowledgements}

The corresponding author (MY) acknowledges support from the Leukaemia Research Fund and the Kay Kendall Leukaemia Trust.

\section{References}

[1] Matutes, E., Brito-Babapulle, V., Swansbury, J., Ellis, J., Morilla, R., Dearden, C., Sempere, A. and Catovsky, D. Clinical and laboratory features of 78 cases of T-prolymphocytic leukemia. Blood 78, (1991) 3269-3274.

[2] Pawson, R., Dyer, M.J.S., Barge, R., Matutes, E., Thornton, P.D., Emmett, E., Kluin-Nelemans, J.C., Fibbe, W.E., Willemze, R. and Catovsky, D. Treatment of T-cell prolymphocytic leukaemia with human CDw52 antibody. J. Clin. Oncol. 15, (1997) 2667-2672.

[3] Brito-Babapulle, V. and Catovsky, D. Inversions and tandem translocations involving chromosome $14 \mathrm{q} 11$ and $14 \mathrm{q} 32$ in T-cell prolymphocytic leukemia and T-cell leukemias in patients with ataxia-telangiectasia. Cancer Genet. Cytogenet. 55, (1991) 1-9.

[4] Vorechovsky, I., Luo, L., Dyer, M.J.S., Catovsky, D., Amlot, P.L., Yaxley, J.C., Foroni, L., Hammarström, L., Webster, A.D.B. and Yuille, M.A.R. Clustering of missense mutations in the ataxia-telangiectasia gene in a sporadic T-cell leukaemia. Nature Genetics 17, (1997) 96-99.

[5] Yuille, M.A.R., Galiegue-Zouitina, S., Hiorns, L., Jadayel, D., De Schouwer, P.J.J.C., Catovsky, D., Dyer, M.J.S. and Kerckaert, J.-P. Heterogeneity of breakpoints at the transcriptional co-activator gene, BOB-1, in lymphoproliferative disease. Leukemia 10, (1996) 1492-1496.

[6] Lakin, N.D., Weber, P., Stankovic, T., Rottinhaus, S.T., Taylor, A.M.R., Jackson, S.P. Analysis of the ATM protein in wild-type and ataxia telangiectasia cells. Oncogene 13, (1996) 2707-2716. 


\title{
Patients with Ataxia Telangiectasia (AT) are unable to produce IGG antibodies to pneumococcal polysaccharides
}

\author{
S. Zielen ${ }^{1}$, R. Schubert ${ }^{1}$, D. Schindler ${ }^{2}$ and I. Bühring ${ }^{1}$ \\ ${ }^{I}$ Department of Paediatrics, J.W. Goethe Universität, Theodor Stern Kai 7, 60596 Frankfurt, Germany \\ ${ }^{2}$ Institute of Humangenetik, Biozentrum, Am Hubland, 97074 Würzburg, Germany
}

It is well known that the majority of patients with AT suffer from IgG subclass and/or IgA deficiency $[1,2]$. In contrast a polyclonal increase of IgM (resembling Hyper-IgM-syndrome) is typically found in these patients. Current knowledge of IgG subclass deficiency suggests that low levels are only an indicator of a disturbed humoral immune system. Immunization with polysaccharide vaccines has been recommended to check the patients ability to respond to antigen stimulation for diagnostic reasons [3]. To study whether the response to the pneumococcal antigens is helpful to characterize further the immunodeficiency in AT we investigated natural and induced IgG and IgM antibodies in a large group of patients $(n=36)$.

Measurement of serotype specific antibodies $(4,6 \mathrm{~B}, 9,14,18 \mathrm{C}, 19 \mathrm{~F}$ and $23 \mathrm{~F})$ were performed as described in detail [4]. Briefly, a new ELISA technique using Nunc Covalink NH microtiter plates was developed for direct immobilisation of polysaccharides to measure Pnc antibodies. Prior to Pnc assay all sera were preincubated with $10 \mu \mathrm{g} / \mathrm{ml}$ pneumococcal polysaccharide $\mathrm{C}$ for $60 \mathrm{~min}$ to block all antibodies to this contaminant. IgG and IgM Pnc antibody content were quantified using the reference serum 89SF, kindly provided by Carl Frash (FDA, USA).

Specific IgG antibodies $(>0.1 \mu \mathrm{g} / \mathrm{ml})$ were absent in all patients, whereas $\operatorname{IgM}>1 \mu \mathrm{g} / \mathrm{ml}$ was demonstrable in at least one of 7 pneumococcal serotypes in 33 of 36 cases. Next we immunized 8 patients that are regularly seen in our clinic with pneumococcal vaccine (Pneumovax). Again none of the patients was able to produce specific antibodies independent of age and underlying IgG subclass or IgA deficiency indicating a polysaccharide specific switch defect. As expected the ability to produce IgG antibodies to proteins (Tetanus) was normal and known switch factors for $\mathrm{T}$ cell dependent antibodies (CD40L, CTLA4 and B7) were not impaired in our patients.

The reasons for the impaired $\mathrm{IgG}$ response to polysaccharide antigens in AT are unclear. Polysaccharide specific immunodeficiency (PSI) has been found in a variety of immunodeficiencies (IgGsubclass deficiency, Wiskott-Aldrich Syndrome, DiGeorge Anomaly, AIDS, Complement Component deficiency) and in the presence of normal immunoglobulin and IgG-subclass distribution. This new immunodeficiency describes the inability to generate polysaccharide antibodies, while antibody-responses after vaccination with protein vaccines (Tetanus -Toxoid, Diphtheria) are normal. A detailed review on PSI has been published by Rijkers et al [5].

The origin of the patients inability to produce IgG antibodies to polysaccharides antigens is not yet clearly understood. Several mechanisms have been suggested, but none could constantly be demonstrated in all patients with PSI so far. A genetic disposition like the GM2Mn-allotype and certain C4complement-alleles, a defective expression of the complement receptor 2 on B-cells and a functional disturbance of natural-killer-cells have been described [5].

Irrespective of the underlying condition for PSI patients with AT are at high risk for recurrent pneumococcal infections, manifesting as pneumonia and sinusitis. Thus either treatment by prophylactic antibiotics or immunoglobulin therapy is recommended. In the future a strategy to convert the antipolysaccharide antibody response into one with a T-cell dependent nature by new pneumococcal conjugate vaccines could be a alternative approach to prevent recurrent infections in patients with AT. 
References

[1] Oxelius, V.A., Berkel, A. and Hanson, L.A. IgG2 deficiency in ataxia telangiectasia. N. Engl. J. Med. 281, (1982) 469-474.

[2] Güngör, T., Bühring, I. and Zielen, S. Pathogenese, Diagnostik, und therapeutische Aspekte der Ataxia teleangiektatika. Klin. Pädiatrie 209, (1997) 328-335.

[3] Wasserman, R.L. Antibody deficiency: IgG subclass deficiency and vaccine nonresponder states. Pediatr. Infect. Dis. J. 9, (1990) 424-433.

[4] Zielen, S., Bröker, M., Strnad, N. et al. Simple determination of polysaccharide specific antibodies by means of chemically modified ELISA-Plates. J. Immunol. Methods 193, (1996) 1-7.

[5] Rijkers, G.T., Sanders, L.A.M. and Zegers, B.J.M. Anti-capsular polysaccharide antibody deficency states. Immunodeficiency 5, (1993) 1-21. 


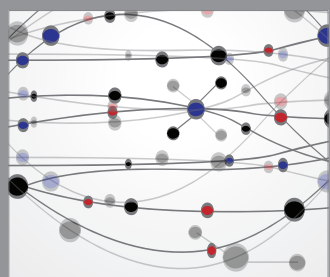

The Scientific World Journal
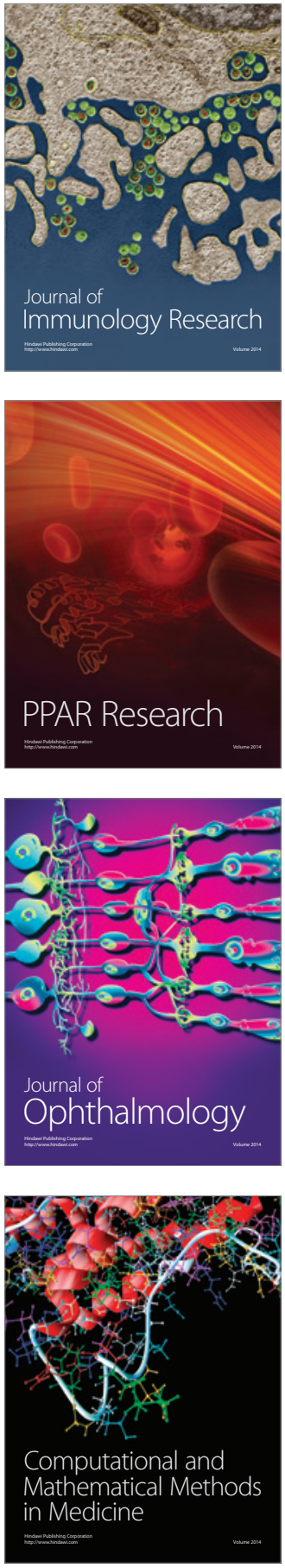

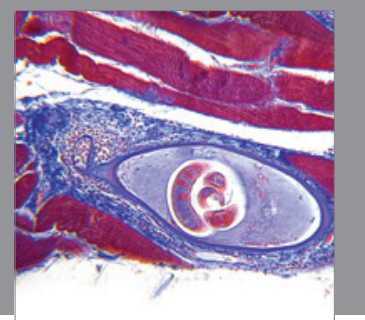

Gastroenterology

Research and Practice
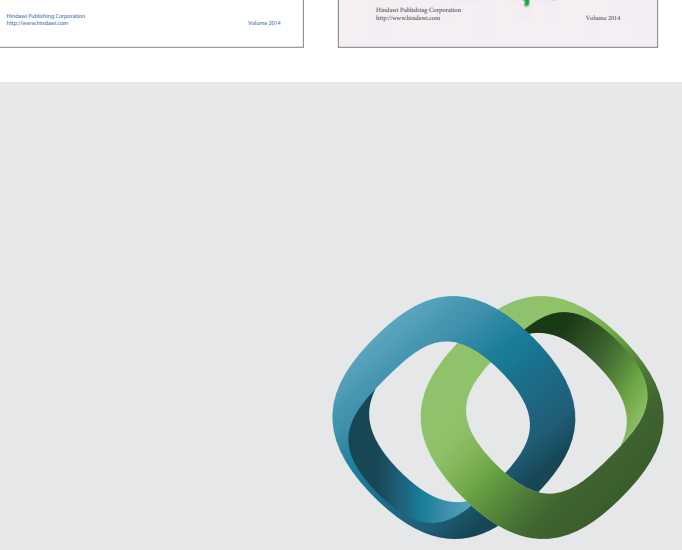

\section{Hindawi}

Submit your manuscripts at

http://www.hindawi.com
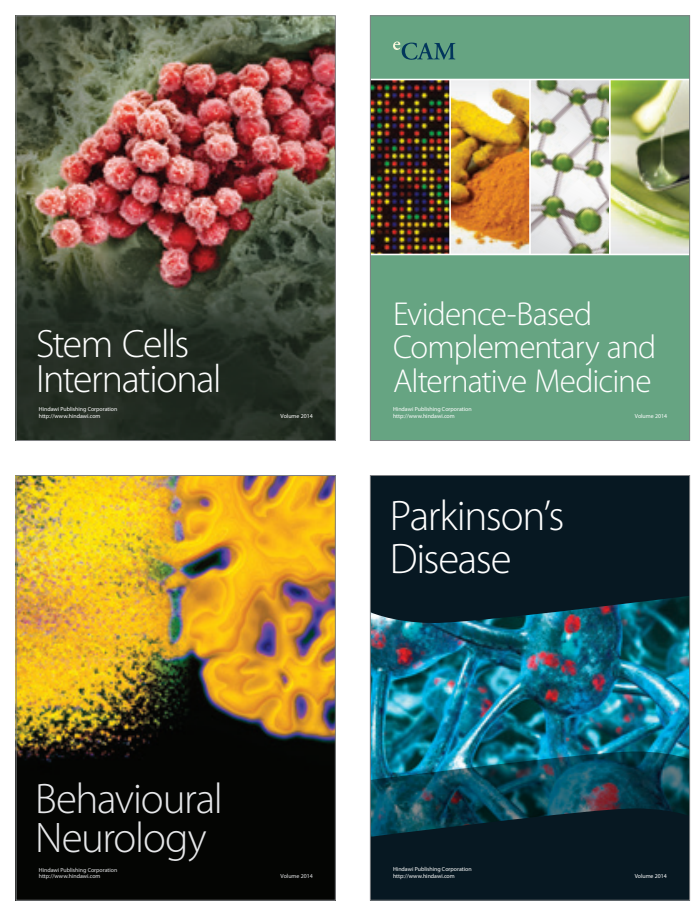

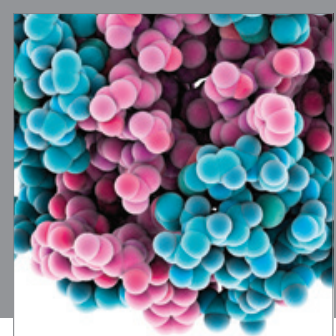

Journal of
Diabetes Research

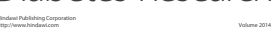

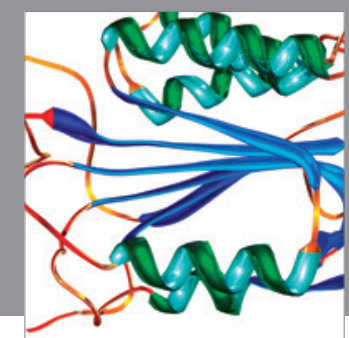

Disease Markers
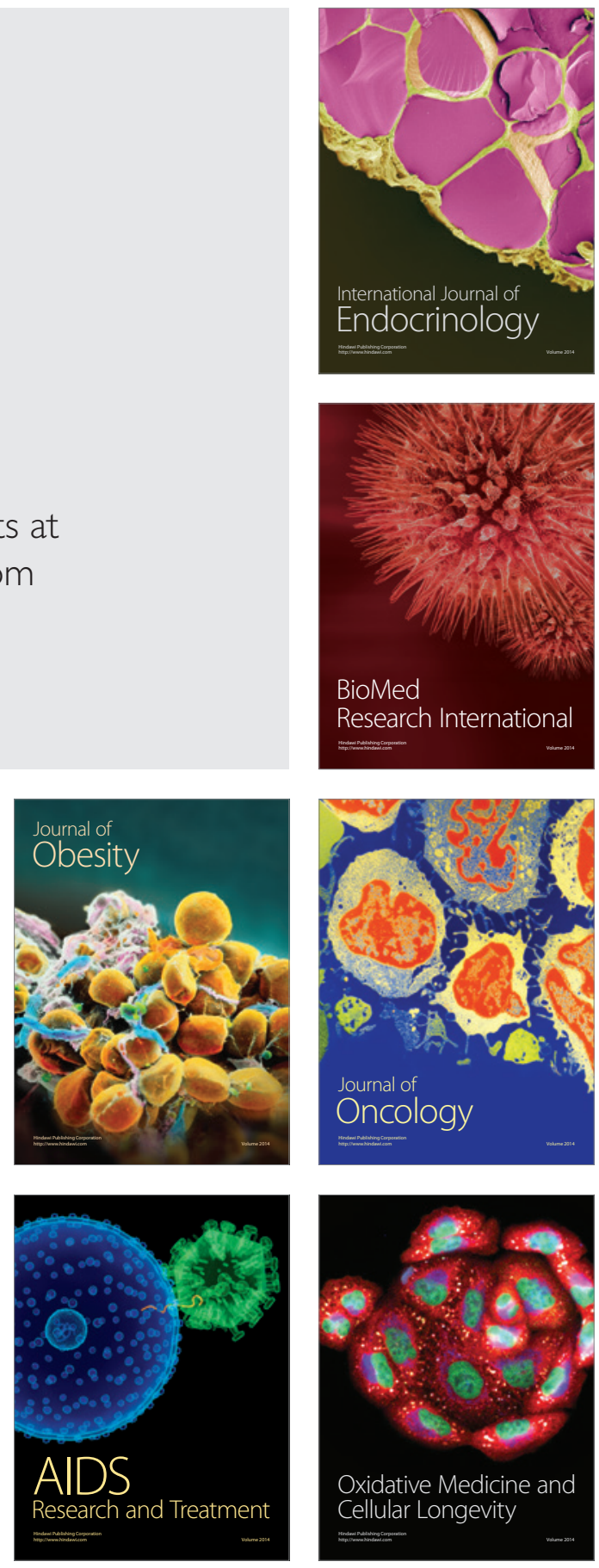